\title{
Education and labour migration in Solomon Islands: Policy interaction between the education system and the labour market.
}

\section{Ezekiel Parairae}

A thesis submitted to Victoria University of Wellington in partial fulfilment for the degree of Masters of Development Studies

School of Geography, Environment and Earth Sciences, Victoria University of Wellington, 2017 


\begin{abstract}
Education is considered, in every sense, as one of the fundamental factors of development. No country can achieve sustainable development and economic growth without a systematic education system. Education raises people's productivity and competency to build a strong economy and society. Many different development theories have influence and inform education systems in many countries in different ways.
\end{abstract}

Solomon Islands' education system has shifted from traditional knowledge to Western oriented style of learning influenced by different development ideas, modernisation, capitalism and globalisation. Traditional knowledge existed for many generations before the introduction of Western education system. The transition period encountered more policy setbacks, rejection of traditional knowledge and incoherent policy models. These transformations happened in the political spheres, social ideas and economic system, influenced by the modern education system.

Today, Solomon Islands' economy and population are largely diverse across the country. The recognition of alternative opportunities available through diverse economies model by Gibson-Graham will help national policymakers to see different education priorities and development needs. Even with the rapid change in the state's modern machineries, political system and institutions, more responsibility and cooperation is required to tackle the relation between education, migration and development. Education must empower people of ages and market levels to realise their full potentials by becoming an effective instrument to provide an answer for linking education, migration and development. The policy dialogue and discussion must open despite many agreements and disagreements. 


\section{Acknowledgements}

I would first like to thank my supervisor Professor John Overton of Development Studies, School of Geography, Environment and Earth Science, Victoria University of Wellington. Professor Overton took me on a journey of learning and experiencing a new world. He consistently allowed this paper to be my own work, but steered me in the right direction.

I would also like to thank the participants from Solomon Islands' government and academic institutions who were involved in the interviews for this research project. Without their passionate participation and input, the interviews could not have been successfully conducted. I would like to thank my fellow classmates for sharing the pains and gains of writing a thesis.

Finally, I must express my very profound gratitude and thank you to my partner and two daughters for providing me with unfailing support and inspiration throughout my two years of study and during the writing of this thesis. This accomplishment would not have been possible without them. 


\section{Contents}

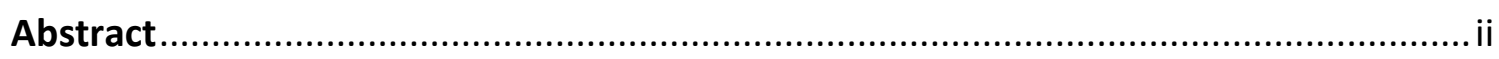

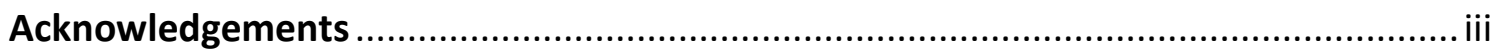

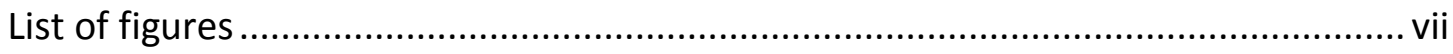

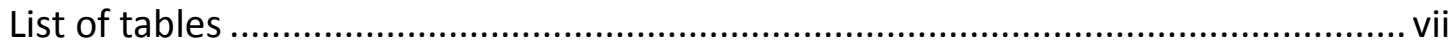

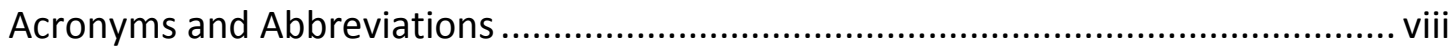

Chapter 1: Introduction ........................................................................... 1

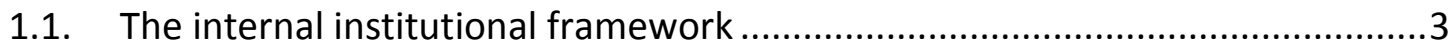

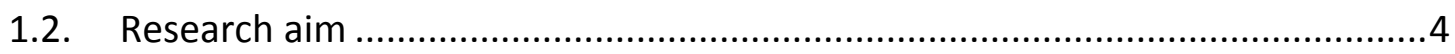

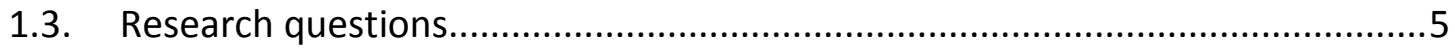

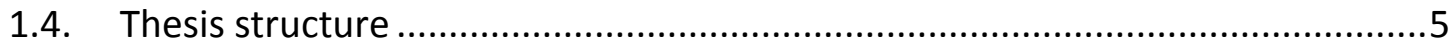

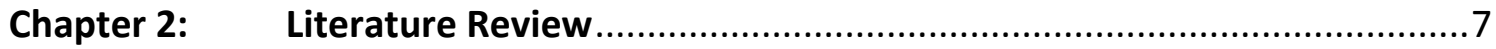

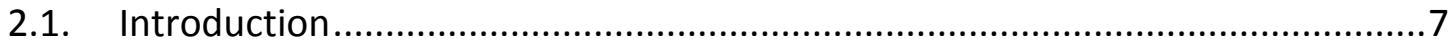

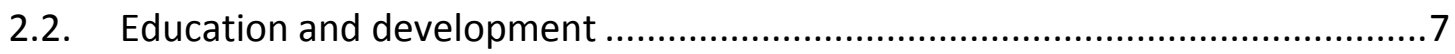

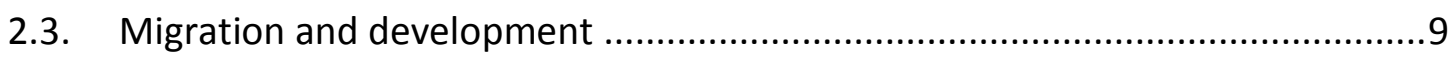

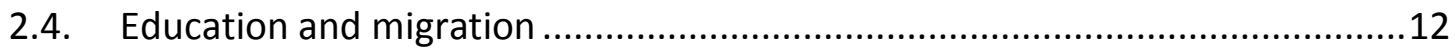

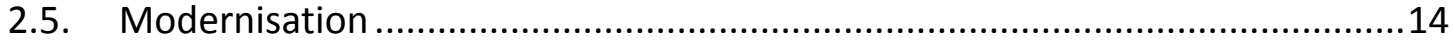

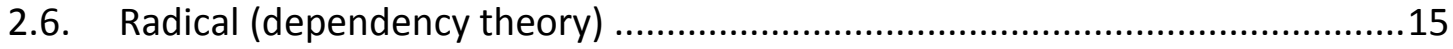

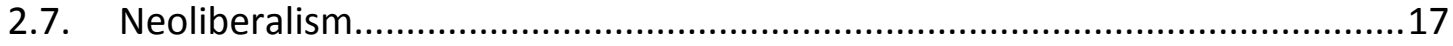

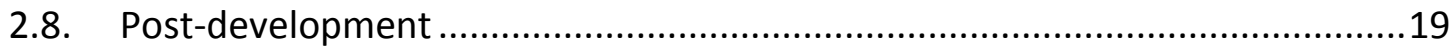

2.9. Development theories and different education strategies..............................23

2.10. Different development theories and levels of education ...........................24

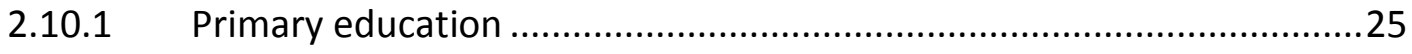

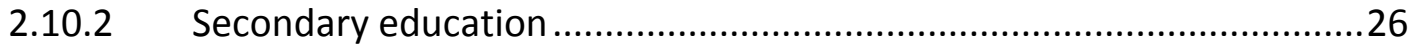

2.10.3 The role of technical and vocational education training .......................28

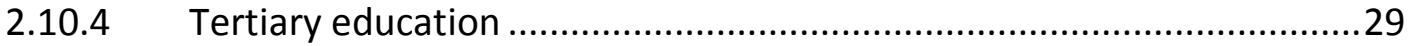

2.10.5 Local and indigenous knowledge .................................................... 30

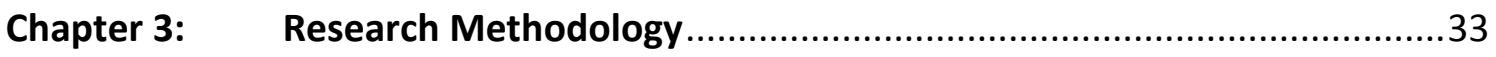

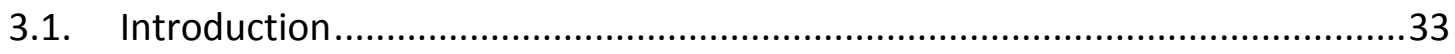

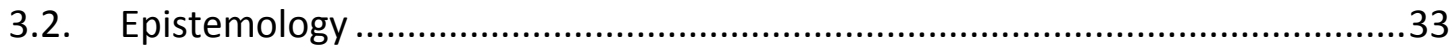

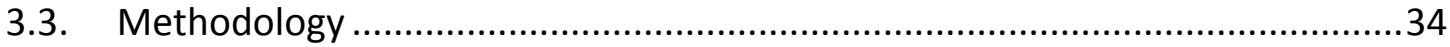

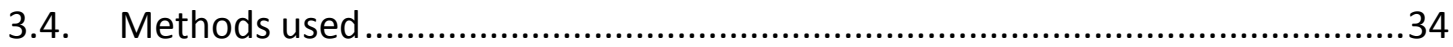


3.4.1. Semi-structured questionnaires and in-depth interviews .34

3.4.2. Ontology and epistemology of talanoa method ...................................35

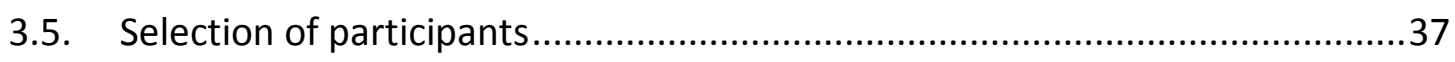

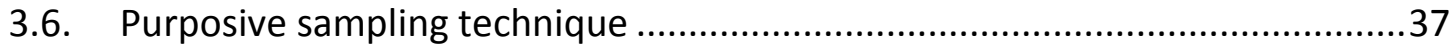

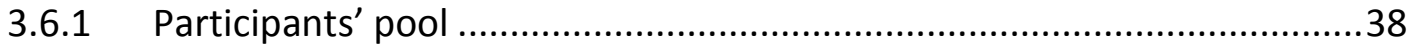

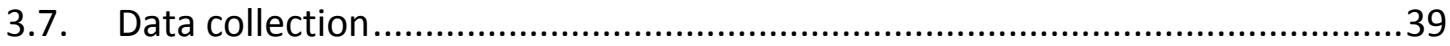

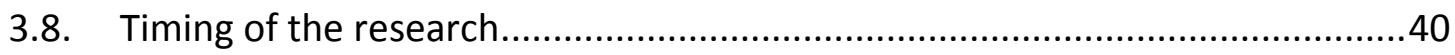

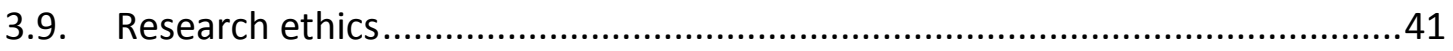

3.10. Positionality, reflexivity and power relations ..........................................42

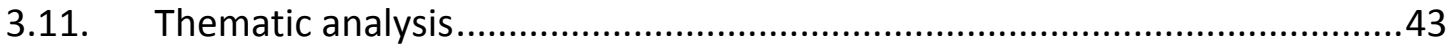

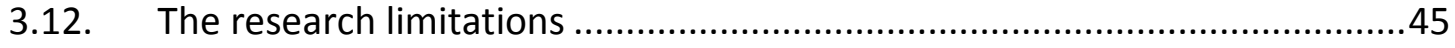

Chapter 4: Solomon Islands context in development ....................................49

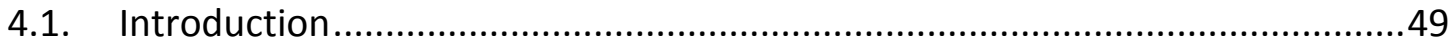

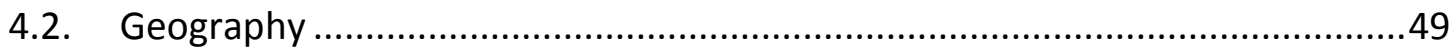

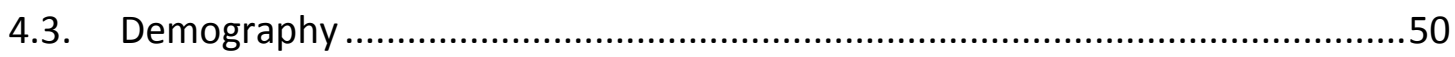

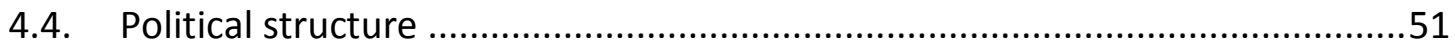

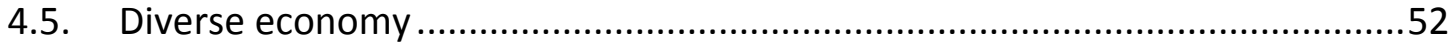

4.6. Solomon Island development landscape ....................................................54

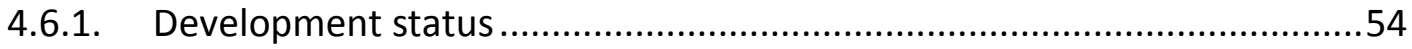

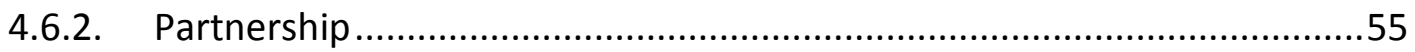

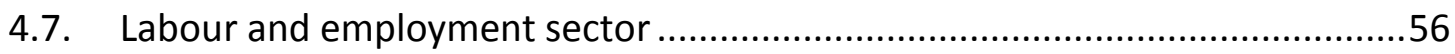

4.8. Labour migration in Solomon Islands.......................................................60

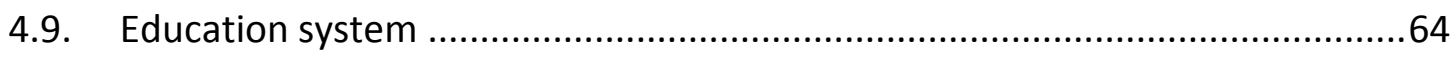

4.9.1. Curriculum for primary and secondary education .................................66

4.9.2. Tertiary education and policy focus .....................................................70

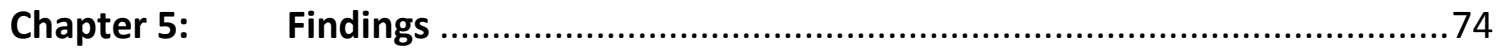

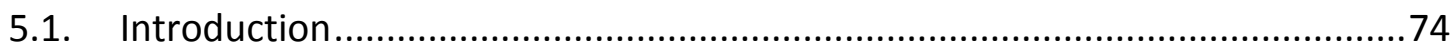

5.2. Diverse education system in Solomon Islands ........................................... 74

5.2.1. Education for personal development and local economy ........................74

5.2.2. The role and rationality behind national education system .....................78

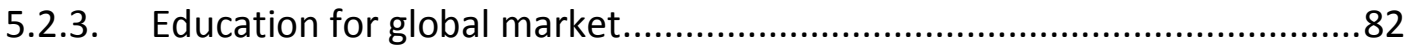

5.3. Internal Policy framework that supports the diverse education regime ..........86

5.3.1. The internal institutional and policy framework ..................................86

5.3.2. Improve accreditation and qualification framework to correspond with diverse markets 
5.3.3. Growing mismatch between graduate skills and job market needs .89

5.4. National concerns on regional and global integration .................................91

5.4.1. Regional integration in education......................................................91

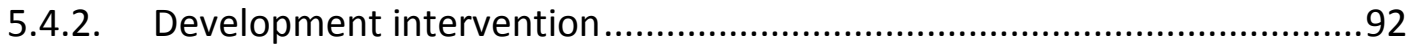

5.4.3. Increasing perception on international labour migration .......................94

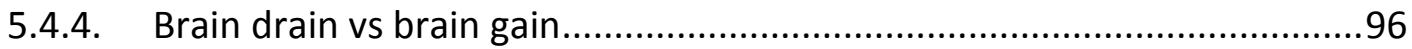

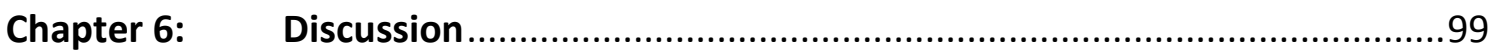

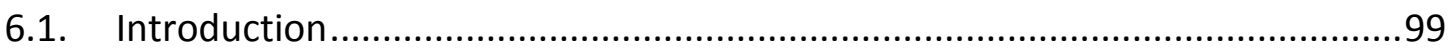

6.2. Diverse education that supports local needs ............................................99

6.3. Education for national labour market and economy ....................................105

6.4. National education for regional and global labour market..........................111

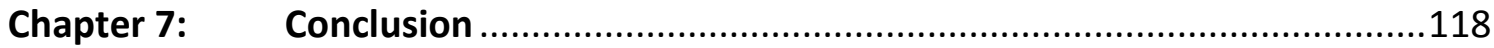

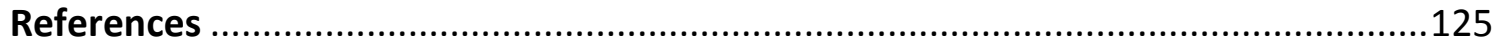

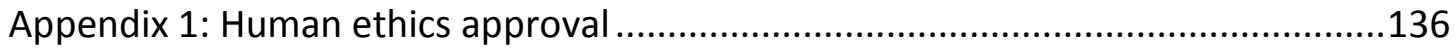

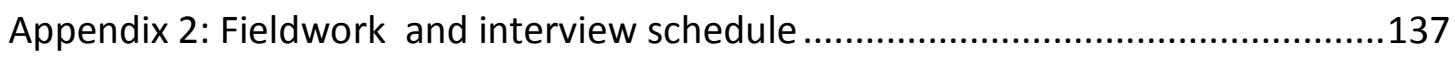

Appendix 3: Ministry of Education and Human Resources Approval .......................140

Appendix 4: Participant information sheet..........................................................

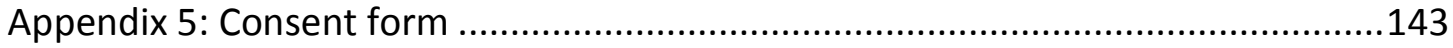




\section{List of figures}

FIGURE 2. 1 DIVERSE ECONOMIC FRAMEWORK

FIGURE 2. 2 TYPOLOGY OF EDUCATION STRATEGIES

FIGURE 2. 3 ADJUSTED NET ENROLMENT RATIO IN PRIMARY EDUCATION, AVERAGE 1999-2009

FIGURE 4. 1 SOLOMON ISLANDS MAP 50

FIGURE 4. 2 SHARE OF EMPLOYEES' POSITIONS BY SECTOR AND SEX, SOLOMON ISLANDS, 2009. 59

FIGURE 4. 3 THE NATIONAL EDUCATION STRUCTURE OF SOLOMON ISLANDS 66

FIGURE 4. 4 CURRICULUM REFORM AIMS 69

\section{List of tables}

TABLE 2. 1 MIGRATION OF TERTIARY EDUCATED MIGRANT IN PACIFIC FROM 2010 TO 2011

TABLE 3. 1 THE FOLLOWING TABLE OUTLINES THE NUMBER OF PARTICIPANTS AND THEIR PLACE OF WORK.

TABLE 4. 1 ECONOMIC ACTIVITY STATUS BY SEX AND URBAN AND RURAL LOCATION, SOLOMON ISLANDS, POPULATION AGED 12 AND ABOVE.

TABLE 4. 2 SOLOMON ISLANDS OVERSEAS RESIDENCE. 63

TABLE 4. 3 THE TABLE BELOW SHOWS THE LEVEL OF ENROLMENT AND LITERACY RATE 68

TABLE 4. 4 SOLOMON ISLANDS TERTIARY POLICY GOALS 71 


\section{Acronyms and Abbreviations}

APTC

AUSAID

CITREC

EIF

ILO

IMF

MCILI

MDG

MEHRD

MFAET

MOFT

MSG

NTC

OECD

PACER Plus

RAMSI

RSE

RTC

SGD

SIG

SIQF

SITEC

SIQA

SINU

SWP

TVET

UPNG

UNDP

UNESCO
Australia Pacific Technical College

Australian Agency for International Development

Canadian International Training and Education Corporation

Enhanced Integrated Framework

International Labour Organization

International Monetary Fund

Ministry of Commerce, Industry, Labour and Immigration

Millennium Development Goals

Ministry of Education Human Resources and Development

Ministry of Foreign Affairs and External Trade

Ministry of Finance and Treasury

Melanesian Spearhead Group

National Training Council

Organisation for Economic Co-operation and Development

Pacific Agreement on Closer Economic Relations Plus

Regional Assistance Mission to Solomon Islands

Recognised Seasonal Employer

Rural Training Centre

Sustainable Development Goals

Solomon Islands Government

Solomon Islands Qualification Framework

Solomon Islands Tertiary Education Commission

Solomon Islands Qualification Authority

Solomon Islands National University

Seasonal Worker Program

Technical Vocational Education and Training

University of Papua New Guinea

United Nation Development Programme

United National Education and Cultural Organization 
UN

UN-DESA

USP

WB

WTO
United Nations

United Nation - Department of Economic and Social Affairs

University of the South Pacific

World Bank

World Trade Organization 


\section{Chapter 1: Introduction}

We will develop the capabilities of students to be future generators of sustainable value for business and society at large and to work for inclusive and sustainable global economy (Godemann et al., 2014).

Generations of Solomon Islanders have embraced traditional ways of learning through long-established protocols and rituals before the advent of modernisation, globalisation and the Western education system. Traditional communities have passed down knowledge and skills by example whether in subsistence agriculture, fishing, art, dance or building traditional houses. Such valuable patterns of learning are central to accepted behaviours, the establishment of harmony and the retention of skills that comprise the wealth of the society. The traditional ways of living and knowledge are still alive and a vibrant part of many Solomon Islands' rural societies today, although the creep of Western popular cultures and modern education raise concerns for many in the country. Even today in the $21^{\text {st }}$ century, life has not changed very much to reflect the rapid changes generated by Western-style development.

As more Solomon Islanders have gained a formal education in recent decades, they started to seek formal employment in the national labour market, often at the expense of traditional life. The growing industrial and commercial activities attracted many workers to migrate to urban centres to find formal employment. The early migration of workers occurred internally to help expand the local economy, which centred on subsistence agriculture and primary industries of coconut and cocoa plantations (Bennett, 1987). During the protectorate period, the engagement with the formal cash economy brought a lot of modern ideas and development initiatives to the rural people. This was one of the main ways in which education and employment brought by globalisation and modernisation started to permeate into, and contrast with, the traditional epistemologies and ontologies of Solomon Island people. The transformation of society into a modern setting has impacted on every level of the society, culture and environment. Solomon Islands with rigid and conservative 
traditional values and society was caught up between change and development on one hand and tradition and stability on the other (Bennett, 1987). The arrival of health services, education and a national political system provided avenues for individuals to participate and experience the Western lifestyle and economic transformation. As communities expanded and experienced the perceptions and doctrines offered by Western education, people became passionate to learn about its impacts and aspirations. Thus, the regular contact and involvement in the development process through education, formal work and accessing of social services became a point of integration between Western and traditional ways of knowledge and living.

Moreover, in rural and urban centres, every school and technical institution, both private and public, are offering a Western syllabus and curriculum. This indicates the level of influence and amount of change that Western worldviews have brought to the Solomon Islands over the past decades. The education system has become an important part of life and development of modern Solomon Islands to produce a range of skills and knowledge to the national economy. People embrace traditional epistemologies and conventional education side by side without much close dialogue or intimidation from the other. While traditional learning brings vital skills and cultural significance in the local economy, it does not fit easily into the modern commercial world (Gegeo \& Watson-Gegeo, 1999). Although Solomon Islanders have embraced Westernisation and globalisation more than traditional knowledge in the formal sector, the education system does not degrade the significance of having diverse learning and traditional knowledge continue to exist in the Solomon Islands.

As Solomon Islands is getting more interconnected to the global community and economy, education and labour migration are becoming relevant policy matters. In recent years, Solomon Islands has been heavily involved in political discussions regarding labour migration due to the growing population of working-age people. However, if this is to expand, the national education system must prepare to supply a range of different skills for offshore labour markets. Although many doubts are targeted at the current education policy and standards regarding whether it can cope 
with the skills demand for labour migration, it is also fair to consider the potential benefits associated with labour migration and development. Since this is a new area, bringing multidimensional dialogue from academics, policymakers and development practitioners is vital for gaining insights into how education will respond to labour migration. Allowing formal discussion to provide critiques and inputs on the prospect of an effective education system is crucial to deal with the foreseen constraints of the diverse market needs.

\subsection{The internal institutional framework}

Solomon Islands' education sector is governed by the Education Act and subsequent reviews have taken place to achieve a more inclusive and effective education model that responds to the economy's labour needs. Up until now, many transformations have been experienced in terms of the education sector and its policies. Most core policies focus on TVET, primary, secondary and tertiary education to provide a range from basic education to professional technical education, cognitive skills, attributes and knowledge to supply the diverse labour markets and economy. However, the current

education system has been going through many structural and policy challenges to provide adequate and quality education to Solomon Islands. The increasing population also adds to the many challenges faced by the education capacity to fulfil its role of developing skills for the national labour market. Today, Solomon Islands is developing and expanding exponentially, ahead of the education system, to match the growing diverse labour demands and needs of the country. The limitations exposed in the national education framework hinder the efforts to steer formal education to adequately respond to the needs and skills required in the diverse labour market. It affects the whole of Solomon Islands from the local economy to the global labour market. The national education and policy framework are not effective enough to harmonize and strengthen the link between national education, the local economy and global labour migration. However, these different levels of labour market are active and regarded as potential for Solomon Islands' development once all stakeholders cooperate. 
There are certain provisions stipulated within the existing legislation and policy frameworks that outline the national education roles and functions for domestic and global labour markets (ILO, 2009). Although some of the national policies and regulations are limited in their coverage, they are still not explicitly clear on the policy link in terms of structures, regulations and procedures between education, the national economy and different labour market needs. This gap in the education regime and policy is a significant aspect that is worth investigating. With its incoherent policy environment and inconsistent institutional support, Solomon Islands struggles to align its education training to labour market forces and demands. The weak policy coordination and collaboration across different ministries are major impediments to national progress and development. Thus, national education must incorporate a comprehensive policy framework that is wide-reaching and captures different educational levels to address broader development and market needs. Without an educated and productive labour force, the needs of a diverse labour market will be insufficiently met, which will result in poorly aligned skills development for Solomon Islands' diverse economy and development.

\subsection{Research aim}

The aim of this research is to investigate and study Solomon Islands education regime whether the national education's institutional frameworks, policies and strategies link and support labour migration. Secondly, to discover if Solomon Islands education system correspond to other different levels of labour and human development needs. The research will explore how different theories of development have informed Solomon Islands education and migration, and which conceptual models and educational strategies have been poorly adopted. Firstly, because it is a policy issue within the Ministry of Education and other associated key stakeholders, it is worth investigating the current national policies and institutional framework's strengths and limitations. Secondly, to determine from the findings what the actionable measures are to improve the education policy and management of education and human resources 
development in response to the economy's different labour market demands. Thirdly, there has been relatively little academic study done on the interaction between education and labour migration in Solomon Islands. Therefore, it inspires the need to undertake academic research to provide academic analysis and results about Solomon Islands' education and its role in skill development for the diverse and changing labour market. The possible research outcomes will help other academics in the field to further expand on the findings and academic knowledge of this research. Finally, this research will test the interplay between development theory and practice, and how it analyses data and findings by constructing authentic worldviews and translating knowledge into useful practical education policies and regulations in Solomon Islands.

\subsection{Research questions}

The central research question of this thesis is:

What are the aims and rationale behind Solomon Islands' education system and policies in relation to the national economy and labour market?

This leads to a related secondary question:

How does the policy link between education and the diverse labour market fit into the national development of Solomon Islands?

\subsection{Thesis structure}

This research will examine and explore the policy relation between education and labour migration in Solomon Islands. The Introduction covers the basic background and purpose of this research in Solomon Islands. Chapter 2 is the literature review and most of the discussion includes a conceptual framework using different development theories in relation to education and labour migration. Chapter 3 focuses on methodology, which provides a clear outline of the research design and methods employed during the research. The Solomon Islands context forms Chapter 4, which discusses the social context, economy and geopolitical setting in Solomon Islands. Chapter 5 is the findings which outline and present views collected from the interviews into logical thematic categories for greater understanding. Chapter 6 is the discussion that deliberates, analyses and critiques the results and findings, constructing rational argument and worldview on the link between education, the labour market and the 
development of Solomon Islands. Finally, the conclusion in Chapter 7 will provide an overall summary on the findings of education regime and its contribution to Solomon Islands' human resource enhancement and development.

In summary, Solomon Islands is a developing country that embraces the Westernoriented capitalist model and modern economic system and labour market. The education system has transformed through cultural, historical and structural phases, while at the local level, many people are still attached to the traditional knowledge and local economy. The urban centres continue to depend on the capitalist ideas and Western formal education system. Both diverse economies and development are concurrently occurring in the country. The transformations and interaction between traditional knowledge and a Western education system causes structural and policy gaps that inspires this research to use developmental ideas and practice to investigate the status of education and diverse economy. The purpose of this research is to examine the rationale behind Solomon Islands' education system in relation to the national development. 


\section{Chapter 2: $\quad$ Literature Review}

\subsection{Introduction}

In this literature review, the primary emphasis is on regional and global education and its relation to development and migration. The main focus is how education and migration contribute to development from different development theoretical perspectives. The conceptual framework is based on a review of modernisation, radical, neoliberalism and post-development theories of development and the paradigm shift towards globalisation and international cooperation. The conceptual framework will guide the discussion to understand the interaction between education, the labour sector and the international economy. It represents education's broad and international policy context and its relationship to the global economy. The discussion will further explore different types of education strategies and how they inform, impact and relate to migration and global development.

\subsection{Education and development}

The one continuing purpose of education, since ancient times, has been to bring people to as full a realization as possible of what it is to be a human being. Other statements of educational purpose have also been widely accepted: to develop the intellect, to serve social needs, to contribute to the economy, to create an effective workforce, to prepare students for a job or career, to promote a particular social or political system. The broader humanistic purpose includes all of them, and goes beyond them, for it seeks to encompass all the dimensions of human experience (Foshay, 1991, p. 277).

The global relation between education and development is broadly recognised. The relation is logical because as more individuals receive a formal education, they will, ultimately, end up contributing to the labour market. Historically, formal education has been at the heart of Western civilization and modernisation. Both developed and developing countries embrace education and training of skills to support the core functions of industries and governments to achieve economic growth and development 
(Chinnammai, 2005). Education facilitates human capital development. It is impossible to deny that at a global level education is good for development, both in the sense that education may be intrinsically developmental and that it is instrumentally important for a range of other developmental outcomes (Gamlen et al., 2016, p. 15). Through modern education, countries have anchored development policies, processes and curriculum on the production of labour and skills as necessary for development both locally and globally. The arrival of modernisation and globalisation has propelled the dynamics of education from country-based systems to globally driven and competitive education. According to Chinnammai (2005), the effects of modernisation and globalisation on education have caused rapid developments in curriculum, process, governance, technology and communications that ultimately influence learning systems to change as ideas, values, knowledge and students' and teachers' roles change, and this generates a shift towards commercial, information-based society and global development with the advancement of technology and communication, increasingly, boosting the human capital development level over the last decades.

Human capital development still remains one of the core roles of education both in developing and developed countries. The promotion of improved education facilities and curriculum aims to enhance more investment in human capital for national development. Education is regarded as a lifelong learning and training process, where it facilitates the development of knowledge and skills into a tradable commodities that can be competitively marketable in the local and global markets (Chinnammai, 2005). Through education, the economy can meet its labour market demands. Education, then, promotes development by delivering a quality and skilled workforce - from basic education and vocational skills to high-level professionals - for national development and economic growth (Gamlen et al., 2016). The rapid increase, from the late eighteenth century onward, in the production of educational ideologies, educational theories and educational knowledge more generally has to be seen in connection with the growing acceptance of programmes and policies encouraged by the state-run 'national systems of education' (Schriewer \& Nóvoa, 2015). Despite the massive advancement of learning styles, scale and modes, education still acts as a vehicle for 
production of a higher-quality labour force with the right talents and skills to match current labour market and economic needs.

Lastly, education acts as a catalyst for the humanistic approach, which links education to development through a social justice lens. This provides learning to the mass of a population, including the underprivileged, to become aware and understand development and its impacts. As suggested by Freire (1974), education promotes more general awareness and action for oppressed people to know about the causes of oppression and poverty. In other words, underdevelopment is caused by development but can be tackled through awareness raising and people's subsequent action. Today, education has been described as a basic human right for everyone and this sits at the centre of educational strategies of many countries. It is part of a social justice movement to empower people to engage with global economy and social-political systems. Also, basic education can help liberate women to tackle inequality by engaging more in social, political and economic activities. In addition, women's education usually results in a decline in birth rate and more investment in each child's job prospects (Gamlen et al., 2016). Development requires an educated society to participate and contribute effectively.

\subsection{Migration and development}

Despite more agreement on the connection between education and development and education and migration, the disagreement between migration and development still has some challenges at a policy level (Gamlen et al., 2016). The society and state experience many new challenges every day. Policymakers and politicians in the world were once caught up in matters beyond their prerogative and sovereignty. The most relevant question now, after seeing a huge influx of people of many origins, is whether migration assists or hinders development (Castles, 2000). Migration is the medium through which transfers of capital and human skills occur from developing to developed countries and vice versa. Opposing views on migration and development have resulted in a heated debate concerning the rise of international migration over the last five decades (De Haas, 2010). On one end of the spectrum, many countries feel 
optimistic and believe migration has reciprocal benefits for the global economy. At the other end, some believe that migration leads to a loss of key human resources from places where they are needed most. These two opposing views have been in debate and migration is still a relevant issue in development (De Haas, 2010).

The optimistic view is that migration will stimulate development as long as the migration policy and framework are right, and international migration benefits everyone (Gamlen, 2014). At the international level, governments and international organisations have been at the forefront of pushing for recognition of migration and development as two connected concepts in development. Global initiatives by the UN, other organisations and academic research have shifted more focus on migration and development as intertwined concepts that needs global obligation. In support of this, the new optimism of migration and development in 1990 advocates that remittances generated through migration work will stimulate local economic development through multiplier effects (Gamlen, 2014). The benefits are thought to be for both the sending and recipient countries of migration. The so called New Economic of Labour Migration theories put remittances at the centre of international mobility (Gamlen et al., 2016). It considered that transfer of skills and knowledge, and paying taxes, contributed to economic growth and development of destination countries. Also, migrant workers' access to improved social services and education contributes to improved standards of living. From this optimistic perspective, migration is good for development because it is considered instrumental in providing benefits for both the destination and sending countries.

However, on the risk side, excessive costs, repressive policy and exploitive agents may reduce the migration contribution to development (Gamlen, 2014). These concerns include cumulative loss of skills through a 'brain drain' and this affects the productive industries and economy of developing economies. It is estimated that a high percentage of emigration is of people who have completed tertiary education with specialised skills and talents. In the Pacific, there is an increasingly internal and historical migration from small islands states to New Zealand and Australia (Connell \& 
Brown, 1995). The impacts on local economy is small but in the long run, the workforce will require more training to replace the skills of emigrants. More recently, setting up educational programmes, university campuses and institutions in various countries aims to facilitate skill development for international students to cater for migration of skills to overseas labour market. In order to overcome associated costs with migration, proper regulation and policy are needed rather than expecting the global market to dictate the flow of migration and its benefits.

The pessimistic view argues that migration has political and economic costs for development (Gamlen, 2014). The pessimists believe the connection between migration and development will result in failures and socioeconomic inequality and political uncertainty. In addition, some countries are too sceptical and pessimistic on the paradigm shift because of the tendency for the sudden depletion of already limited supplies of skilled labour. More qualified workers will migrate which will cause a 'brain drain'. This will result in a loss in the most productive workforces of developing sending countries. As mentioned by De Haas (2010):

In fact, these new views turned the argument of neoclassical and developmentalist approaches completely upside down: instead of decreasing, migration was now seen as increasing spatial (inter-region and international) disparities in developmental levels (p. 233).

Thus, the pessimistic view emerged as a transition from the state-led industrialisation dominant in the 1950s and 1960s to the neoliberal era in the 1990s. Neoliberal thinking advocates for empowerment of community, migrants, diasporas and transnational communities are seen as actors that would link migration to development (Gamlen, 2014 , p. 587). There is continuous expectation and pessimism in different periods to finally see when migration and development will link and contribute directly to economic growth and development. 


\subsection{Education and migration}

The relation between education and migration is strong. There are two propositions to support this link: 1) the opening of greater educational opportunities, and 2) high levels of education open a wider range of opportunities and incentives for people who want to migrate (Gamlen et al., 2016). The essence is that both reasons promote upskilling and training of individuals in order to acquire quality and professional skills. The desire to migrate is triggered by many drivers and factors. Some see employment conditions as key incentives to move. Others see better living environment and social support as more attractive. Many small countries in the Pacific would see these social and economic supports as potential benefits to send their children to undertake education overseas because some cannot receive similar quality services in their home countries. There is historical migration in the Pacific, mostly among kin and relations increasingly from small island states to New Zealand and Australia (Connell \& Brown, 1995). This kin bond continues to connect people while the top educated population mobility is also high.

More so, higher education opens a wider range of opportunities to migrate into the global market; highly technical and specialised skills are an advantage over the lowerskilled migrants. The demand for such skills exists in the global market. Development theories refer to education as a key mobility-enabling resource (Gamlen et al., 2016). Tertiary education upskills the workforce to become self-reliant and competent at any level in the labour market. The mobilization of skills and talent from one region to another is part of human migration. As individuals migrate, their talent and skills also transfer to where they migrate. The question is to what extent can education help individuals migrate overseas (Rodriguez-Pose \& Vilalta-Bufi, 2005)? Many reasons and arguments can be made on both the positive and the negative sides. Many believe that the effects of tertiary education on individuals' success in the labour market warrant several measures: disproportionate wage, the chance to be unemployed, career path and innovation. If the skill level of individuals rises towards specialisation, the expectation for more rewards, recognition, satisfaction and better pay also rises. These 
human expectations are considered to be some of the chief factors behind labour migration in many countries.

Table 2. 1 Migration of tertiary educated migrant in Pacific from 2010 to 2011

\begin{tabular}{|c|c|c|c|c|}
\hline \multicolumn{5}{|c|}{ Total population } \\
\hline $\begin{array}{c}\text { Region and } \\
\text { countries }\end{array}$ & $\begin{array}{l}\text { Emigrant } \\
\text { population } \\
\text { (thousands) }\end{array}$ & $\begin{array}{c}\text { Highly educated } \\
\text { emigrant } \\
\text { population } \\
\text { (thousands) }\end{array}$ & $\begin{array}{c}\text { Emigration } \\
\text { rate (\%) }\end{array}$ & $\begin{array}{l}\text { Emigration } \\
\text { rate of the } \\
\text { highly } \\
\text { educated (\%) }\end{array}$ \\
\hline Oceania & 1314 & 422 & 4.4 & 4.8 \\
\hline New Zealand & 538 & 164 & 13.9 & 8.8 \\
\hline Australia & 317 & 157 & 1.8 & 2.6 \\
\hline Fiji & 159 & 46 & 20.5 & 31.3 \\
\hline Tonga & 46 & 6 & 40.9 & 44.1 \\
\hline $\begin{array}{l}\text { Papua New } \\
\text { Guinea }\end{array}$ & 29 & 11 & 0.7 & 17.9 \\
\hline
\end{tabular}

Source: (UN-DESA and OECD, 2013)

Table 2.1 shows that the proportion of highly educated persons residing in Pacific countries was significant for Tonga at $44 \%$ and Fiji 31\%. PNG also experienced a rate of $17.9 \%$ of outflow of highly educated individuals according to the records (UN-DESA and OECD, 2013). The statistics by OECD show that tertiary education also contributes to labour migration in the Pacific region (UN-DESA and OECD, 2013). Migration decisions in the Pacific are usually shaped within a mixture of family context, career and economic vision. Individual migrants leave to meet both family and personal expectations alongside kinship and social attachments. In addition, it reflects the government's investment in tertiary education to expand the skilled workforce to meet the global market. Once overseas markets have demands that match domestic skills, then qualified people can seize job opportunities. Thus, this evidence highlights that Pacific tertiary education produces skilled workers who are competitive and contribute 
significantly to labour migration. This scale is an important indication of how many Pacific countries are struggling to provide decent and enough jobs to retain its highly educated graduates from migrating.

In terms of development, migrants can improve welfare and well-being because of more accessibility to social benefits, quality health and education opportunities. For small Pacific island countries in the region, sending a relative off to a job overseas is considered a great privilege because of the returns he/she will send back home (Connell, 2014). Migration has been viewed as a safety net to reduce pressures from national governments in the Pacific on social welfare services and employment opportunities. Remittances from labour migration are indeed a source of income for households in small islands' economies. It is an important source of foreign exchange for Pacific countries. For example, Samoa and Tonga, with $22 \%$ and $20 \%$ respectively of their GDP coming from remittances, are surpassed only by Tajikistan on a global scale (Connell, 2014). Through tertiary educated migrants, money is sent home to support their relatives and close families to improve their standard of living.

\subsection{Modernisation}

There are many approaches to development thinking, one of which is the modernisation model. The underlying notion of modernisation is the change from traditional settings to achieve national development in ways that mirror Western paths to economic and social transformation. The transformation should include national systems of education, health and infrastructure, as well as economic policies and regulations that promote a modernised system. In terms of education, modernisation promotes the view that education is a key national priority and must link to the national needs to fuel national development and growth. Education is regarded as a human right and thus, governments should invest heavily in universal education strategies to boost equal opportunities, improve standards of living and empower a more literate society to participate in national development projects and decision making. 
Western curricula have dominated modern education systems. 'Modern' education is widely adopted in both the developed and developing worlds. Accepting modern ideas and processes of development is considered critical to achieving a modern state with Western philosophies, economic systems and institutions that support development (Desai \& Potter, 2014 ). Thus, Rostow's notion of take-off promotes a modern capitalist path to 'progress' and development and following the Western model of education, industrialisation and infrastructure development will replace traditional societies with modern ones (Smelser, 1966). Many countries have adopted the modern educational model to guide national education policies and strategies. This is to stimulate development that focuses on national stability and progress. Western education is regarded by policymakers as scientifically and rationally appropriate for solving many development problems of the economy. Prioritizing modern ideas and doctrines will direct a country's path to nation building and progress. By contrast, modernisation theory sees little or no value in established traditional knowledge, cultures and systems of learning.

A large problem with the modernisation approach is that it has failed to deliver positive impacts on the living standard for the bulk of the world's population (Desai \& Potter, 2014 , p. 128). The modernisation model dismisses traditional knowledge as important learning curricula as a core part of the modern educational system. The modernisation model regards traditional knowledge as backward, unscientific and a hindrance to national development (Briggs, 2005). Learning must be shifted away from local diverse ideas to introduce modern and Western scientific education curricula. This notion has separated and marginalised these diverse worldviews and forms of knowledge for many years. It promotes Western education over traditional knowledge as a universal instrument to create human capital for development.

\subsection{Radical (dependency theory)}

Development comes with both benefits and costs, and understanding the implications on the state, economy and society is crucial. The radical concept of development expressed in dependency theory unlocks the notion that development processes and 
paths connect the economic and political landscape of developing countries with dominant global economic system (Desai \& Potter, 2014, p. 181). The assumption that poverty and oppression happens in isolation between developing and developed countries is disputed under this radical perception. The dependency on the global north by the global south, and vice versa, contributes to the misery and social problems in developing countries. Education in this regard is used as the medium for conscience awareness regarding the causes of underdevelopment and marginalisation (Freire, 1974). Education is seen less as a means for vocational training by acquiring skills and knowledge and more as means to empower people to understand their surrounding structures and the way these cause oppression, poverty and inequality.

This radical view of education is critical of the way 'modern' education uses global Western-based science and knowledge systems. Being connecting to the global education system forces students to accept reinvented knowledge and global ideas without questioning. The space for innovation and creativity has been locked away by formal education systems which deprive learners (Freire, 2000). On the other hand, the introduction of universal primary and secondary education can promote progressive development and social justice. Learning social and humanistic values should thus be a common responsibility in order to achieve a just and progressive society. Everyone, regardless of gender, race and religion, should have the right to access quality education to understand and improve their society. This aims to expand citizens' general understanding of the core functions and processes of the economy and state.

The radical approach argues for a different pedagogical approach. In more conventional modern education, students are passive subjects accepting knowledge without questioning the reason and rationale behind that knowledge and concept (Freire, 2000). It is what Paulo Friere referred to as the 'banking' philosophy of education which permits students to aspire only as far as what they receive from the education system taught by teachers (Freire, 2000, p. 72). Instead, Freire and others argue for much more active and questioning approaches to learning, whereby students learn from each other and by exploring and challenging their surroundings. 
Furthermore, radical ideas aim to understand the causes of poverty and oppression brought by established development ideas. The humanistic perception views universal primary and secondary education as a core privilege and requirement of a 'progressive' society. Education raises awareness ('conscientisation') and understanding of the causes of oppression, underdevelopment and poverty (Freire, 1974). Respect for human rights and access to education is seen as a key, highly valued component of global development. Knowledge is classified as shared resources; thus, hierarchal institutions and providers must take actions to focus more on education for improving the lives of the marginalised and poor. Rather than depending on more formal and hierarchal institutions to provide education, many non-government organisations and community organisations must also overtly challenge the establishment to change the system to also value the needs of the middle and oppressed classes of the society (Gamlen et al., 2016). It allows the marginalised class to rise up against the powerful structures and demand transformation rather than silently agreeing with capitalism to run the economy.

\subsection{Neoliberalism}

So, from a small, unpopular sect with virtually no influence, neoliberalism has become the major world religion with its dogmatic doctrine, its priesthood, its law-giving institutions and perhaps most important of all, its hell for heathen and sinners who dare to contest the revealed truth (Desai \& Potter, 2014, p. 107).

According to the neoliberal perspective, market forces should promote economic growth. Government intervention and domination distorts real development and economic growth (Desai \& Potter, 2014). The shift in developmental thinking, from national development to a liberal and open economy, aims to respond to a range of different labour needs. With regard to education, the global expansion of economies and technology demands workers with flexible skills but globally recognised education. The commodification of education falls within the neoliberal view of education. The labour markets demand skills for economic functions and specialised teaching and 
learning are considered the solution to these skills gaps. Neoliberal national education policies are needed in order to provide basic numeracy and literacy for the bottom end of the labour market. The middle class, including managers, administrative staff and the semi-skilled workforce, needs specialist and secondary training to equip them with required skills and know-how. At the top of the labour market, high level and technical and scientific education is required for those who aspire to be employed in research, innovation, marketing and information and financial management (Gamlen et al., 2016). Neoliberalism rejects the notion that the state should be solely responsible for providing education for the hugely diverse labour market. Instead, it suggests a variety of private sector education providers alongside basic state systems.

Neoliberalism proposes the privatisation of academic institutions like universities and technical colleges to help meet the growing labour and economic demands. Education is considered an agent for human capital development to sustain economic growth and development. In addition, the commodification of education empowers different classes to realise and pursue potential skills with private institutions that offer the best programmes and courses that correspond to changing market needs. By connecting to privatised and globally recognised education systems, graduates are marketable anywhere in the world due to the global demand for reputable technical skills and high quality of education. Universities like Harvard and Cambridge have been associated with the prestige brands of top and professional academic institutions. The private players and individuals read market signals and forces and how best to invest in education to get the best returns and manage the risks associated (Gamlen et al., 2016). Labour market demands and trends inform appropriate training policies and strategies. More competition is required in the education sector to ensure that providers deliver professional and quality training that suits a range of different labour needs. It gives more options for learners as consumers of knowledge and skills to make decisions based on their preference and occupations.

However, the negative implications of neoliberal domination result from stringent requirements and high tuition costs that are beyond the affordability of many 
individuals. As highlighted by Maringe, in many countries, the states are not prepared to loosen their grip on the policy mechanisms and processes associated with the education system and quality and standard of tertiary education (Maringe, 2015). Thus,

the opposite happens as only a few elite and wealthy people can afford tertiary standard education while the rest are structurally displaced from the education system (Maringe, 2015). Mass education suffers and there is not equality of opportunity. Many developing countries have access to quality tertiary education but only through support from international aid. The social disparity and inequality of access to tertiary education policy in developed and developing countries can be wide when educational strategies are based on neoliberalism. High competition may also lead to a trend of more inequality and decline of quality of education in developing countries (Maringe, 2015). Privatisation of education has pushed the majority from accessing education due to its high cost. The education structure favours those with privilege and wealth over the poor and marginalised classes. It is likely that mobility of skilled labour will happen at the top end while the largely middle and lower classes continue to wait for support and the trickle-down effect, which often never happens in developing countries.

\subsection{Post-development}

Mainstream development has occupied the centre of policy and practice in many aspects of economies. Post-development emerged as a form of rejection and resistance to the capitalist development model. The post-development notion attempts to address the concept of development outside the dominant development paradigm (Fleming \& Palomino Schalscha, 2016). Development should not be seen as one size fits all. The perspective of post-development is also looking at the shadow of development by offering alternatives to deal with the dark side of development (Nederveen Pieterse, 2010). Similarly, alternative development focuses on the lack of popular participation, which highlights the injustices associated with the mainstream development. As suggested by Fleming and Schalscha (2016), the subversive role of post-development is to dismantle the dominance of development rhetoric and practices. This is to recognise the development aspirations of many developing countries that hold distinct cultures, lifestyles and economies compared to the developed Western economies. 
Development should not be seen as a static concept but can be manifested in other development models or concepts to fit diverse economies, especially in the global south. Thus, post-development focuses on the underlying premises and motives of development, and what sets it apart from other critical approaches is its rejection of development (Fleming \& Palomino Schalscha, 2016).

The post-development argument has pushed for the recognition of alternative development models rather than waiting for capitalism and development to deliver the promise of economic growth and progress (Fleming \& Palomino Schalscha, 2016). Although post-development has been decentered from main discourses of development to a certain extent, it opens up new spaces for other cultures, nature and non-economic aspects of other diverse economies (Escobar, 2010). The assumption that development is universally suitable for all countries is questionable. Countries should seek development paths that best deliver opportunities to its economy and society. As supported by a post-capitalist view that many countries and communities are made up of different economies: capitalist, alternative and non-formal forms where the economy is not fully occupied by capitalism but promotes different economies, are sometimes based on principles of solidarity and cooperation (Gibson-Graham, 2008). Countries should recognise local economies based on context and needs. 
Figure 2. 1 Diverse economic framework

\begin{tabular}{|c|c|c|}
\hline Transactions & Labour & Enterprise \\
\hline MARKET & WAGE & CAPITALIST \\
\hline $\begin{array}{c}\text { ALTERNATIVE } \\
\text { MARKET } \\
\text { Sale of public goods } \\
\text { Ethical 'fair-trade' markets } \\
\text { Local trading systems } \\
\text { Alternative currencies } \\
\text { Underground market } \\
\text { Co-op exchange } \\
\text { Barter } \\
\text { Informal market }\end{array}$ & $\begin{array}{l}\text { ALTERNATIVE } \\
\text { PAID } \\
\text { Self-employed } \\
\text { Cooperative } \\
\text { Indentured } \\
\text { Reciprocal labour } \\
\text { In kind } \\
\text { Work for welfare }\end{array}$ & $\begin{array}{c}\text { ALTERNATIVE } \\
\text { CAPITALIST } \\
\text { State enterprise } \\
\text { Green capitalist } \\
\text { Socially responsible firm } \\
\text { Non-profit }\end{array}$ \\
\hline $\begin{array}{c}\text { NON-MARKET } \\
\text { Household flows } \\
\text { Gift giving } \\
\text { Indigenous exchange } \\
\text { State allocations } \\
\text { State appropriations } \\
\text { Gleaning } \\
\text { Hunting, fishing, gathering } \\
\text { Theft, poaching }\end{array}$ & $\begin{array}{c}\text { UNPAID } \\
\text { Housework } \\
\text { Family care } \\
\text { Neighbourhood work } \\
\text { Volunteer } \\
\text { Self-provisioning labour } \\
\text { Slave labour }\end{array}$ & $\begin{array}{c}\text { NON-CAPITALIST } \\
\text { Communal } \\
\text { Independent } \\
\text { Feudal } \\
\text { Slave }\end{array}$ \\
\hline
\end{tabular}

Source: (Gibson-Graham, 2008, p. 4)

The diverse economies framework (Figure 2.1) highlights the existence of a capitalist system that is beyond the formal and Western promoted capitalist system. The market and economies remunerate and reward its labour according to different reward systems. Gibson-Graham (2008) suggested that 'alternative' and 'direct' should be used practice rather than informal and non-formal. These diverse economies coexist in many developing countries today including Solomon Islands. In Fleming's 2015 thesis titled "Diverse Education for Diverse Economies: The relevance of Rural Training Centres in the Solomon Islands" for example, suggested some of these in relation to Solomon Islands (Fleming, 2015). 
Post-development ideas can also inform education strategies. Thus, the Western education model should not be broadly applied as the solution to the development and growth of many developing countries. The alternative development concept brings recognition and acknowledgement of other learning systems and knowledge that been marginalized by the Western education approaches. Many countries still embrace traditional knowledge in skills that remain common and vital practises to them. The diverse economies framework values and respects the ways other economies reward and appreciate communal values and practices. A diverse economies perspective rejects the view that only Western formal education enhances production of skills towards development while neglecting the traditional knowledge. The essence of alternative development is to build a pathway to sustaining and strengthening the diverse practices that support subsistence and produce wellbeing directly to the local community (Gibson-Graham, 2005). Thus, it can help to fuel community resilience and suitability through own ways of skills development and productivity. Post-development helps to see development from the perspective of traditional economies by stimulating formal education strategies and policies. Development should take care of the marginalised and vulnerable segments of the economy as well whose learning and knowledge are contradictory with the mainstream development ideas yet their education model remains valuable asset to local economies. 


\subsection{Development theories and different education strategies}

Figure 2. 2 Typology of education strategies

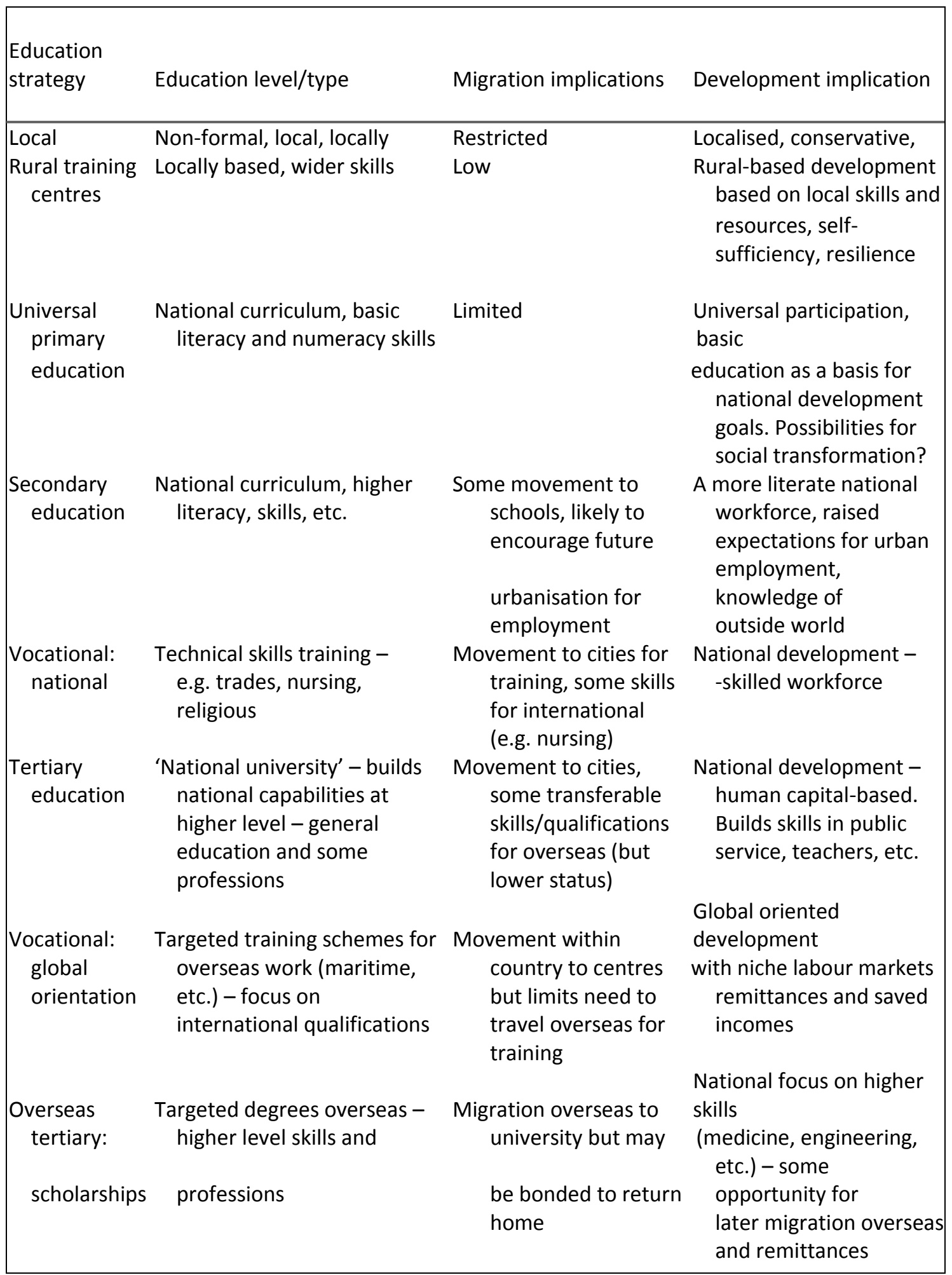

Source: (Gamlen et al., 2016) 
The above structure (Figure2.2) illustrates a network of interaction and influences by different education strategies and levels on migration and development. Education systems in countries are diverse and have different developmental outcomes in terms of economic standard of living, political freedoms, social equality and cultural wellbeing (Gamlen et al., 2016). The table outlines the educational training and its implications on migration and development of countries. These education strategies are relevant to many countries in different development needs and priorities. Many countries connect to the global economy through trade, development assistance, commerce, education, technology and communication. Therefore, how education policies and strategies are formulated will reflect such development needs. Different development models influence the way national states behave, and how policies and laws are designed in various ways. In a broader context, they are dominated by key development theories and global agendas and principles through which global hegemonic power is constructed and expanded through globalisation.

\subsection{Different development theories and levels of education}

As Figure 2.2 suggests, development theories inform education strategies in many countries differently. Many countries adopt some of these distinctive levels of education and strategies based on the national development needs and agendas. However, most of these types of education occur alongside one another to address education up to the tertiary education. It requires a holistic and inclusive approach to enhance training to meet the various needs of the economy. Despite different aims, these levels of education are affected equally by different development ideas that influence educational structures, curricula and policies, governance, cooperation and market forces. The goals and contribution by these education modes represent skills development, values in development, migration and economic growth, even though policy manifestations are different. 


\subsubsection{Primary education}

The modernisation and radical approaches inform the delivery of primary education. The Western-oriented learning model promotes basic education for national development and empowerment. Primary education has been one of the top priorities of development policies and international cooperation over the last decades. Since the creation of the United Nations (UN) in 1945, the signatories of the UN charter have expressed their belief in "full and equal opportunities for education for all" (d'Aiglepierre \& Wagner, 2013). From the radical perspective, primary education is considered a universal right that promotes social justice. The global effort towards universal primary education is one of the centre pieces of the UN's efforts to promote development. The aim is to urge member countries, especially developing countries, to provide equitable and adequate access to primary education for its citizens. Without recognition of primary education, the state cannot achieve participation of citizens in the development process and progress.

Moreover, 'Education for All' has been clothed with a radical influence to promote primary education around the world as a global force. Basic education is a source of social empowerment against the poverty and disruption caused by development. This movement has gained global momentum and recognition as Education for All is regarded as an integral part of international cooperation and globalisation (UNESCO, 2015). The Millennium Development Goals (MDGs) came into existence in 2000 which also set the target from 2000 to 2015 to focus more on global issues of poverty, quality education, health, environment and economic growth. In 2016, the Sustainable Development Goals (SDGs) replaced the MDGs with the title 'Transforming our World: the 2030 Agenda for Sustainable Development' (Sustainable Development Goals, 2015). Education has become a central part and vocabulary to revive awareness about development and globalisation. All of the global efforts in education support the notions of modernisation and radical concepts where social equality and responsibility takes the centre development dialogue. The international institutions such as UNESCO and the UN utilizes the global frameworks and cooperation to promote quality 
education and educational for all rhetoric as fundamentals for success and sustainable development.

Figure 2. 3 Adjusted net enrolment ratio in primary education, average 1999-2009.

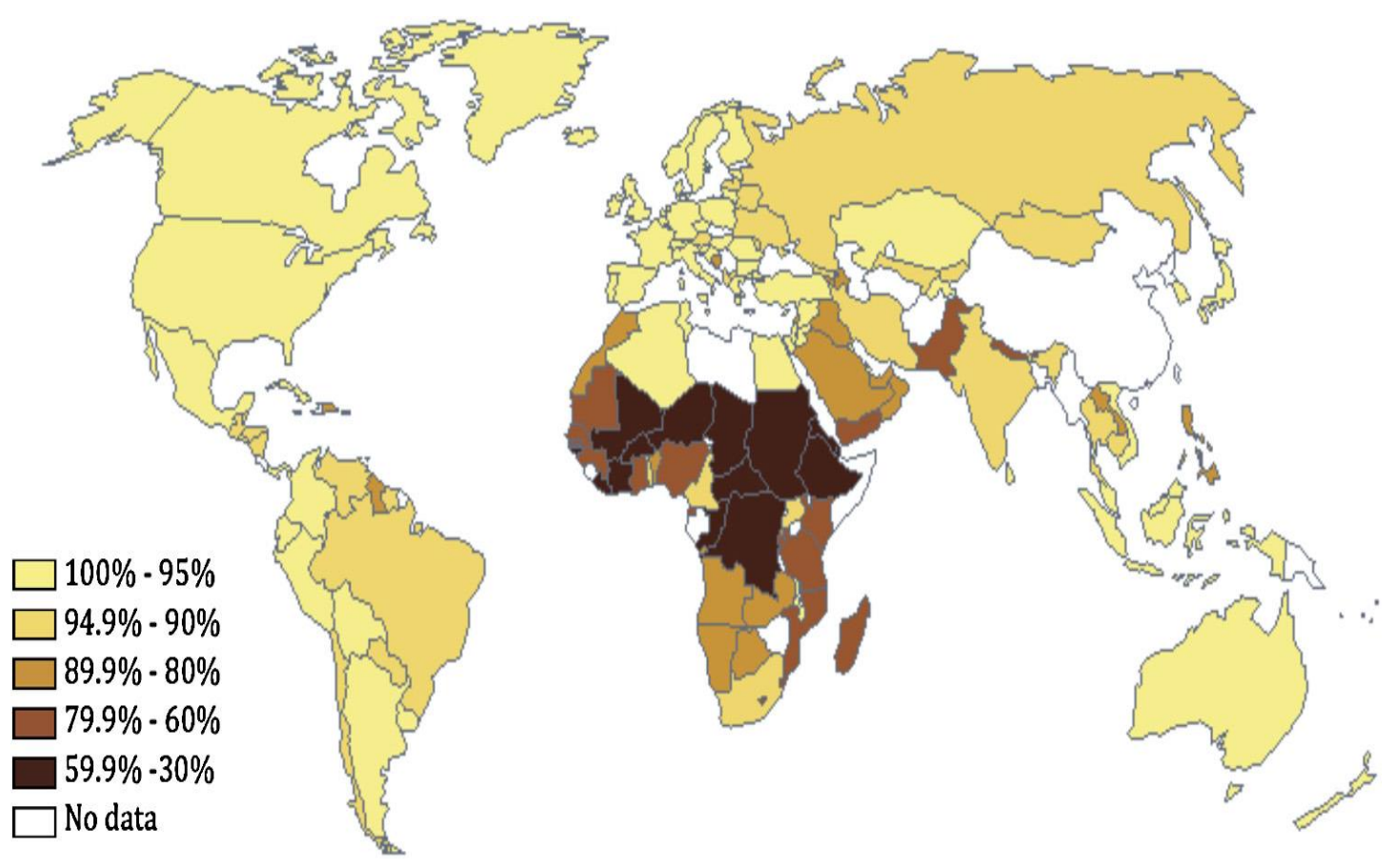

Source: (d'Aiglepierre \& Wagner, 2013)

A global overview in terms of primary education shows considerable inequality in enrolments but also that most countries with low enrolment rates in primary education came from developing countries (Figure 2.3). The need to increase participation in primary education is, therefore, pressing in many countries, especially in Africa. The overall radical view is to use universal primary and basic education as a tool to help underdeveloped world to understand the how the global structures and policies caused underdevelopment.

\subsubsection{Secondary education}

The modernisation and neoliberalism concepts shape the world's secondary education focus and strategies. Secondary education is an extension of primary education to expand human resource and national development (OECD, 2012). It does not really train students into specialised subjects but allows individuals to expand their knowledge on broader issues. The aim is to transform from traditional into a modern 
education system in terms of policies and strategies. It seems reasonable to say that as secondary education expands and becomes an extension to mass primary education, it too comes under the heavy influence of standard world models linking education with notions of social and economic 'progress' (Kamens et al., 1996). Neoliberal ideas boost the expansion and recognition of secondary education in terms of human resource development to meet private and public sector labour demand. In addition, secondary education has become a significant preparatory step towards tertiary education and provides basic skills to the national economy. It contributes to an increase in urbanisation in search of both education and middle-class jobs.

In relation to the global labour market, secondary education contributes to a small scale of labour migration. But its main goal is to provide quality and internationally recognised subjects that provide an effective pathway for younger children to become productive in the national economy. Secondary education also promotes more open models which promotes globally recognised curriculum and subjects. For instance, in Hong Kong, mainstream secondary schools, including both public and private schools that teach a globally recognised curriculum, provide a channel through which societies educate their young to prepare for the outside world (Bray et al, 2014). This represents a shift from a modernisation-oriented secondary education system to an open secondary education approach. But broadly, its role is to provide quality education services to the national economy. Most developing countries have increased their investment in secondary education to continue updating their education system. Others engage in neoliberal measures to allow privatisation of secondary education to meet the current education demands in more open and free economy. The migration of secondary students to overseas markets is generally limited (Bray et al., 2014). Thus, secondary education has a less direct implication for fuelling international labour migration but it contributes to improvement and expansion of accessibility and affordability of education for national development, and it can contribute to increased internal migration and urbanisation. 


\subsubsection{The role of technical and vocational education training}

Technical and vocational education training (TVET) emerged early in the context of the industrial revolution as a concept and philosophy of 'productivism' (Ananiadou, 2013). The assumption was that TVET is a dynamic and significant function in providing human capital for industries. TVET promotes the importance of nation building and progress, which is the central notion of modernisation framework. In order to achieve and sustain national development, technical skills and knowledge are necessary. There are many critics about the roles and the relation to the labour market and employment sector. Policymakers and researchers are questioning the positive impact TVET will have on preparation of young people into the rapidly changing and global labour market (Fuller, 2015). However, the principal purpose of TVET is to provide young people with the necessary skills and knowledge to join the job market to assist national development (Fuller, 2015).

TVET is based on the modernisation philosophy to provide capital and skills for national labour market and industries. Hiring external technical and trade skills is far more costly for the economy rather than training a country's own manpower to supply the domestic labour market. TVET and post-basic levels of education and training are considered forms of empowerment to disadvantage individuals in low and middleincome countries by equipping them with the necessary skills and talents to participate in the 'global knowledge economy' (Ananiadou, 2013). But according to Ananiadou, 'growth, development and poverty reduction depend on the knowledge and skills that people acquire, not the number of years that they sit in a classroom (Ananiadou, 2013). While UNESCO also applies the same reference to TVET as the opportunity not only to train and educate for a stable job, but to produce innovative talent capable of evolving and adapting to current and changing circumstances (Maclean, 2009). Therefore, governments and education systems still adopt TVET as an instrument to achieve national progress and development. Its importance basically lies in the continuous effort to improve education systems to meet modern and quality standards. 


\subsubsection{Tertiary education}

With the rapid socioeconomic and political changes in the 21st century, tertiary education faces major challenges to its governance, systems, curriculum, mission focus, external relations, research and financing (Shin \& Harman, 2009). The evidence of these challenges can be seen as both threats and opportunities in the current global trends. The neoliberal ideas are thought to inform the basis of tertiary education policies. Contemporary tertiary education has been influenced and subjected to neoliberal views under two mega trends: commodification and globalisation (Shin \& Harman, 2009).

\section{Globalization typically makes reference to the broad, economic, technological, and scientific trends that directly affect tertiary education and are largely inevitable in the contemporary world (Altbach, Reisberg, \& Rumbley, 2009, p. 23).}

The primary focus on commodification and globalisation is not simply because it is an extension of enhanced access but the scale of the globalisation process has changed the whole tertiary education landscape, impacting governance, finance, quality, curriculum, faculty and students' demographics (Shin \& Harman, 2009). Tertiary education is based on neoliberal and modernisation perspectives to transform into a modern and scientific-oriented learning environment. The more deregulated the tertiary education sector is, the more it will increase competition to ensure entrepreneurial and technical skills to shape human capital for the global labour market. Also, tertiary education encourages specialist training to upskill individuals for global, high-paid jobs. More so, financing of tertiary education aims to achieve quality training and education supported by effective government policies, curriculum and transparent regulatory institutions.

Tertiary education engages in high level and specialist skills training and production to respond to global labour demands (Gamlen et al., 2016). The privatisation and deregulation of the state's aim is to give more autonomy to the private sector to compete in the free and global market tertiary education. The global standard ranking 
of education systems has challenged many governments, education leaders, educational researchers and the education sector as a whole to work on rebuilding low education performance status to achieve high-quality education systems that can be recognised by the global community (Zhao, 2015). Tertiary education, without exception, is changing in order to meet global standards. Many providers of tertiary education have been engaged in activities that aim to comply with, and compete against, a set of global standards, just like other commercial businesses do to demonstrate their ability to provide efficient services and practices to the people (Zhao, 2015). For instance, specialists such as information technologists, medical doctors and scientists are some of the top professionals that tertiary education aims to produce. With such technical and professional skills and knowledge, graduates are sometimes prone to migrate to work in other countries due to the high demand for their skills. Global competition not only seeks the best brains but also tries to train the best brains through tertiary education (Kritz, 2006).

\subsubsection{Local and indigenous knowledge}

The rhetoric of indigenous knowledge has been heralded as seemingly offering a way out of the development impasse (Briggs \& Sharp, 2004, p. 661). From a policy perspective, indigenous knowledge offers alternative ways to design education policies and curricula that are locally relevant and contribute towards community development. There is little attention given to traditional knowledge in development theory and practice known as 'listening to other voices' (Briggs \& Sharp, 2004). Postdevelopment theory provides an alternative framework that recognises traditional knowledge as a strong community development model. It resurrects hope for alternative experiences and learning to represent marginalised societies. The postdevelopment argument in support of other learning systems offers traditional knowledge an essential boost in promotion of local development, sustainability and conservation of resources. Indigenous knowledge must be regarded as key part of diverse economies; thus, the formal engagement and formulation of national education strategies should consider traditional knowledge as part of national economy and not failure to development. 
The post-development view is also shared by international organisations who support the recognition of traditional knowledge. The World Bank has established a framework for action in 1998 to support indigenous knowledge for development by suggesting that there is a need not only to help bring global knowledge (Western knowledge) to developing countries, but also to learn about indigenous knowledge from these countries, paying particular attention to the knowledge base of the poor (Briggs \& Sharp, 2004, p. 667). It provides options to understand development from local perceptions. The differences between traditional and Western scientific education systems are vast. However, there is space to exchange views and understand how knowledge fits into the economic growth and development of modern society. The regular use of traditional knowledge in environmental actions, resilience and resource management justifies that alternative development is still applicable in many developing countries. The dominance of the Western education notion of schooling has overlooked appropriate local epistemologies to development (Gegeo \& Watson-Gegeo, 1999). However, the continuous rejection by Western-centred education disciplines and development restricted traditional knowledge as irrelevant to development. In reality, pursuing traditional knowledge is still critical and valid for many economies to inform national education strategies and pedagogies for national development.

In summary, different development theories inform educational strategies and policies at different market levels. These different development ideas play out in Solomon Islands' education strategies, including traditional knowledge, primary, secondary and tertiary education to sustain diverse labour market needs. Whether it be national development and economic or global labour demand, different education strategies are guided by varying conceptual frameworks and are paramount in shaping decisions to take appropriate training to correspond the development agendas. Furthermore, the relation between education, migration and development has some agreement about its socioeconomic and political contributions. However, there are many costs and limitations in these arguments as well. Development theories and practices will continue to inform policymakers, government and international organisations on the 
latest analyses and contributions on the link between education, migration and development. This is an ongoing and critical topic in development. Solomon Islands, without any doubt, has unevenly adopted and framed education strategies based on these development ideas and frameworks. Thus, the discussed literatures and different conceptual frameworks would help to examine and understand the purpose of this research. 'What is rationale behind Solomon Islands' education system in relation to the labour migration and national development'? The subsequent chapters will also help to explore how education links to labour market and development guided by these different development approaches. 


\section{Chapter 3: $\quad$ Research Methodology}

\subsection{Introduction}

The research methodology chapter will cover areas of research design, epistemology, methods, ethics, positionality and the limitations of the research. The research aims to examine the behaviours and attitudes of bureaucrats, policymakers and planners in Solomon Islands' public and private institutions towards the policy relation between education and labour migration. The research uses a qualitative approach and interviews with key participants. The focus is to study the institutional capacity, education policies and labour policies, and how they interact to support labour migration. It will cover associated attributes including, curricula, national legislations and state, socioeconomic and political environments.

\subsection{Epistemology}

There are alternative ways of doing qualitative research based on context and place, and it is important to recognise that diversity (Ritchie, 2010). Indeed, how researchers carry out research depends on beliefs about the nature of the social world and what can be known about it (ontology), the nature of knowledge and how it can be acquired (epistemology), the purpose(s) and goals of the research, the characteristics of the research participants, the audience for the research and the research environment (Ritchie, 2010). This research applied social constructivism as an epistemology where knowledge is constructed through interaction with people which, in this research, interaction with participants in Solomon Islands was through semi-structured interviews. The research used interviews as a medium of interaction by engaging the participants to create, formulate and construct knowledge that is culturally meaningful to Solomon Islands (Gegeo \& Watson-Gegeo, 2002). Through the recognition of indigenous epistemologies, we understand better the behaviours, interactions and experiences of Solomon Island policy players and how these relate to national development. Therefore, the research is anchored on traditional discourses and cultural practices and experiences to construct a meaningful knowledge that truly 
reflects people's culture, behaviours and characteristics towards development and policy in a culturally diverse environment like Solomon Islands.

\subsection{Methodology}

A qualitative research methodology was used in this research to study and investigate the policy relations between education and labour migration in Solomon Islands, that is, to study the behaviours and perception of policymakers, both in public and private sectors, on the policy link between education and labour migration. Because of its facility to examine and focus on the subject's in-depth context, qualitative research is an appropriate approach for studying what underpins a behaviour, decision or other phenomena (Ritchie \& Lewis, 2003). In this case, the research applied a qualitative semi-structured interview method to collect data from a list of selected participants. The aim was to explore the relationship between education and migration, and understand what the relational factors are and how they impact on the development of Solomon Islands. Qualitative design tries to answer the 'why' and 'what' questions in order to give insights into the constructions of knowledge about the research topic (Ritchie \& Lewis, 2003). It also encourages flexibility and openness for participants from different organisations and roles to share and tell their experiences and views regarding the asked research questions.

\subsection{Methods used}

The two main research methods used a combination of semi-structured interviews and a Pacific research method called talanoa ${ }^{1}$. Talanoa involves in-depth discussion with participants, using semi-structured questions. The application of talanoa and semistructured interviews is considered appropriate and relevant to Solomon Islands' diverse cultural, socioeconomic and political country.

\subsubsection{Semi-structured questionnaires and in-depth interviews}

Knowledge is understood as buried metal and the interviewer is a miner

\footnotetext{
${ }^{1}$ Talanoa is regarded as an approach in Tonga and variants exist in the Pacific such as storian. Talanoa is used in a Solomon Islands context to recognise its appropriate general characteristics, which fit well for this research.
} 
who unearths the valuable metal ... the knowledge is waiting in the subject's interior to be uncovered, uncontaminated by the miner. The interviewer digs nuggets of data or meanings out of a subject's pure experiences, unpolluted by any leading questions (Kvale, 2008, p. 19).

Participants were given a set of open, key questions about the research topic. A semistructured style was employed to achieve a balance between ensuring important known topics were covered while allowing the exploration of unknown but important topics (Cook \& Crang, 1995). Questions were open and qualitative to extract a combination of information, views and understanding of the research topic in a broader and in-depth perspective. The semi-structured interviews used a flexible schedule of topics and questions to gain insights into the research topic. Playing an active but responsible role with the interviewees was encouraged to engage in an interactive nature that facilitated the flow of the discussion. Most of the interviews were agreed and done in participants' offices because of convenience and the nature of the topic. As a researcher, I agreed to meet participants in their offices because there they felt comfortable to speak openly. As part of my ethical duty as a researcher, I had to respect participants' rights and agreed conditions to get unbiased views. The use of unstructured questionnaires and semi-structured interviews gives participants the opportunity to respond in their own words rather than forcing them to select answers from predetermined responses. The use of probing questions helped to investigate the topic in detail by getting comprehensive information and perspectives.

\subsubsection{Ontology and epistemology of talanoa method}

The ontology of the unstructured interview is the same as that for talanoa. The epistemology of talanoa is closely associated with the relationship between the researcher and participant, although very similar, is arguably not as entrenched as with talanoa (Prescott, 2008, p. 131).

Historically, Western research has been driven by testing hypotheses with approved questionnaires guided by institutions' ethics and formal requirements (Vaioleti, 2006). I 
applied the talanoa method because of its relevance and applicability in a Solomon Islands research context. Talanoa can be defined as a conversation, a talk, an exchange of ideas or thinking whether informal or formal (Vaioleti, 2006). The use of talanoa is fitting to the relaxed and flexible style of interviews but based on trust and flexibility, which became relevant for this research. Therefore, I employed the talanoa research method because of its value and significance, and because it is a commonly used Pacific research methodology. In considering epistemology and ontology of knowledge, talanoa fits in well with the Solomon Islands' context to construct knowledge that is original and unique, and provides reality about people and society or country. The blending of talanoa and semi-structured interviews fit in well with the interview sessions. However, in this research the epistemological essence was establishment of a true relationship that disregards knowledge as stolen but a shared matter between participants and the researcher. Subsequently, the talanoa method is applied in an ease mode to release the pressure of being in a formal research situation (Vaioleti, 2006). Respect is upheld to give time for participants to settle down without pressurising for the purpose of extracting their knowledge (Sultana, 2007). Formal interview settings were guided by university ethics and protocols and participants were given due respect to present their views without coercion.

Leading with talanoa created space to listen to participants' experiences and how they felt about the topic before going into the formal interview and discussion. In Pacific society, it is often a sensitive process to connect participants direct to the research (Suaalii-Sauni \& Fulu-Aiolupotea, 2014). Talanoa as a research method builds that bridge and understanding leading up to the formal interview. As a researcher coming from a New Zealand university, it requires the establishment of an honest relationship to fit into the culturally diverse working environment of Solomon Islands. Yet, being from the Solomon Islands and a former government official, the talanoa approach suited a relaxed and conversational style of research very well. This is considered a means to remove any hesitation and privacy concerns so that the information and views given are respected and used only for the research purpose. There is a danger in generalising about the epistemology of knowledge by assuming that all knowledge 
comes from the same origin, whether from Western or Pacific Islands (Suaalii-Sauni \& Fulu-Aiolupotea, 2014). In applying talanoa in Solomon Island policy context and situation, it allows for getting knowledge that is raw, authentic and unique to the place but at the same time transforms that knowledge into acceptable universal and Western-oriented academic research; thus it enhances rational examination and contribution to the link between education and labour migration.

\subsection{Selection of participants}

The selection of participants highlighted the purposive technique used to choose the pool of participants. The participants' pool represents a group of expertise at the policy level.

\subsection{Purposive sampling technique}

The participants were selected based on a purposive sampling method to gain their expertise and insights into the topic (Neuman, 2005). The reason being that undertaking data collections in policy areas requires participants who have in-depth knowledge and experience in Solomon Islands policy background. It is a sensitive research topic area as well, especially when interviewing very senior government staff at a policy level. Interviewing participants from academic institutions also adds academic dimension to the data. Before the actual interview, a list of potential participants was selected based on their roles and organisations. However, a few replacements occurred during the interview period as some invitations were declined. The participants' selection criterion is based on functional and professional within organisation's hierarchy setting (Neuman, 2005). The interview process was conducted with key selected professionals who held policy and decision-making roles in the national government and private institutions. Having a fair representation of views and perspectives from both private and public at the policy level also deepens the understanding and investigation of the researched topic with more and first-hand data. Logically, including experts and professionals in the education and labour sectors as primary sources of data is significant and relevant for the content of the research. 
With purposive sampling, the interview focuses only on a specific topic by using expert sampling to avoid bias and personal connection (Neuman, 2005). This is to avoid possible distortion of the credibility and reliability. The sampling also eliminates the temptation to select from among work-related ties, gender, ethnicity or even use the local cultural system known as the 'wantok system'. The wantok system is a part of Solomon Islands' common cultural fabric based on common linguistic and kinship bonds (Dinnen \& Firth, 2008). Purposive sampling completely avoids any elements of 'wantok system' or favouritism. Furthermore, interviews were audiotaped to have an accurate record of data for summary, analysis and interpretation.

\subsubsection{Participants' pool}

The pool of participants that took part in the interview consisted, primarily, of senior officers from four government ministries and two academic institutions (Table 3.1). The selected government ministries included Ministry of Education and Human Resources Development (MEHRD), Ministry of Commerce, Industry, Labour and Immigration (MCILI), Ministry of Finance and Treasury (MOFT) and Ministry of Foreign Affairs and External Trade (MFAET). In addition, the Acting Director of the University of South Pacific (USP) extension campus in Honiara Solomon Islands, was also included. USP is significant institution that continues to play a crucial role in Solomon Islands' human resource development. The interview also included the Solomon Islands National University (SINU) as the only national training institution that continues to provide tertiary education for students who are unable to make it to regional and international tertiary institutions. Therefore, two very senior staff from SINU were selected and interviewed, which contributes to the handful of insightful information and views from a national education academic service provider's point of view. 
Table 3. 1 The following table outlines the number of participants and their place of work.

\begin{tabular}{|l|c|c|}
\hline Organisation & Location & Number of participants \\
\hline $\begin{array}{l}\text { Labour Division: Ministry of Commerce, } \\
\text { Industry, Labour and Immigration }\end{array}$ & Honiara & 5 \\
\hline MEHRD & Honiara & 7 \\
\hline SINU & & 2 \\
\hline Extension Campus - USP & Honiara & 1 \\
\hline Economic Reform Unit: MOFT & Honiara & 1 \\
\hline External Trade Department: MFAET & Honiara & 4 \\
\hline Total & Honiara & 20 \\
\hline
\end{tabular}

\subsection{Data collection}

The data collection employed primary data collection using an in-depth semi-structured interview approach. The in-depth interview used a semi-structured schedule of questions that allowed for dynamic interaction and exchanges of views and answers. In-depth interviews provide opportunities for detailed investigations of participants' experiences, views and understanding of the research context and topic. It enables individuals to discuss personal history and experience in relation to the content and scope of Solomon Islands' policy culture. The interviews were conducted using a mixture of Solomon Islands Pidgin and English. However, the summary is completed in English to produce themes in a meaningful and clear way.

Although this research was selective in the number of participants, status and official responsibility in relation to the topic, it was very important that the interview covered a holistic and detailed interaction. A mixture of English and Pidgin allowed participants 
to speak confidently while adding uniqueness, richness and authenticity to the raw data collected. Likewise, it offered breadth with the support from participants to widen the scope of understanding of the topic. It facilitated the collection of information and wealth of knowledge that supported the direction and content of the research. There were 20 participants who took part in the semi-structured interviews. Of the 20 participants interviewed, 19 interviews were audio recorded to ensure flow of discussion without disruption or distraction. Only one participant was not audio recorded because of a technical problem with the recorder but agreed to be interviewed with note taking guided by the open-ended questionnaires. Appendix 2.0: Fieldwork and interview schedule provides an outline of the key questionnaires used for the interviews.

\subsection{Timing of the research}

The data collection was done concurrently to avoid coming back to the research field for the second data collection phase. All interviews were completed within a two and half month period. The initial plan for data collection for the research was six weeks. However, due to some previously identified participants declining to be interviewed, an extension was agreed in order to complete interviews with the new participants. Therefore, an additional four weeks' extension was granted, bringing it to 10 weeks in total to complete the required fieldwork and interviews. Interview and data collection primarily depended on the participants' availability because of their official duties and job responsibilities. All interviews were between 30 and 40 minutes and carried out during the day; most of the participants were only available for interview during their official hours. There were a few instances of interview rescheduling as participants were delayed or forgot their appointment time. However, through persistence, understanding and regular contact with the participants directly, the interviews were completed. 


\subsection{Research ethics}

For both internal and external researchers, being honest during the research fieldwork is critical (Johnson-Bailey et al., 2000, Caretta, 2015). Normally, the issues of race, gender, class and cultural dynamics surface during the process. Solomon Islands is made up of very diverse cultures and different ways of doing things. As a researcher who has worked for the government and is from Solomon Islands, it is very difficult to be neutral and unbiased in fieldwork. But with the ethical guidelines and ethical conscientiousness of my responsibility as a researcher, I was able to manage these challenges ethically. My fieldwork also applied the same ethical treatment in Solomon Islands by interviewing participants within ethical boundaries and accepted research requirements. Although there were mixed feelings of anxiety, complexities and obstacles working with a diverse society or environment like Solomon Islands, with diligent recognition of power and ethical responsibilities, these difficult issues were dealt with during the fieldwork and interviews. Creating enough space and time helped me to establish understanding with my participants and their organisations or departments regarding formal ethical procedures.

As part of the formal ethics requirement, ethical approval was obtained from the Victoria University of Wellington Human Ethics Committee (see Appendix 1.0: Human Ethics approval). Before starting the interviews, participants were given an information sheet in order to understand the aim of the research (See Appendix 4.0: Participants information sheet). Once the participants agreed, they signed the consent form (See Appendix 5.0: Consent form). I was also given a research permit by the Solomon Islands MEHRD under Research Act 1982(No.90) (see Appendix 3.0: Research permit). In such a situation, as a researcher coming from Victoria University of Wellington, I gave away some power and accepted the protocols of Solomon Islands formal working environment. The ethical and research guidelines formed my compass in navigating my negotiation and interview arrangement while in Honiara, Solomon Islands. I embraced their important role in the research by empowering the participants with respect and 
politeness and their share of contributions towards the research and potential impact in Solomon Islands.

The interview involves a talanoa conversation or formal interview depending on the situation and participant's preference and request. Usually, the interview process began with informal conversation and ended up with a more formal interactive discussion. But before going into the interview session, each participant was given time to read through the information sheet to understand the research ethics and aim. After that, participants agreed by signing the consent form before the interview began. Ethical research requirements must be observed for the interview to go ahead. During the interview process, there was no major disturbance from any of the participants, their departments, ministries or organisations. Delays occurred sometimes but, overall, participants were happy with the way the semi-structured questionnaires and interviews were structured and they were really engaged and interactive. The interviews were cited with number codes in the finding to uphold the confidentiality of the respondents. Ethics require interview participants' identities to remain anonymous.

\subsection{Positionality, reflexivity and power relations}

Conducting research in Solomon Islands is a challenge for me especially knowing that I have a strong cultural, personal and official connection with the government, private sector and the community. Research work involves paying more attention to issues of reflexivity, positionality and power relations while working in the field with diverse context (Sultana, 2007). In order to extract authentic information and truth from and about people, it is important to consider negotiating your way into the community with honesty and trust. Ethical values and job protocols are core prerequisites and helped this research to have a well-respected relationship with the participants (Caretta, 2015). The understanding between both researcher's and participants' positionalities

within the research context helped to protect one's integrity and confidentiality without compromising each other's roles. 
In addition, I previously held a senior trade officer position with the Ministry of Foreign Affairs and Trade; it was very tempting to exploit my existing networks in the public service to help my role as researcher. I spent five years working on various trade issues, including labour mobility and trade in goods and services, which Solomon Islands signed onto in the Pacific region, before coming to Victoria University as a student in 2015. I upheld all protocols and ethical requirements set by the university; I did not rely on my career and professional network to benefit and influence this research. My understanding of social inequalities and the cultural and political system in Solomon Islands helped me to negotiate and undertake my field work in an ethical and honest way. Otherwise, my data collection and findings might have been compromised. It was critical that I used my knowledge impartially, which helped to manage these complexities while navigating positionality in different situations.

Finally, it is important to recognise your own position and the position of the research participants (Rose, 1997). That compromise is relevant to ensure that the sustainability and confidentiality of the information and knowledge are guaranteed by either side. The argument is that knowledge originated from somewhere and denying its originality and structure is making false claims using positionality to apply researched knowledge as universally applicable is unethical (Rose, 1997, Caretta, 2015). Always conscious of the interview process as a medium of information giving and taking with equal participation (Sultana, 2007). Therefore, when I used my position as a researcher coming from Victoria University, I constantly reminded myself to be prepared for unseen circumstances that were risks in fieldwork. With those assurances in mind, I negotiated my interview appointments and conducted my interviews with patience and appreciation without major disruption. Being aware of different power dynamics in Solomon Islands helps to guide how to access information through in-depth interviews in an ethical manner.

\subsection{Thematic analysis}

Thematic analysis was chosen to highlight and summarise the key themes that appear in the data set. Thematic analysis is defined as a method that provides systematic 
identification, offering insight into patterns of themes across data set with meaning (Braun \& Clarke, 2012). Thematic analysis allowed me to focus on the data set and produce meaning that made sense for a wider audience and the public domain. A considerable amount of time was required to familiarise myself with the data by listening to the audio recordings many times, noting and writing down the main themes mentioned and discussed in the interviews. In any research, thematic analysis is considered the most appropriate way to determine themes, using interpretations and examining frequency of themes to assume accurate data analysis with content while conferring accuracy and intricacy, and enhancing the whole meaning of the research (Alhojailan, 2012). With that I spent time re-examining the summary text to ensure the themes were coded and categorised consistently with the research content. Being analytical and critical of the data is crucial meant actively engaging in reading and rereading so that I could deliver a true and authentic representation of the findings.

Finally, under thematic analysis, I used data coding and categorising of themes. Thematic analysis provides an entry into identifying only the themes that can otherwise seem vague, mystifying, conceptually challenging and over complex (Braun \& Clarke, 2012). Qualitative codes ensured that the essence and significance of themes were captured. In addition, main themes were selected based on relevancy and validity to the research to form a pattern of similarity that facilitated development of categories (Braun \& Clarke, 2012). I also used open coding to find what the distinct concepts were and created categories. I systematically placed them under overarching themes and used this for my final results. The findings and the discussion provided further explanation to the themes identified. Although this phase is called searching the main themes, it is not like an archaeologist digging around but searching the themes within the data collected (Braun \& Clarke, 2012). It is a flexible and accessible approach, which includes analysing and coding data across the data sets and interviews. The coding and categorisation process is open simply to allow identification of as many themes as possible before merging them under final concepts or categories that are important to the research. It gave me less pressure and guidelines to restrict myself to the preselected categories system. 


\subsection{The research limitations}

Solomon Islands has been through several major social and political upheavals over the last decade. Fragile security and social order, poor governance and unstable political systems are major hindrances with regards public trust for academic research. The current situation is still volatile with the negative effects still resonating within the national transition and recovery efforts. I felt the same wariness during my fieldwork while conducting my interviews. There was a sense of suspicion and absence of trust existing everywhere as I negotiated with ministries to arrange for the interviews. Even though my interviews did not result in any major disturbances, long delays and refusals indicated that sentiments of a difficult past remain active and continue to impact on the research work in Solomon Islands.

The first challenge I encountered during my fieldwork was the restriction of the use of purposive sampling. The unexpected decline by a number of top policy professionals in the public service at the last minute was said to be due to job commitments. Others declined to participate due to political and personal reasons because they felt that being part of the research interview might force them to lose their jobs for making critical statements against the government. In addition, the interviews also missed the opportunity to get valuable contribution and wealth of experiences from subordinate staff with years of working experience in the public and private sectors. However, with the narrowness of the purposive sampling method, interviewing only elite samples at education and labour policy level, it restricted interviews from achieving broader perspectives and views. The requirements and criteria for purposive sampling are challenging issues for a small workforce like Solomon Islands, such that identifying participants in the same role and of similar experience for interview is difficult. Arranging replacements and new interview appointments meant the availability of a very limited pool of policy expertise and the lack of top-level staff added to the dilemma. 
Another limitation is payment of a research fee to the Ministry of Education. I did not realise that I had to pay a research fee until I arrived in Honiara. The MEHRD is supposed to encourage and lead the country in research and development yet it enforces a student research fee which, arguably, sends the wrong message for future research work. It is part of the Education Act but it defeats the purpose of an open economy that promotes quality education and strongly supports research and development in the country. It took about two weeks before approval was granted by the Minister of Education, which added another layer of delay to the process. From the researcher's point of view, research fees and bureaucratic requirements are considered as limitations to motivate researchers to engage in academic research that are associated with the national economy and politics.

Furthermore, low response rates, especially with interview arrangements, or even general enquiries, are a major concern. Some of the front desk people have poor customer services. I sat long hours waiting to make enquiries and some days left without a response. On some occasions, receptionists or front desk support officers ignored my request although I was right in front of their enquiry desk. As a researcher, relying on organisation's support staff to make arrangements is a major obstacle in Solomon Islands. Sending enquiries through emails was also a major obstacle for my research. I had to follow up emails by calling participants directly followed by a face-toface conversation before participants agreed to the interviews. It proved wrong, to make a general assumption that coming to my own country would be helpful. The opposite was true. Slow responses, delays and suspension of arrangements were common limitations encountered that contributed to a slow interview process.

Moreover, with the semi-structured interview method, there was too much room for discussion to go off topic. Due to time constraints and official duties, some interviews were hurriedly done to allow participants to go back to work. It impacted on the comprehensiveness and scope of data and information as some views presented are brief. In addition, the proportion of information and final data set were limited in terms of richness and relevance because more time was spent on unimportant matters. As a 
researcher, it is difficult to manage a semi-structured interview in a short amount of time when the intention is to get in-depth information. Some of the participants were constructive but not all of the participants were able to respond directly to the questionnaires or the research topic.

Finally, accessibility to national government ministries' official reports and documents was difficult. There are inadequate official information and policy documents. Unreliable information collection and documentation of key statistical information and policy reports affected this research work and data collection. I had to seek the participants' help to get the needed official reports and policy documents, which added to the slowness of data collection. After several attempts with relevant ministries and departments such poor response became frustrating. The lack of support and value for academic research is still a huge gap in Solomon Islands. As a researcher, I encountered difficulty getting access to the relevant official labour migration and education information and documents. There has not been any research done in Solomon Islands in this specific area, therefore, the understanding and available information as a background on this specific topic is still minimal. Most of the government ministries lack adequate information and proper guidelines which was unhelpful for the collection of needed information and documents for my research.

In summary, this chapter covers methodology and methods applied during the interviews. A qualitative approach is used in the research. The methods used semistructured interviews leading with open questions. Talanoa method was also applied because its epistemology and ontology of knowledge fits with the Solomon Islands context. In addition, the research method adopted a social constructivism framework that guided the interviews. The participants were selected from key government ministries and two private academic institutions based on purposive sampling approach. Mainly, the views from participants were taken through an ethical process supported by Victoria University's ethical guidelines. Findings and analyses were completed using thematic categories to ensure validity. A coding system of numbers was employed to ensure participant confidentiality. There were limitations during the 
interviews but through the research protocols and ethical guidelines have shaped and directed this research without major problems. 


\section{Chapter 4: $\quad$ Solomon Islands context in development}

\subsection{Introduction}

In this chapter, I discuss the context of Solomon Islands. Firstly, I focus on Solomon Islands' background, including geography, demography, economy and political system. The second part covers Solomon Islands' development issues and partnership with the development community. The labour and employment sectors form the third section. Finally, the discussion will focus on the education in Solomon Islands.

\subsection{Geography}

Solomon Islands is an independent state of 992 islands, situated in the South Pacific and has a total land area of 28,400 square kilometres (United Nation Development Programme, 2010). As shown in Figure 2.2, many islands scattered across the ocean. Honiara is the national capital situated on Guadalcanal Island, a province of its own. English is the official language (lingua franca) of instruction at school, although pidgin is widely spoken as a national language. There are over 80 local dialects or languages spoken across different islands. The islands are wide-spread across the ocean, which becomes a challenging factor for inter-island mobility and movement of essential services and development projects. Transportation to the most isolated communities, whether by air or sea, is a common, challenging issue for the business sector, education and health services. The costs associated with the delivery of social and economic services are major limitations due to geographic isolation from urban administration and centres of economic activity. 
Figure 4. 1 Solomon Islands map

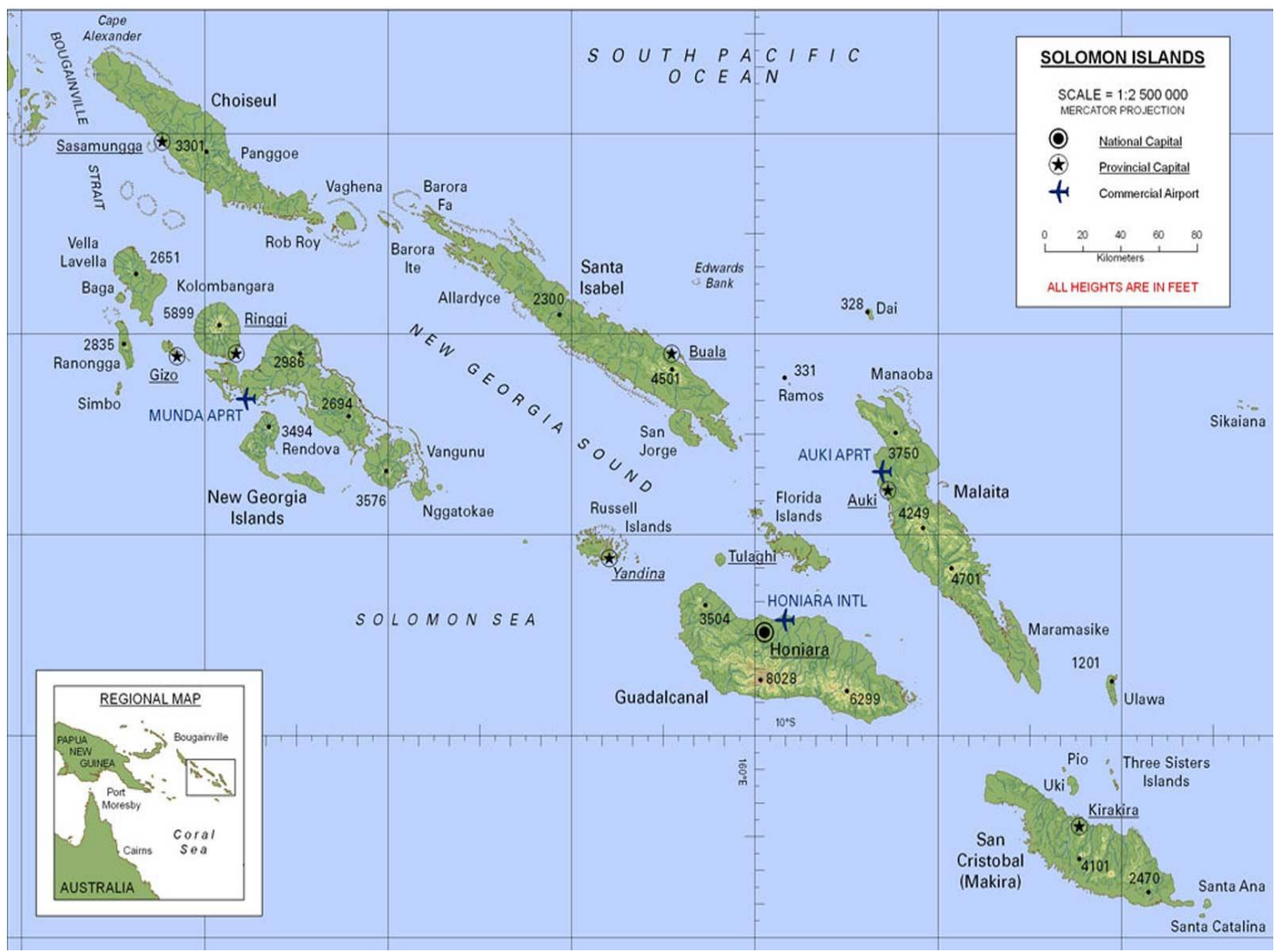

Source: (http://www.surfsolomons.com)

\subsection{Demography}

According to the census, 2009 summary, the total population of Solomon Islands is 515,870 (Solomon Islands Government, 2009). It is a multi-ethnic and multicultural society but most people are occupied with subsistence agriculture for their livelihood. Over $85 \%$ of the total population lives in the rural areas, engaging in the subsistence economy. The country is known for its natural resources from rich minerals deposits, marine resources, forests and fertile land. The rapid urban migration of rural people into Honiara and other provincial centres over the past two decades has raised concerns. It is estimated that the total population will continue to increase at $2.5 \%$ growth rate and urban population will be higher than this (ILO, 2009). The young population, aged between 16 and 30, makes up the large portion of the population. Most of the young working age population are unemployed, which triggers a major problem for the economy and future development of the country. 


\subsection{Political structure}

Solomon Islands gained political independence from the British government in 1978. Since, then, the state adopted Western-style laws and a constitution, promoted formal education and established national administrative government. Most of the government systems and decision processes are centralised. However, resistance and objections of centralised government has been expressed through a political movement called 'Maasina Rule' (Akin, 2013). The Maasina Rule (brotherhood) movement aims to decentralise and localise development so that local people can participate equally in the development process. In the post-independence period, the system of government consists of the Governor General as the Head of State representative of the Queen. The national parliament consists of 50 elected members, and a 20-member Cabinet of Ministers headed by the Prime Minister. There are political parties, including People Alliance Party (PA), National Party (NP) and Liberal Party (LP) (Dinnen \& Firth, 2008). The parliamentarians are legislators of national laws and constitutions. National policies and corporate plans reflect national interests and priorities without undermining the Acts of Parliament. However, since its independence, political instability is a common feature for Solomon Islands as most political parties are not guided by a strong tradition of voting disciplines and constitution (Solomon Islands, 2002). A consistent pattern of political crises and corruption hamper development efforts. As a result of the political instability, the Regional Assistance Mission to Solomon Islands (RAMSI), a regional force, intervened in 2003 to restore the state from collapsing (Dinnen \& Firth, 2008). A conventional Westminster system, which has the government and opposition, rejects the culturally diverse Solomon Islands resulting in divisions among islands, districts and linguistic lines (Dinnen \& Firth, 2008). Solomon Islanders have confidence in the democratic system but elected leaders have not displayed maturity and transparent leadership. The national government's ability to provide essential services like health and education and public utilities is very fragile (Solomon Islands, 2002). 


\subsection{Diverse economy}

Traditional societies are predominantly involved in subsistence economy and depend very much on traditional knowledge and inherited skills. Localism prevailed over nationalism in virtually every sphere of social, economic and, significantly, political life up to now (Dinnen \& Firth, 2008). Barter systems still remain in some traditional and rural parts of Solomon Islands with natural resources and community work. Solomon Islands as a diverse economy, accepts many different types of transactions, from formal market transactions to non-market exchanges, broadening the understanding of economy that fits the diverse situation (Gibson-Graham \& Roelvink, 2011). Reciprocity, giving and taking without money but with a future expectation of return in other means, is the cornerstone of the unity, relationship and peace between societies (Solomon Islands, 2002). These alternative economies are common and an important part of the tradition and social relationships but they come with moral obligations to exchange transaction in some form to the giver in the future. Solomon Islands is a nation of villages and villagers who depend on subsistence activities, yet participates in development democratic system (Dinnen \& Firth, 2008). In addition, many traditional societies are still using traditional shell money as a medium of transaction for goods, services and cultural events. Communal and traditional values in alternative economies are still active among kinship because of its significance and positive impacts on the social and economic wellbeing of people. People have moral and communal responsibility to help kin or relatives when they are in need without demanding any compensation or reward in cash.

However, the formal economy has now started to overtake the alternative economies practised in traditional societies. Today, the popularity of the commercial economy and availability of formal employment has hugely impacted on the values of alternative economies and traditional practices. The economy experienced a major setback between 1999 and 2003 during the ethnic unrest in the Solomon Islands. The breakdown of law and order had a detrimental impact on the business and industrial sector performance and slowed down the development of the country. For example, 
the Forestry Division, provincial government and community leaders did not have resources to monitor and police logging in Solomon Islands (Dinnen \& Firth, 2008). The economy mainly depended on its primary export sectors - logging, mining, agriculture and fisheries - to raise its revenue to support services. Most of the industrial and economic activities occur in urban centres and more especially in Honiara. Solomon Islands' business faced significant challenges of poor demand, high transports costs, inadequate infrastructures and security problems. The economy is also directly affected by the falling commodities' prices in the international market, which impact the business households' operation and profitability and, therefore resulted in loss of jobs, reduced government revenues and affected wellbeing of people (King's College London, 2013).

Additionally, major reforms and reviews of key sectors in the economy have been ongoing in the public and private sectors. Solomon Islands has been undergoing legislative and regulatory reforms, which is a positive direction for national business and the private sector development. The major reforms occurred in areas of telecommunication and the national energy sector to lower the costs of services for the economy (King's College London, 2013). The arrival of RAMSI strengthened the legal and policy framework and the financial sectors enabling improvement in government systems (Dinnen \& Firth, 2008). The liberalisation of domestic market also resulted in a flow of investment into major sectors of education, tourism, fisheries and transport infrastructures. These reforms aim to remove bureaucratic barriers and market irregularities and increase investments to create more jobs and improve the standard of living in Solomon Islands. The outlook of the economy is to encourage legislative and policy reforms, develop infrastructure and improve information and communication technology to open the economy and attract more foreign investment in key sectors to boost development and fuel economic growth. 


\subsection{Solomon Island development landscape}

\subsubsection{Development status}

Solomon Islands still remains a least developed country according to the UN standards. The term LDC is given to Solomon Islands because of its overall rating in terms of economic, social and political indicators (OECD, 2012). Solomon Islands continues to face obstacles in good governance, national security, low economic growth and unsustainable development plans. The current GDP per capita of USD 1030 for 2010, makes it the poorest country in the Pacific region (OECD, 2012). Heavy dependence on unsustainable harvesting of a few natural resources, such as mineral deposits and forest, is not sustainable to the economy in the long run. Unfavourable market forces such as unstable global prices and financial shocks impact on the domestic industry. In 2011, growth was based around log export, which accounted for $46 \%$ of export revenues, minerals (16\%), fish (11\%) and palm oil (10\%) (OECD, 2012). Poor governance and institutional limitations resulted in a poor regulatory environment where freedom and real free market principle cannot dictate itself (King's College London, 2013). To a certain degree, the corruptive activities and poor governance put the political system and economy under threat and reduced public confidence. Poor leadership with nontransparent decision making deprives the public of their right for better services. Deteriorating public infrastructures and facilities causes a lot of unreliable and expensive services to the private and public sector. Therefore, it is unlikely that Solomon Islands will move up the ladder to developing country status any time soon because of its heavy reliance on traditional commodities, development assistance and a weak economic and political system. National development policies will not shift or change as long as government attitude and policy agendas remain ignorant of valueadded initiatives and a sustainable economic base.

Furthermore, Solomon Islands is still classified as an aid and development recipient country. Aid constituted 67\% of Gross National Income in 2010, 48\% in 2011 and 34\% in 2012 (OECD, 2012). The amount of external funding towards supporting national sectorial policies, including health and education sector is huge. It continues to 
contribute to key budget lines to meet long-term training and skill development of the country. Through established cooperation and development partnership, Solomon Islands continues to benefit from external funding and technical support. Close connections to the international community through cooperation, development support and diplomatic relations build trust and responsible actions between Solomon Islands and development partners. The balance of power has, therefore, changed from government, a very state-centred perspective, to a 'multilayered, multidimensional and multiplayer' governance (Held, 2004). In a nutshell, the networks of international integration have changed the power of the state by diminishing its decision-making role, sovereignty and political autonomy (Held, 2004). Within this interconnected global society, Solomon Islands has resorted to building stronger alliances, both bilateral and multilateral. Through development assistance, the country can respond to, and is able to tackle, some of the domestic challenges like high internal migration, poor socioeconomic services and inadequate education training services. In contrast, the development community has priority development areas where their funds are tailored towards supporting. And so, agendas like education and the labour market, or even labour migration, are normally excluded from development cooperation agreements or arrangements. Therefore, national policies sometimes overlook or make no reference to certain areas like education and labour migration policy because of the development partners' upperhand on the policy focus. But formal dialogue between development partners and national policymakers focuses only on education in general, health, rural development projects, security and good governance.

\subsubsection{Partnership}

Over the last decades, Solomon Islands has established long-term bilateral relations with donor partners, including Australia, Japan, New Zealand and the European Union (EU). In addition, multilateral relations have been formed with development partners such as World Bank, United Nations Development Programme (UNDP), Asian Development Bank (ADB) and World Trade Organization (WTO), and these continue to play a supportive and crucial role in funding different sectorial projects. For instance, New Zealand has been a key donor partner in funding the Solomon Islands' education 
sector, more specifically, in primary and secondary education, and in providing scholarships to tertiary students (ILO, 2009). On the other hand, WTO is currently supporting Solomon Islands through an Enhanced Integrated Framework initiative by establishing a national trade policy framework that highlights some of the key policy and institutional capacity constraints and market opportunities, including labour migration schemes. Solomon Islands government led sector programmes aimed to foster development guided by the sectorial relationship established between national government and donor partners (OECD, 2012). With predetermined development agendas, donor partners play an influential role in ensuring national policies and plans reflect their interests. However, the domestic labour market continues to suffer because of development assistance, and aid dictates the behaviours of policy making and strategic plans in Solomon Islands. Education has been one of the top funded sectors in Solomon Islands by donors but basically at the primary and secondary levels. The traditional knowledge and tertiary sectors are, by far, the least supported sectors domestically when it comes to development assistance, so it paralyses the prospects to train local students to fit local economy and look beyond the national borders for economic and employment opportunities in the global market.

\subsection{Labour and employment sector}

The Labour Act 1978 is the early legal instrument for labour in Solomon Islands. Later revised to the Labour Act 1996 and Employment Act 1982 as the two principal laws governing migrant workers coming into, and going out of, the country for employment (ILO, 2009). The provisions within these Acts promote an open economy where foreigners are allowed to come in and work as specialised professionals in selected job areas. Employment permits are granted by both the Immigration Department and Labour Division once all employment requirements are correctly fulfilled. In terms of labour migration outside of the country, the Labour Division has authority to scrutinise and verify the foreign employment agreement and the status of the employer to see whether employment contracts are genuine. The basic aim is to ensure that workers are protected from exploitation and discrimination, and their rights and conditions of employment are taken care of within the employment laws and requirements of the 
host country. Other than this provision, there are no formal guidelines and provisions existing in the current Labour Act and Employment Act that mandate the Labour Division to establish a formal structure to promote and facilitate labour migration. Normally, the priority is to supply a sufficient and effective workforce for the domestic labour market. Policy statements and plans are passive on labour migration as a national priority, which adds to the set of structural, institutional, policy and legislation challenges faced by the state and the economy.

Solomon Islands, like many other small islands states, continue to faces a lot of unemployment and socioeconomic challenges. The country could not provide enough opportunities to support its rapid growing population with its high percentage of very young people. According to a World Bank report, more than $40 \%$ of youths are inactive in the employment sector (World Bank, 2012). Similarly, a labour market data report by ILO stated that more than three quarters of the total population is attached to local agricultural economy largely on a subsistence basis (ILO, 2009). This report also highlighted that the number of individuals in paid employment is estimated at 57,472 in 2004, including 39,761 males and 17,711 females (ILO, 2009). 
Table 4. 1 Economic activity status by sex and urban and rural location, Solomon Islands, Population aged 12 and above.

\begin{tabular}{|c|c|c|c|c|c|c|}
\hline & \multicolumn{2}{|c|}{ Solomon Islands } & \multicolumn{2}{|c|}{ Urban } & \multicolumn{2}{|l|}{ Rural } \\
\hline & Males & Females & Males & Females & Males & Females \\
\hline Employed & 107,692 & 102,693 & 20,419 & 15,746 & 87,273 & 86,947 \\
\hline Paid employment & 54,571 & 26,669 & 17,978 & 9,798 & 36,593 & 16,871 \\
\hline Unemployed & 2,490 & 1,841 & 1,444 & 1,067 & 1,046 & 774 \\
\hline $\begin{array}{l}\text { Labour force } \\
\text { (employed + unemployed) }\end{array}$ & 110,182 & 104,534 & 21,863 & 16,813 & 88,319 & 87,721 \\
\hline Outside the labour force & 63,849 & 63,859 & 17,032 & 18,107 & 46,817 & 45,752 \\
\hline Total population (aged $12+$ ) & 174,031 & 168,393 & 38,895 & 34,920 & 135,136 & 133,473 \\
\hline $\begin{array}{l}\text { Employment to population rate } \\
\text { (\%) }\end{array}$ & 61.9 & 61.0 & 52.5 & 45.1 & 64.6 & 65.1 \\
\hline Paid work to population rate (\%) & 31.4 & 15.8 & 46.2 & 28.1 & 27.1 & 12.6 \\
\hline Unemployment rate (\%) & 2.3 & 1.8 & 6.6 & 6.3 & 1.2 & 0.9 \\
\hline $\begin{array}{l}\text { Labour force participation rate } \\
(\%)\end{array}$ & 63.3 & 62.1 & 56.2 & 48.1 & 65.4 & 65.7 \\
\hline Economic inactivity rate (\%) & 36.7 & 37.9 & 43.8 & 51.9 & 34.6 & 34.3 \\
\hline
\end{tabular}

Source: (Policy Statement and guidelines for National Curriculum: Solomon Islands, 2009).

The national labour force consists of both the urban and rural market (Table 4.1). The public service as the largest employer in the country is employing over 11,000 public servants. The private sector is predominantly located in Honiara and the western part of the Solomon Islands. In general, the job market differs vastly between urban and rural areas. Males have been largely dominant in the labour force in both private and public employment sectors (Figure 4.2). 
Figure 4. 2 Share of employees' positions by sector and sex, Solomon Islands, 2009.

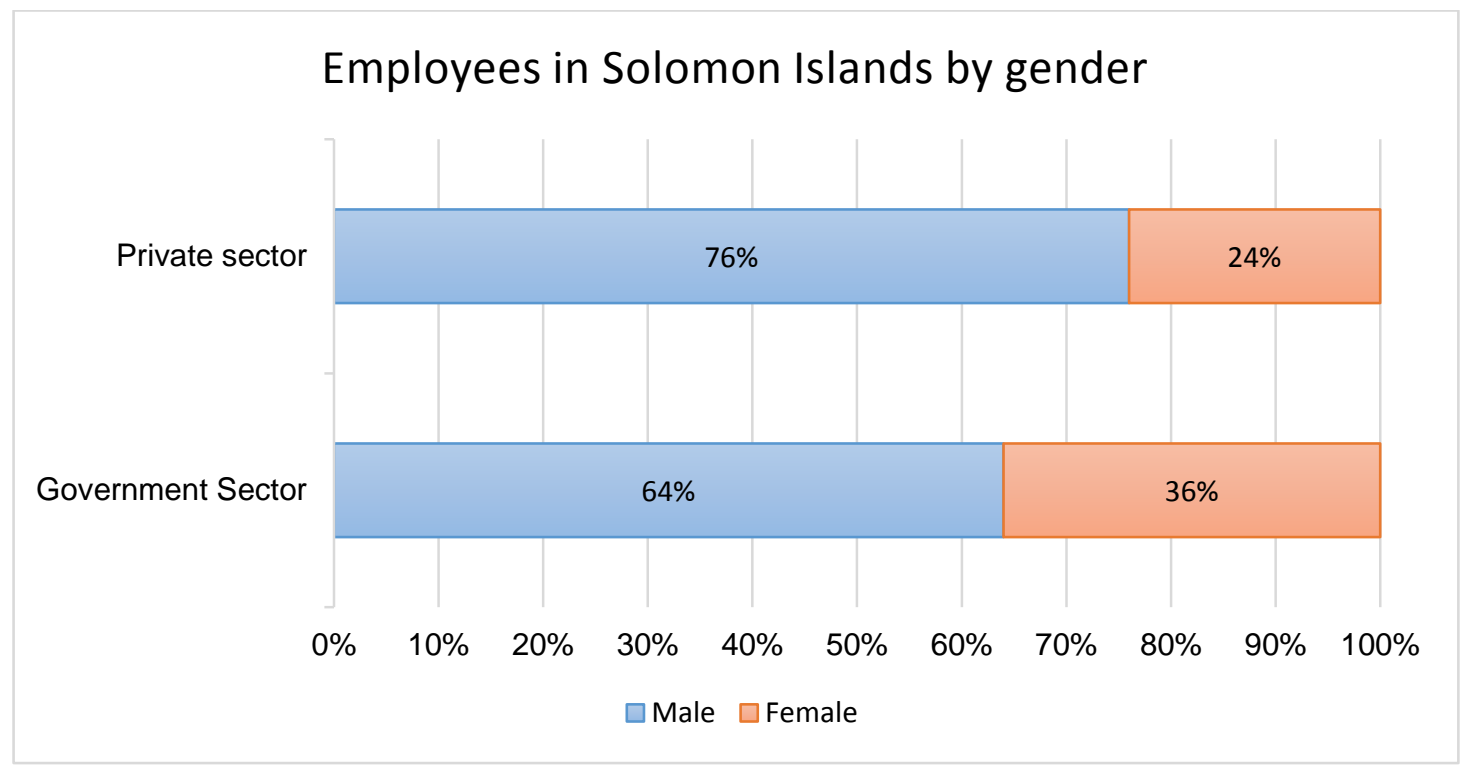

Source: (Policy Statement and guidelines for National Curriculum: Solomon Islands, 2009).

The arrival of the RAMSI in 2003 at the end of the ethnic tension, has helped restore the law and order, stabilise the economy and improve the business environment to attract more foreign investors to come into the country (Dinnen \& Firth, 2008). The private sector consists of few industrial companies and two of the most notable are the Guadalcanal Plains Palm Oil Limited (GPPOL) and the Solomon Tuna Company. Both companies employ few-hundred workers on both a temporary and a permanent basis. Other businesses engage in small-scale entrepreneurial activities which employ few workers often for very low wages. Most businesses operating in the domestic economy are medium-sized enterprises like families running shops, taxis, selling marine resources for living and inter-islands sea transport (King's College London, 2013). Despite the improved business and labour market environment and increased employment opportunities, there is still insufficient capacity within the labour market to absorb all the young working population coming through the education system (ILO, 2009). A high number of youths are without adequate skills to get formal employment. There is an urgent need for the domestic economy to expand the economic base to 
support the booming young population to have access to diverse job opportunities by increasing tertiary education services. In the end, this will help to explore other external labour opportunities to absorb the highly educated, skilled and qualified portion of the labour force and release the pressure on already stressed domestic labour sector.

The youth unemployment ratio is $42.4 \%$, which is a big concern for the economy (World Bank, 2012). Most school leavers are poorly equipped to compete for scarce jobs in terms of attained knowledge and learnt skills. The high numbers of children pushed out from the education system have only reached either primary or junior secondary education, which is not marketable in the labour market (World Bank, 2012). Solomon Islands' current education policies are not responding to the diverse skills required in the job market, which were flagged as market challenges to labour migration. The labour market is composed of more unskilled workforce that are suitable only to local economy and low skilled employment opportunities. There is also a lack of appropriate services and plans to support young people as they move from school to work (ILO, 2008). The majority of the labour sector is semi-skilled and unskilled impacting on the slow development of an effective and skilled labour market. Consequently, most youths who are pushed out of school early have only two options: to return to their villages to become a subsistence farmer or to remain in towns looking for work in the informal sector with very low pay.

\subsection{Labour migration in Solomon Islands.}

The British declared protectorate over Solomon Islands in 1893, with the aim of regulating the labour and trade in order to appease the Australasian colonies and avoid imperial control from other European nations (Bennett \& Others, 2002). Solomon Islands was a significant labour source for Australia and Fiji in the late $18^{\text {th }}$ to early $19^{\text {th }}$ century. According to Moore, between 1870 and 1911, Solomon Islanders made up 18,000 of the migrant workers who were taken to Australia alone as indentured labourers (Moore, 2007). Labour migration happened during the liberal imperial era where colonialism was a dominant ideology. A number of researchers supported that 
many of Solomon Islands' labourers were taken under the black birding regime carried out under forceful conditions, including kidnappings and violent recruitment (Craig \& Bedford, 2013; Craig et al., 2014, p. 12; Corris \& Others, 1970). During the protectorate period, this historical evidence painted a new perspective around migration of workers. A very few fortunate Solomon Islanders were sponsored by the colonial British administration and Christian Missions to travel overseas to undertake their formal education (MEHRD, 2015). It was during those early legacies that recognition and amalgamation of education and employment started taking roots in modern economy and government institutions. Early education in the colonial migration era is widely regarded as the opening to the understanding between education, migration and formal employment.

Moreover, old legislation and policies adopted during post-colonial and modernisation era are still in use today. While current amendments to the existing policy regimes are occasionally driven, it is equally vital that the current economic needs and policy limitations in education and labour sectors are not sidetracked. In the execution of mandated functions and responsibilities, the Labour Division is governed by the Labour and Employment Acts. However, these two pieces of legislation focused on the following areas: occupational health and safety, industrial relations, employment services, international labour standards and prosecution and national trade training and testing (Corporate Plan 2016-2019: Ministry of Commerce, Industry, Labour and Immigration, 2016). The current Labour and Employment Acts still need reviewing to reflect the current labour and economic status. Policy discussion and plans often consider the economic uncertainties and labour market gaps as core features of the economy and national laws, but now, it has become a critical matter that national institutions and policy elites must consider.

The Labour Division of the MCILI has raised a concern that many of the critical issues are administered in different ministries. For example, TVET is administered by MEHRD and partly supported by the Aid Coordination Ministry (ILO, 2009). Lack of skilled personnel and resources has compromised capacity within the Labour Division. The 
absence of a clear policy mechanism in support of labour migration adds to the dilemmas. But the major concern is the level of fragmentation in national policies and coordination between different government ministries and departments to jointly address the skills gaps and needs of the economy (World Bank, 2012). The economy is small but gradually growing so new opportunities are emerging in sectors of tourism and medium enterprise businesses and abroad under labour migration schemes. But Solomon Islands' economy continues to face a shortage of skilled labour to take these opportunities. Even labour policies and strategic plans are not yet ready to deal with labour migration opportunities. The awareness at department level is increasing; however, very minimal actions are taking place towards reviewing the labour legislations and policies to accommodate training and skills needs of the country.

In a recent launched Pacific report, Solomon Islands is classified as a low mobility nation overseas compared to other Pacific countries (SI a low mobility nation, 2016; ILO, 2015). Solomon Islands is currently without a comprehensive trade or productive sector development policy to respond to emerging trade issues and labour migration schemes (Daniel, 2009). This is one of the reasons the level of labour migration is low. Without favourable agreements with countries such as Australia and New Zealand the chances of Solomon Islands migrants gaining visas are low. The pattern of internal labour migration in Solomon Islands is varied and has been on the rise in the last decades. In 2009, around 9\% of females and 10\% of males aged five years and over were recent migrants, meaning they were living in a different province compared to where they were in 2004 (Policy Statement and guidelines for National Curriculum: Solomon Islands, 2009).

External migration and labour mobilisation is happening and is, on many occasions, instigated by family and personal decisions facilitated under unsystematic models. According to 2009 government statistic census, education is one of the main explanations for the overseas movements of Solomon Islanders, as suggested by the age structure of those who had returned in the five-year period leading up to the Census (Table 4.2): about one-half of these were aged 25 to 39, suggesting that these 
are post-tertiary movements' (Solomon Islands Government, 2009). Skilled and qualified professionals utilise their own means while the unskilled workforce are facilitated under temporary mechanisms which showed the divergence in national approaches to labour migration. There are many inconsistencies in the national system especially in domestic frameworks, which contribute to the low number of Solomon Islands' workers migrating overseas. Existing national education and labour instruments also fail to link and regulate labour migration in an efficient way.

Table 4. 2 Solomon Islands overseas residence

\begin{tabular}{|l|c|c|c|c|}
\hline \multirow{2}{*}{$\begin{array}{l}\text { Place of residence 5 } \\
\text { years ago }\end{array}$} & $\begin{array}{c}\text { Sountry of } \\
\text { residence 5 } \\
\text { years ago }\end{array}$ & $\begin{array}{c}\text { Citizens by } \\
\text { naturalisation }\end{array}$ & All citizens & $\begin{array}{c}\text { \% of total } \\
\text { overseas }\end{array}$ \\
\hline Papua New Guinea & 236 & 33 & 269 & 25.7 \\
\hline Fiji & 201 & 11 & 212 & 20.2 \\
\hline Vanuatu & 55 & 4 & 59 & 5.6 \\
\hline Other Pacific & 22 & 19 & 41 & 3.9 \\
\hline Australia & 149 & 9 & 158 & 15.1 \\
\hline New Zealand & 20 & 4 & 24 & 2.3 \\
\hline Europe (Inc. UK) & 20 & 7 & 27 & 2.6 \\
\hline USA & 19 & 1 & 20 & 1.9 \\
\hline Other Country & 48 & 10 & 58 & 5.5 \\
\hline Total & 903 & 144 & 1047 & 100.0 \\
\hline
\end{tabular}

Source: (Solomon Islands Government, 2009) - Solomon Islands Population and Housing Census 2009. Report on Migration and Urbanization, Government of the Solomon Islands.

Table 4.2 above shows that more than 1,000 Solomon Islands citizens had been overseas in 2004, and about one-half of these were in other Melanesian countries (PNG, Fiji and Vanuatu) (Solomon Islands Government, 2009). Education is one of the main explanations for the overseas movements of Solomon Islanders, as suggested by 
the percentage of those who had returned in the five-year period leading up to the Census. Many of those overseas attended tertiary education institutions in PNG and Fiji.

Even though the level of labour migration and movement of Solomon Islands externally is low compared to other Pacific countries, it does not disregard the national interest and the potential to bring positive social and economic benefits for the country. A temporary labour mobility arrangement is currently implemented under the regional labour mobility policy initiated under the current Pacific Agreement on Closer Economic Relations (PACER plus) negotiations. The Australia Seasonal Work Program (SWP) and New Zealand Recognised Seasonal Employer (RSE) employ unskilled workers from the Pacific, including Solomon Islands, to work in horticulture and viticulture industries. So far it is estimated that about 500 Solomon Islands' seasonal workers have participated under New Zealand RSE and a total of 50 for Australia SWP in 2015 (MFAET, 2015). Many Solomon Islanders who have been pushed out from the formal education sector have travelled under the seasonal schemes and expressed strong support for the labour migration initiatives. The temporary movement of labour across borders is a fast-emerging issue in Solomon Islands and is a growing body of research and debate in the Pacific region (Daniel, 2009, p. 194). At the national level, technical support and formal dialogue started to emerge but needs to materialise so that labour migration becomes a key development policy initiative for the country. Thus, aligning of education system and labour policies is crucial to be more competitive from regional and international labour markets to generate more socioeconomic benefits for Solomon Islands.

\subsection{Education system}

Education in Solomon Islands prior to independence in 1978 was the responsibility of the early Missions and the Protectorate government. Modern education was first introduced by the early Christian Missions in the mid-1860s (MEHRD 2015). The 1978 Education Act introduced a formal education system. A good number of Solomon Islanders attended the Melanesian Mission in Norfolk Islands to learn how to read the 
Bible and to be instructed in Christian values, beliefs system and later returned to the islands (MEHRD, 2015). Early education in Solomon Islands was denomination-based. Christianity came when the first Europeans arrived in the Solomon Islands. Different denominations such as Anglican, Roman Catholic and United Church established their missions in Solomon Islands with the primary aim of conversion of souls from traditional beliefs to Christianity. Learners around missionary stations were taught basic reading, writing, arithmetic and religious knowledge. At that time, there was no formal industrial education, although students were engaged in practical learning activities such as boat building, concrete work, house building and other learning on the jobs activities (MEHRD, 2015). The curriculum was limited and established purposely to address immediate administration work and the needs of the mission and its Christian ideologies. Later, the education system shifted more towards meeting the needs of the colonial administration. 
Figure 4. 3 The national education structure of Solomon Islands

\section{STRUCTURE OF EDUCATION SYSTEM}

( $\mathrm{U}=$ University level education at USP, UPNG, FIT, UNITECH etc.)

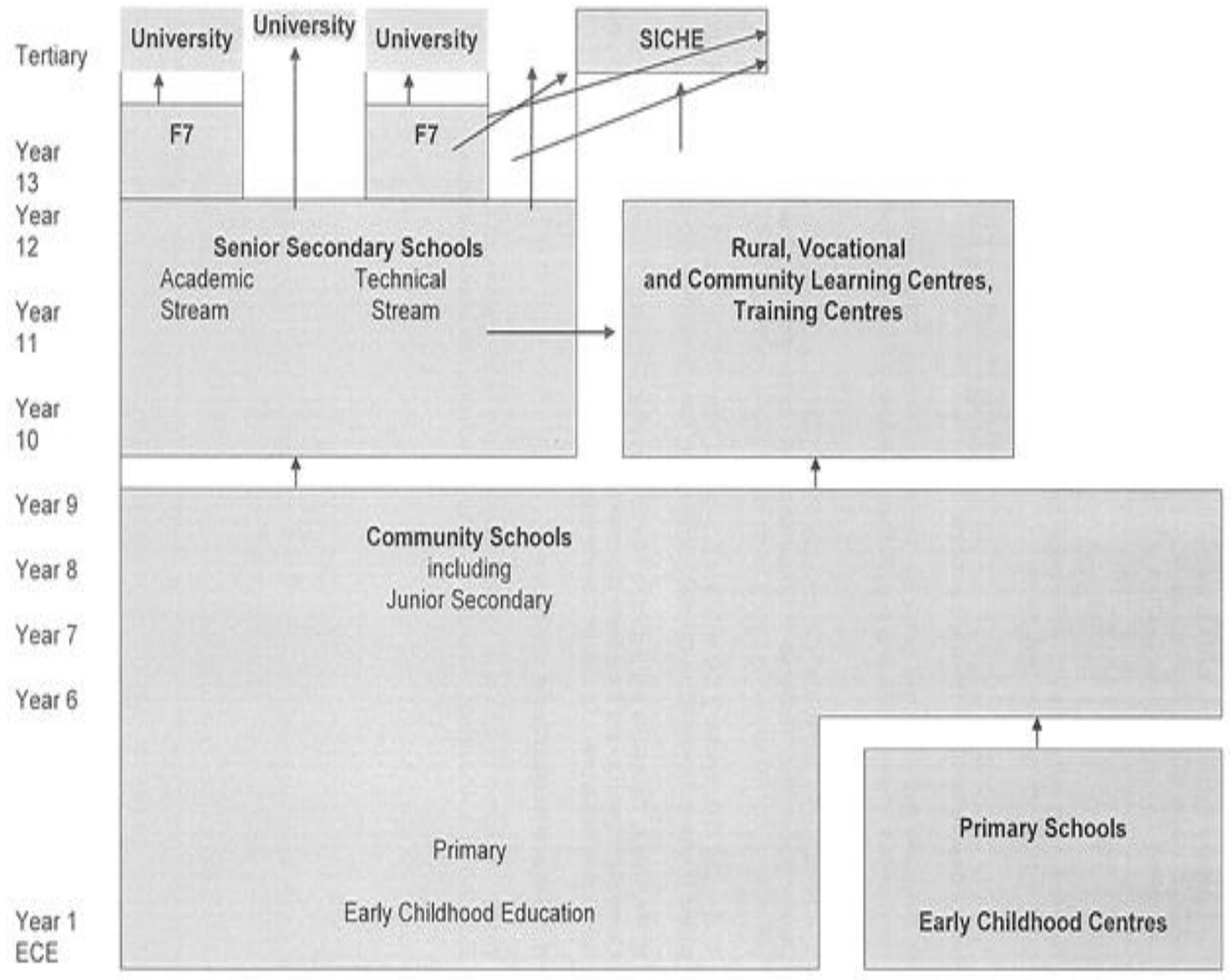

Source: ("Policy Statement and guidelines for National Curriculum: Solomon Islands," 2009)

The Solomon Islands education system consists of primary, secondary and tertiary education. The national education policies and curriculum emphasise that the education system is to support learning from early primary education right up to tertiary level. But between these levels of education, exams are conducted to identify those with high passing marks who should continue climbing up the education structures based on national set criteria and academic requirements.

\subsubsection{Curriculum for primary and secondary education}

The vision of the education system is that all Solomon Islanders will develop as individuals and possess knowledge, skills and attitudes 
needed to earn a living and to live in harmony with others and their environment. We envision an education and training system responsive to its clients and efficiently managed by its stakeholders and clients. We wish to deliver quality education for everyone in Solomon Islands (Policy Statement and guidelines for National Curriculum: Solomon Islands, 2009, p. 10).

The current education curriculum is comprehensive and wide-reaching compared to the early mission education tradition and focus. It is driven by a Western education framework. Although basic education in Solomon Islands is rated as a fundamental area for participation in Solomon Islands' economy, it still lacks productive contribution to the national labour market. The curriculum outlines the learning standards, learning objectives and education mission of primary and secondary education without direct influence on skill development. Thus, the national curriculum set programmes for teachers and students in primary and secondary education with clear expectations to contribute to the overall human resources development of the country. 
Table 4. 3 The table below shows the level of enrolment and literacy rate

\begin{tabular}{|c|c|}
\hline \multicolumn{2}{|l|}{ Education } \\
\hline Literacy rate, 15 + (Census 2009) & $84.1 \%$ \\
- Males & $88.9 \%$ \\
\hline School enrolment, 6-12 & $79.2 \%$ \\
- Males & $83.3 \%$ \\
Net Primary enrolment & $82.8 \%$ \\
\hline Net Junior Secondary enrolment & $83.9 \%$ \\
\hline Proportion of Population aged 12 and older with: & $91.0 \%$ \\
- no school completed & $20.0 \%$ \\
- primary education & $16.1 \%$ \\
- $\quad$ secondary education & $56.8 \%$ \\
- vocational/professional: qualification & $18.9 \%$ \\
\hline
\end{tabular}

Source: (World Bank, 2012)

Solomon Islands has made significant improvement in primary education access, which stands at the rate of $91 \%$. However, $86.6 \%$ of primary school attendees dropped out along the way from primary education to tertiary education, which is a grave concern for development and productive workforces. Only $4.4 \%$ continued further to complete tertiary education.

In addition, the education system has prioritised reforms to align Solomon Islands' education curriculum with the current education needs and agendas. Although the national education curriculum is highly centralised, its development is centred on a participatory model. The current system promotes a holistic and integrated human development approach facilitated through team work and partnership between the MEHRD, Education Authorities, institutions and other key stakeholders (Policy 
Statement and guidelines for National Curriculum: Solomon Islands, 2009). Key stakeholders are significant partners and contributors to the formulation of practical curricula programme to extend the focus and to achieve a detailed policy with logical formation. Some of the key areas and aims that are considered crucial in promoting quality education for Solomon Islands have been highlighted and summarised in Figure

\section{4.}

Figure 4. 4 Curriculum reform aims

The aims of the curriculum reform are:

I. To enhance the knowledge, understanding, skills and abilities of all learners, and to assist all learners to develop positive values and attitudes.

II. To revise the Early Childhood Education (ECE), Primary, Secondary and TVET curriculum to ensure that its scope is sufficient to meet current and future learning priorities of the nation, and to make it more culturally relevant to the needs of learners in Solomon Islands.

III. To shift from a curriculum approach that mainly provides students with a large body of information to one that brings about a deeper understanding of relevant knowledge, and leads to the development of higher order and creative thinking processes and skills

IV. To develop and implement a National School Curriculum that identifies relevant and achievable learning outcomes and provides appropriate learning opportunities at each stage of schooling for each learner, ensuring that there is depth, breadth, continuity and progression of learning.

V. To help teachers develop professionally in their teaching and learning and their understanding of the revised curriculum, through initial training, professional development activities at the school level and teacher networking, for them to achieve the vision in the National Education Action Plans, 2007 - 2009, 2010-2012 and implementation of the Policy Statement and Guidelines for the National Curriculum

Source: (Policy Statement and guidelines for National Curriculum: Solomon Islands, 2009). 


\subsubsection{Tertiary education and policy focus}

According to the 1999 census, only one fifth of the total population had achieved tertiary level education and approximately 50\% have attained primary education (ILO, 2009). Most higher education is provided by Solomon Islands National University (formally known as Solomon Islands College of Higher Education) and the USP. A number of university students also goes to the University of Papua New Guinea (ILO, 2009). Development partners also provide scholarships to Solomon Islanders to undertake their tertiary studies in Australia, Japan, Taiwan, New Zealand and Cuba. Despite huge investment in human development and training, the public and private sector finds it difficult to recruit trained personnel to fill critical positions, in particular, areas in the administration, management, engineering and Information Technology. Current tertiary policy and investment are unable to provide enough qualified people for the workforce. In other words, the current tertiary strategic plans and policy lacks alignment of skills development to market needs and demands. However, there is strong support for tertiary education but inconsistencies exist between the skills training and qualification and the certification system considered necessary for the workforce.

Solomon Islands has a tertiary education policy with a clear vision.

All Solomon Islanders will have equitable access to relevant tertiary education that will enable them to fully participate in economic, social and cultural life in their communities and to develop their skills and competencies needed to make Solomon Islands' workforce globally competitive and to link them to international employment, business and export opportunities (MEHRD, 2010).

The promotion of tertiary education through this policy vision and established national structure is an indication of strong national ambition to build a marketable workforce both domestically and globally (MEHRD, 2010). At the national level, the commitment towards tertiary education as a response to national human capital development is slowly gaining recognition. Solomon Islands' graduates now occupy mainly the public 
and private sector jobs, which represent a positive progress and contribution to the economy. A few Solomon Islands professionals have moved overseas for jobs, which highlights that national tertiary education can really contribute to skills needs and labour migration. The overall tertiary policy regime has stipulated clearly on how to achieve a competent and skilful workforce. In other words, the labour market relies on the tertiary education sector to receive qualified, skilful and specialised human resources to maintain the functions of the state and boost economic growth. Professionals with specialised skills and knowledge who work as doctors, lawyers and engineers help to deliver a social and economic service to the public. There are continuous efforts and collaboration between national government, SINU and regional institutions to improve the tertiary standards and qualifications. By looking at the three main goals of tertiary education policy, none has precisely linked to labour migration but focus more on creating a competent and skilled labour force (Table 4.4). The national education has outlined in its long-term vision and plans the delivery of quality tertiary education that corresponds to the domestic and global labour market.

\section{Table 4. 4 Solomon Islands Tertiary Policy Goals}

\begin{tabular}{|l|l|}
\hline Goal 1 & $\begin{array}{l}\text { To provide high quality tertiary education, that will meet } \\
\text { individual, national and regional needs for a knowledgeable, } \\
\text { skilled, competent and complete people, and a cohesive and } \\
\text { sustainable society }\end{array}$ \\
\hline Goal 2 & $\begin{array}{l}\text { To provide equitable access to high quality tertiary (post- } \\
\text { secondary) education and to close the opportunity gap in tertiary } \\
\text { participation for marginalised groups. }\end{array}$ \\
\hline Goal 3 & To manage resources in an efficient, effective, sustainable and \\
& transparent manner \\
\hline
\end{tabular}

Source: (MEHRD, 2010).

In addition, the Solomon Islands tertiary education policy also embraces TVET as an integral and important educational priority of the country. TVET has been another 
neglected learning and training in Solomon Islands since independence. But under the tertiary education policy, TVET had been emphasised as key stream of education that provides skills development to the economy. TVET and Rural Training Centres are regarded as key alternative service providers that can offer longer-term technical skills or practical life skills training for many Solomon Islanders (Fleming, 2015). It expands training opportunities close to communities and is seen as public effort to address high unemployment and social disorders in communities. Thus, in beneficial nature, this policy can be seen as a bridging learning course to re-engage individuals into mainstream tertiary education with another opportunity to gain the necessary skills to sustain and improve their living standard and contribute positively to development programmes.

Lastly, ILO (2009) also reported that there is an unsystematic certification and qualification framework in Solomon Islands that results in many different certification processes adopted by individual TVET providers. At the bureaucratic and political level, it is discussed in policy statements and reports as a top priority sector but fails implementation at community level. In terms of this policy implementation being a priority, there is inadequate support and insufficient budget allocation available, which confirmed this policy as a failure through the lack of established TVET schools around the country. The maintenance and demanding task of continuous improvement to TVET is another constraint that left many TVET schools either deteriorated or closed down because of lack of government support (ILO, 2009). Furthermore, the TVET education system is only driven by domestic labour market needs and opportunities. Training of individuals lacks long-term vision to meet employment needs of foreign market opportunities. It is considered that TVET will certainly help domestic employment and labour force but the training remains under-utilised for labour migration schemes in Solomon Islands. National analysis and assessment reports showed that TVET is suitable for local labour market only due to its low standards and non-recognition of its qualification by international labour markets (ILO, 2009). Therefore, national education recognises that TVET has similar terms and capacity as tertiary education with the 
confidence that they can both produce skilled workforce for domestic and external labour markets.

In conclusion, Solomon Islands' socioeconomic and political system is founded on capitalist ideas and Western development doctrines. Solomon Islands is diverse along geographical, cultural and ethnic lines. The political system is based on Westminster, which allows free political process to elect new leaders. However, the traditional systems are rejected under the national economic and political systems. The traditional knowledge is still active but operates outside the established education system to support the local economy. In addition, the education is driven by the Western educational framework informed by different development theories and strategies to meet the diverse need of the economy. The Western dominant education system includes primary, secondary and tertiary levels is formally adopted. At the national level, education is a key policy sector for development. The modern economic system mainly operates in the urban centres and, to some extent, in the local setting. Solomon Islands' current socioeconomic and political setting has gone through dramatic changes influenced by globalisation, development cooperation and global economy. Similarly, the demographic structure of the population also changes rapidly. The gap between urban and local education and developments continues to widen. Thus, the education system continues to undertake structural change and reforms to respond to the growing needs and demands of the diverse labour market. 


\section{Chapter 5: $\quad$ Findings}

\subsection{Introduction}

This chapter will highlight and discuss the findings from the semi-structured interviews conducted. There are three main points identified and each point has sub-points with comprehensive discussion. First, the diverse education system for local, national and global market needs. The findings also highlight the standard and quality of education in Solomon Islands at these three levels. The second point of focus is the internal legislation and institutional policy framework and processes that support education. Finally, the chapter highlights domestic concerns regarding regional and global labour migration and influences on the domestic policy regime in the education and labour sectors.

\subsection{Diverse education system in Solomon Islands}

\subsubsection{Education for personal development and local economy}

Firstly, the national education system recognises the local needs of the economy. It provides empowerment to the locals through embracing indigenous knowledge. Participant 103 said the appreciation and informal use of indigenous knowledge as part of the education curriculum in subjects such as social science, culture and arts reflect strongly on the Ministry of Education's commitment to produce a skilled workforce for the local economy. As suggested by interviewee 110, education provides opportunity for individuals to learn, understand and live in harmony with others through engagements guided by constructive behaviours and attributes. Without these basic skills and competencies, individuals will struggle to maintain their livelihood and social cohesion at the local level. As reiterated by participant 116:

"I think traditional knowledge should be embraced as an important learning subject of the national curriculum to revitalise its uniqueness because it plays a significant role in traditional belief, values, social harmony and conservation for environment." 
Indigenous knowledge is the backbone of the traditional economy, therefore, total ignorance of the importance will harm the relation between education and development. So from a national perspective, local economy continues to benefit from the national education disciplines and programmes because of the application of traditional knowledge in educational lessons that fits local economy needs.

Traditional knowledge, as stated by participant 103, still faces a lot of institutional and academic barriers to become an integral and formal learning component of the national curriculum.

"The usefulness of traditional knowledge in many societies is still proven a worthwhile body of knowledge that rural Solomon Islands depend very much on for livelihood, culture and communal relation. Therefore, national authorities should consider traditional knowledge in the national education strategies to continue passing this significant knowledge to the next generation" (103).

Interviewee 103 further stated that TVET and primary schools encourages traditional drawings, dancing and oral story telling. The Ministry of Education acknowledges the importance of traditional knowledge and skills to local economy. However, as reiterated by participant 105 , there are critical challenges, due to diversity and complexity of principles and philosophy, to incorporate and quantify under the Western education measurement system. But participant 105 stated:

"Local economy and people's way of life is heritage and a cultural weapon for meaning and existence. In addition, many rural people rely on traditional knowledge to discuss and value their contribution in community development projects and cultural practices. But more investments and support are required to promote and adopt these two diverse bodies of knowledge to operate side by side in Solomon Islands."

So far, it is slow progress to see traditional knowledge becoming a formal part of the national education system but efforts have been made, as stated by participants 103 and 105 above. The major challenge for policymakers, practitioners and institutions is 
how to accredit traditional knowledge using the formal certification and accreditation structure and criteria. Participant 105 , went on to say:

"Currently, Solomon Islands' formal education system does not formally recognise traditional knowledge because of many variances in Solomon Islands. How does the formal education system measure building a local hut or building a canoe with formal qualification and certification? The current training curriculum and education are struggling to answer such question as there many disincentive ways in the local economy across Solomon Islands. In addition, other critical challenges observed are the meaning of objects, subjects and languages which are different to people in different places".

Thus, alluded to by interviewee 105 , finding a standard and convincing measurement between traditional knowledge and the Western education system is crucial and requires logical structure.

However, in terms of policy and educational strategies, traditional knowledge has been given little attention by the bureaucratic education system. In fact, most participants also acknowledged that the rejection of traditional knowledge at the policy level also exists. This has been a critical policy struggle for the education system for years. Traditional knowledge is regarded as secondary to formal education curricula. As highlighted by participant 103 and 105, it needs a clear national action plan and policy to fill this gap to realise the value and contribution of traditional knowledge to the local economy.

Personal development is also promoted under the national education system. The younger generation is provided with facilities and resources to enhance their learning abilities. The education provides equal opportunities and services to all Solomon Islanders. As mentioned by participant 101:

"Educating women equals educating the whole family, community and the nation, because they spend the most time with kids and their key role is to take care of the family in Solomon Islands' society. Therefore, 
education must provide equal opportunities for women to get more education so that they encourage their children to pursue formal education."

Solomon Islanders who are qualified human resources will support a productive, literate society and progressive local economy. Interviewee 104 summarised the importance by saying:

"The national education's overall vision is to see all Solomon Islanders possess individual knowledge, skills and attitudes to earn a living and pursue personal careers in a sustainable society and country. In addition, education defines the character and contribution of men and women in their society."

Participant 104 stated that the basic aim is to produce an effective and self-reliant labour force to pursue their career path in the diverse economy. A high rate of qualified individuals will boost technical capacity, entrepreneurial talent and the employment sector to create jobs for the people. Through established national institutions such as SINU, as mentioned by participant 101, it offers support to aspiring individuals to learn and expand their capability in various specialised fields. The underlying logic is to have a literate and skilled workforce that can support themselves to achieve their dreams and drive the local market and development of the rural communities.

Primary education also contributes to the local economy through basic competency and skills to support the livelihood of rural and isolated communities. The formal life span of primary education is seven years beginning with 'preparatory year' to standard six (National Education Action Plan of Solomon Islands: 2010-2012, 2009). As outlined by participant 111 :

"Basic education is a planned and systematic introduction of a child to the knowledge, skills and attitudes to realise the full potential that is necessary to prepare him or her to contribute to the community and the economy. Basic numeracy and literacy skills are taught in primary 
education with the aim that it will become useful for indigenous people when dealing with local context and the economy."

Finally, as outlined by interviewee 109, the primary education system embraces diverse subjects, including science, social sciences, community studies, agriculture, art, music and physical education in schools to ensure learners acquire basic skills and understanding of these subjects in their unique context (National Education Action Plan of Solomon Islands: $2010-2012,2009)$. The assumption behind primary education is to teach young people formal and basic education skills and knowledge to prepare them for next stage in life. Some young people may go further in education while others may drop out of formal education to join the traditional economy. With the basic skills learnt plus traditional knowledge and positive attitudes, young people can become productive in their local communities and expand the positive changes in the local market.

\subsubsection{The role and rationality behind national education system}

The role of education at the national level focuses on several key areas. The national education feeds the knowledge edge with skills and talent to influence progress. As suggested by interviewee 110:

"Human resources development is a top priority of the current education policies to help individuals to possess necessary skills, knowledge and attitudes that contribute towards professional career and stimulate the national development of the country."

Furthermore, participant 110 stated that education promotes a united and progressive society where peace, harmony and equitable socioeconomic opportunities for all citizens are available. In other words, through produced skills and expertise, national socioeconomic and political dynamics, structures and policies are effected and carried out.

"The national economy depends on the competencies and professional expertise produced from the national education system. The national education policy is regarded as the best for now and is making a 
gradual impact even though the resources and support from national government are very limited."(110)

Therefore, interviewee 119 suggested that adequate education facilities and resources must be established and managed in effective ways so that every Solomon Islander has access to a better learning environment without compromising an individual's right to quality education. The current national labour market depends on the volume of human resources and skills produced yearly to sustain the national economy and political system.

Education plays a major development role in Solomon Islands' national economy. As reiterated by interviewee 103 , through education, Solomon Islanders can develop skills and knowledge from early age up to adulthood. By acquiring necessary competencies, individuals become literate and productive in their contribution to the national development. It provides basic education as well as offering technical training for Solomon Islands.

"For instance, education provides opportunities for Solomon Islanders to be trained as teachers, nurses, accountants and engineers who in their specialized fields contribute to the development of Solomon Islands."(103)

The underlying aim is to provide quality educational training to equip the young population with the right, and specialised, skills to take Solomon Islands' development to a new level.

In addition, the current national curriculum focuses on developing human capital for the national economy and labour market. The structure of curricula is based on a subject specialist model and teaching capacity (109). But all these subject specialists have a common role in the basic education and human resources development of the country. Now the curriculum focus starts to recognise the learner's' abilities and needs.

"Since 2004, a reform was started and will continue to change the current curriculum from teacher-centred to learner-centred. The aim is 
to focus more on the learning ability of students so that they acquire the necessary skill and competencies that correspond to the national labour market needs. In other words, teachers should only facilitate learning of students by giving students more responsibility to use available curriculum to deepen individuals' learning capacity."(109)

The national curriculum and learning materials are developed in major subjects that stimulate learning abilities at different education levels. Interviewee 109 indicated that the curriculum, as part of the education system, aims to provide quality and up-to-date school materials and resources to facilitate students' learning to meet the demand of the national labour market. As suggested by 110:

"The contemporary education regime, syllabus and policies, focus more on national human resources development and personal skills enhancement and specialization to meet the skills demand and gaps in the national labour market. This changes has shifted away from the old vision and mission of the education curriculum that has been emphasizing the importance of improving and supporting teacher capability and capacity as the solution to address the failures in the national economy."

As recalled by 113 , the stagnant education system and inequalities requires a change in focus and priorities. Now, the introduction of inclusive education policies and, more particularly, TVET into the curriculum should enhance a full realisation of life skills and knowledge that will build and expand the skill base to boost the productivity and economic growth of the country (113).

In addition, secondary education policies and strategies largely produce competencies and skills for the national economy. The secondary sector comes in junior secondary and senior secondary levels. Junior secondary education begins from form one to form three and is offered by the existing secondary schools (National Education Action Plan of Solomon Islands: 2010-2012, 2009). Senior secondary education is the second level after junior secondary education that provides education for students in forms $4,5,6$ 
and 7 (National Education Action Plan of Solomon Islands: 2010-2012, 2009). Interviewee 110 stated:

"At the secondary level, learners are already exposed to subjects in deeper detail and many students are already learning materials that are relevant to national economy and development. The formal education system is considered the source for skill development to address the socioeconomic and political development of the country."

Once students complete senior secondary education, they are ready to go into either tertiary education or the national labour market. According to 111:

"Many secondary school graduates enter into jobs such as retail, customer services, personal assistant roles and other low-paying jobs before they work their way up in the employment sector. Thus, secondary education graduates have been the backbone of Solomon Islands' national economic development and labour market until the 1960s when students started to travel overseas for undergraduate programmes."

Participant 111 said that the Ministry of Education has made the education system heavily examination-based as an academic requirement to identify the bright students who should have the opportunity to pursue their tertiary education while those who are pushed out of the system still have opportunities in the national economy.

Lastly, interviewee 110 stated the decentralisation of secondary education to the rural communities is a significant shift to eliminate bureaucratic barriers to encourage equal distribution of service. However, as raised by the interviewees, there are many issues with the quality of delivery, teaching and facilities, but the national government and provincial education authorities are committed to addressing these problems. According to participant 111:

"The distribution of secondary education to the rural communities and outer islands is an important step to encourage rural people to pursue their careers through formal education and become part of the national economic process and development. This is a fundamental groundwork 
to avoid inequality between the rural and urban areas while provide students with accessibility to quality education and job opportunities in the national labour market."

As supported by participant 110, education prepares students with economic and longterm vision for an easy transition to the national economy, without structural limitations to educational learning. Therefore, it confirms the national education policy statement that highlights secondary education as a vital stream to train a reliable and skilled workforce base to sustain functions of the national economy.

\subsubsection{Education for global market}

Solomon Islands recognises tertiary education as a major driver that not only supports national development but also produces technical skills for the global labour market. As mentioned by participant 114 , the national training unit oversees the tertiary training needs of Solomon Islands. In addition, the national training council (NTC), the executive body established by the Ministry of Education, has representatives from public and private sectors to make decisions and oversee the functions of tertiary education. Participant 106 confirmed:

"Consultations and meetings supposed to be organized between Education Ministry and key stakeholders including Labour Division but that is not frequently enforced. There are many limitations within the core functions of NTC that requires strategic revisions to reduce policy shortcomings and corrupt decision makings."

According to interviewee 113 , the rules and regulations of tertiary education are sometimes vulnerable to political influence and the 'wantok system'. As supported by participant 105, high-jacking of NTC processes to meet personal and political goals affects the national selection of training priorities to meet external market needs. This often leads to predetermined outcomes when NTC is organising meetings for its members to decide on the national skill needs. To address these challenges"

"The Education Ministry is also working towards establishing Solomon Islands Tertiary Education Commission (SITEC) and Solomon Islands 
Qualification Authority (SIQA) to become a formal requirement of the national education policy and system. Once these reforms and national bodies are established under the education legal policy framework and the strategic plan, then it will pave a way for international recognition of Solomon Islands' education and qualifications by foreign countries and international institutions" (114).

So far, the current tertiary policies and strategic plans have been underachieving their potential to benefit from the external labour market. Participant 101 agreed that the education system has recognised, and continues to produce, highly specialised workers for external markets like Vanuatu and PNG, but on a smaller scale. Even though these existing tertiary education mechanisms and institutions are inadequate for now, it does not diminish the overall aim to increase the production of a highly qualified and specialised workforce for the potential global labour market in the long-term.

Furthermore, tertiary education is a top priority for Solomon Islands. According to interviewee 115, more Solomon Islands students have attained training under scholarships every year, which shows the national government's support to expand tertiary education for global market. Interviewee 115 further stated:

"For current economy to function properly, redesigning and alignment of national policies to the global market is paramount to deliver skills and competencies demand by the global labour market. Without attained qualification and specialised skills and talent, it is very difficult to become marketable and competitive in the external labour market."

Participant 119 also affirmed that tertiary education opened doors for students to upskill themselves in their selected specialised programmes to deepen their cognitive thinking skills and knowledge in the field demanded by the knowledge economy today in many countries.

Likewise, according to 102 , the tertiary education is available through SINU and various regional institutions, including the USP and University of Papua New Guinea (UNPNG) 
as the two main ones. Other tertiary students go to Australia and New Zealand under scholarships. These institutions, according to participant 102, are a key source for the production of skilled workforce for Solomon Islands. SINU has been a national institution that supports quality education by training and equipping individuals with competencies to access offshore labour market. As stated by interviewee 101:

"The overarching goal of the SINU, School of Education, is to train local teachers to meet teaching standards so that they can be absorbed into the local and global labour markets by pursuing their career in teaching. The expectation from the School of Education is to see more trained teachers migrate overseas while the rest go back to their own provinces or islands to help improve the quality of education and literacy level."

Thus, participants 101 and 102 confirm that there is a gradual increase in the number of graduates from SINU and other regional institutions in Australia, New Zealand, Fiji and PNG every year under the current tertiary institutional set-up and policies. An increasing trend of highly qualified Solomon Islanders moving overseas for professional jobs can also be seen.

There are ongoing reforms happening to address tertiary education out-dated legislations and obsolete policies to be more effective and parallel to the rapidly growing job opportunities overseas. According to participant 111:

"Tertiary education is what I would call a 'vehicle' for development in Solomon Islands and can be achieved through having an effective institutional process, clear tertiary policies and a quality education system. Currently, the tertiary education moderately produces enough highly skilled and qualified people who are capable for global labour markets."

Now, as mentioned by 115, the Ministry of Education is working closely with other key institutions and the private sector to jointly address the defunct structural and institutional policy frameworks, especially in its education's qualifications and standards, to align with the global benchmark. Many consultations and meetings have been undertaken with key stakeholders to comprehend and deliberate on the 
importance of adopting a relevant and quality education policy that is competitive and forward looking (115). Thus, many of the participants raised similar views and suggestions on the need to redirect the focus and priorities on investing more on skills production and supply to the global labour market.

The recent increase in Solomon Islands' government-sponsored students to various international institutions, indicates the strong conviction and backing for skills investment in the next generation (114). Participant 114 further stated that the national government has started to send students to the Philippines, Indonesia, Taiwan, Australia and the United Kingdom (UK) under a new Solomon Islands government sponsorship programme. It is a new shift to expose Solomon Islanders to, and prepare them for, potential job opportunities in the global market. This has not happened previously; only students sponsored by development partners undertook studies outside the Pacific. Traditionally, as referred to by participant 112 , Solomon Islands government scholarships are only for students studying in Fiji and PNG universities. The policy outlook has changed and shifted beyond the South Pacific region to enable students to acquire skills and knowledge compatible with the global market. As suggested by participant 119,

"Solomon Islands is integrated and connected to the rest of the world through globalisation, so the country must prepare its human resources to utilise the opportunities of labour migration to bring remittances and know-how for Solomon Islands economy. Also, local highly educated individuals will follow those who are already working overseas."

Finally, participant 114 suggested that there are ongoing significant reviews and reforms on the out-dated policies and strategies to improve the standard of education. The upgrading of the education system will enable local graduates and professionals to become marketable assets for Solomon Islands globally. According to interviewee 101, there are some potential markets, like PNG and Vanuatu, in areas of teaching and nursing that Solomon Islands' education regime must take seriously in order to produce 
the workforce for these neighbouring labour markets. A classic case was outlined by participant 101:

"PNG has offered a formal request to recruit teachers from Solomon Islands to work in various provinces in PNG but that plan has not eventuated because of low number of graduate teachers from SINU to meet external demand. ... the external labour market offers opportunities for Solomon Islands skills and talents but SINU must produce a surplus labour force with recognised qualifications before Solomon Islands can send teachers to PNG".

In addition, the regional demand for teachers is high while tertiary education produces a low volume of graduates that caters only for domestic labour market. As highlighted by participant 109, the national education sector is going through a learning process where comparative actions have been taking place against other effective education models in the Pacific to upgrade its standard to match the global benchmark. The ongoing education reviews aim to ensure that policies are practically relevant and respond effectively to domestic economic and employment needs and prepare the workforce for external market demands.

\subsection{Internal Policy framework that supports the diverse education regime}

\subsubsection{The internal institutional and policy framework}

The internal education policy framework supports and facilitates quality education. Through diverse education it generates a professional workforce for these distinctive levels of labour markets. Participant 10 stated that the education development plans strongly support an inclusive policy regime, regulatory and structural framework that caters for local, national and global market. As highlighted by interviewee 107:

"Currently, there is a loosely established institutional framework that loosely links education and labour migration as a joint development goal for the country. However, national education continues, and will continue to, produce and supply relevant human resources and skills to the different labour markets." 
In addition, collaborations are ongoing at the policy and executive level among key stakeholders to accommodate the skills needs of these different markets.

In addition, participant 119 made a reference to a common observation in the national education regime by saying:

"There are existing general policies and frameworks that promote education. In addition, there are policies that promote labour market and skills development. But from my experience, there is poor coherence and implementation of the relation between education system to local, national and global markets in terms of policy and skills training and development to maximise the potentiality of labour migration".

The Ministry of Education has very clear overarching guidelines, policies and regulations in the current corporate plans that promote education for different labour markets. Participant 119, confirmed that, even under the fragmented education policy regime, the overall education system reinforces the support for diverse education disciplines. As highlighted by participant 119 , the skills gap in various national sectors and industries is widening, which reaffirms the struggling state of local economy to supply sufficient skills for the labour market. Participant 103 suggested that consultations among the key departments are crucial to closing the gap between skill trainings and diverse labour needs.

Finally, it is clear from the interviews that the current policy regime is fragmented and lacks regular cooperation and collaboration among key policy stakeholders. However, participant 104, is still optimistic that the Ministry of Education's ongoing reforms and reviews to improve the current education system will have a positive impact on and improve relevant education policies to meet the different educational, economic and labour needs. One of the key factors experienced by the education sector is highlighted below by participant 105 :

"Poor leadership and governance are major contributing factors that continue to affect the quality of working relations between different ministries in Solomon Islands and performance of the education. The 
country lacks visionary leaders who inspire good relations and see issues in innovative perspectives to push for necessary change for today's diverse market needs."

However, these limitations do not dichotomise and distract the national support, commitment and the assistance from development partners to prioritise the development needs of the country under three market categories.

\subsubsection{Improve accreditation and qualification framework to correspond with diverse markets}

The absence of a national qualification framework, as identified by participant 102, has weakened the education standard and reputation. Participant 102 suggested, the current certification and accreditation process is poorly administered, which affects the recognition of national institutions and programmes to meet domestic and external market standards. Currently, Solomon Islands' education standard is already recognised internationally but needs more upgrading to remain competitive on a global level longterm. According to interviewee 102, even SINU continues to face similar barriers in getting formal recognition from regional and international institutions and countries. To support this position, participant 103 suggested:

"Solomon Islands needs to consider all areas of education, including standard, qualification, accreditation, curriculum and policy to tackle the underlying problems. Now, the Ministry of Education is going to finalise the national qualification framework as the vital step. This will benchmark the national education standard with other countries so that international institutions can recognise national education standard and qualifications which will improve Solomon Islands' participation in the global labour market."

So far, as stated by interviewee 103 , that USP courses and programmes are recognised in Australia and New Zealand, which is a leading example for SINU and Solomon Islands' education system to adopt to tap into the global labour market. 
Finally, a national framework called Solomon Islands Qualification Framework (SIQF) is underway, which will address all the issues of standardisation, qualification and accreditation to propel human resource development. The purpose is to harmonise the national education system and align it to global education standards (103). According to the current review and curriculum, the SIQF will highlight the importance of having a formal connection between education and key stakeholders, including Labour Division, SINU and the Association of Industries (113).

"Reforms should start within education to improve qualification framework to be coherent with other foreign education system so that individuals with domestic qualifications can go elsewhere in the world to find jobs without any discrimination or challenges based on his/her academic credentials."(113)

The national education authority is committed to taking the actionable approach required to strategically connect and match the education system to recognise and accredit domestic Rural Training Centres (RTCS) and tertiary institutions. Current frameworks lack the dynamism to promote a standardised and national qualification framework that includes trade skills and higher qualifications. Therefore, with the proposed SIQF, it will harmonise courses, programmes and curricula to a standard qualification that promotes development and good education practices.

\subsubsection{Growing mismatch between graduate skills and job market needs}

The mismatch of skills training to diverse market demand is high due to inadequate assessments and policies between tertiary training and the national market's needs. As suggested by participant 107, training policies are devised without considering what skills and talents are in high demand in the job market. However, existing tertiary education policies are designed to respond to market forces at all levels of the economy including the global market. Apparently, many of the tertiary training priorities, as pointed by the participants, are loosely related to the domestic and global labour market. That gap requires critical consideration from the current education system. Participant 106 pointed out: 
"Education should consider labour market analysis and assessment reports as significant input to support the link between training programmes and market needs. Mostly, education policy and decision makers keep ignoring the valuable skills assessment reports produced by Labour Division, which results in these skills mismatch."

Participant 105 stated that the current skills mismatch experienced in the economy is due to the poor coordination between education and labour authorities to reconcile policy differences. Participant 105 expressed:

"The increasing skills mismatch does not mean that Solomon Islands" education is not fulfilling its obligation to produce qualified professionals for local, national and global labour markets. But it only reflects the weak and fragile policies areas that require overhaul and replacement to sharpen its focus and role to foster high production of skills and knowledge for the economy. "

Furthermore, participants agreed that weak labour market-led policies encourage the poor interaction between the national training unit and Labour Division to align training and skill development in correspondence to diverse labour market needs. Almost every participant understood that the domestic industrial sector often faces labour scarcity in specialised professions, so employers have to resort to overseas recruitment. And this is where labour migration is considered expedient and potential for recruiting skills not available in the country. Interviewee 105 confirmed:

"Definitely this skill mismatching to training is significant and needs review and support to upgrade the education system to connect to demand in the labour market both locally and globally".

According to participant 105, this mismatch emanates from a range of issues, corrupt practices, fragmented tertiary education instruments, and policies and behaviours of policymakers to implement policy decisions to connect skills development and education to diverse labour market needs. Thus, even under intense policy detachment and circumstances, Solomon Islands' education system is still able to provide skills and knowledge to the local, national and global labour market. 
5.4. National concerns on regional and global integration

\subsubsection{Regional integration in education}

Regional integration is one of the major influences in the domestic, social, economic and political setting of Solomon Islands. Solomon Islands has connected to regional and global economic relations, governance and education. As highlighted by participant 103:

"Solomon Islands' education sector has engaged in partnership programmes with the regional and international community. USP is a clear example of a joint Pacific effort to have a regional tertiary institution established to provide a quality tertiary training and learning service to students within the South Pacific region. Solomon Islands is a major beneficiary of USP for yearly production of skills for the diverse labour market."

It is a part of a wider effort to increase social cooperation and economic relations among Pacific countries. Again, participant 103 reiterated:

"Regional market is potential labour market supported by regional organisations that provide jobs for the Pacific, including Solomon Islands. Thus, Solomon Islands adopted Form 7 in senior secondary school, which is equivalent to foundation year at USP while seen as part of education realignment to match Pacific education and labour market."

The courses and materials are designed by USP and provided to member countries, including Solomon Islands. In addition, as stated by interviewee 103:

"Solomon Islands' national education policies incorporate many contributions from USP with the aim of having an easy transition into the Pacific education standard. USP has regular consultations with the Ministry of Education through workshops and meetings to look at training policies to link skills training to national priority sectors by using USP training resources. As I said earlier, that with the support 
from USP, the national training policies is preparing Solomon Islands' workforce for domestic and external markets as well."

Likewise, participant 110, also confirmed that the national education authority started forming partnerships with USP and other regional development partners to provide technical support and resources to address the poor standard of education in Solomon Islands. Therefore, there are key regional powers and cooperation that Solomon Islands signed onto that influence the internal educational policy regime.

\subsubsection{Development intervention}

It is evident that some traces of external influence are still dominant within Solomon Islands' public and private sectors. As suggested by participant 111:

"The economy is highly dependent on foreign development assistance and investment in terms of financial and technical programmes. Enhancing human development and technical support are two highlighted pillars that most development partners are focusing on in terms of technical and financial support."

Likewise, participant 110 suggested:

"Sectorial policies such as education are often impacted on by external intervention and control simply because of global interest and agendas. Development partners use their power to influence and direct development programmes in their own policy interest and priority areas. For instance, Australia and New Zealand are two major partners in supporting Solomon Island's education sector through policy strengthening of primary and secondary education and providing scholarships for tertiary education."

The aim is to link scholarships to fill the skill shortages in the economy. However, as mentioned by 103 , top professionals who have graduated with PhDs are slowly moving overseas for job assignments. Development partners have the upperhand in deciding which sectorial policy they are going to fund. It definitely impacted on domestic policy decision making, trend and dimension. 
"Therefore, global influence through Millennium Development Goals' (Sustainable Development Goals) agendas and influence undoubtedly affect domestic education policy and mission to address key socioeconomic and political issues. The reaction to global education agendas by the national education regime sometimes tests and distracts the internal competency and capacity to focus on the priority needs of domestic and global labour market" (114).

Participant 110 also said:

"The non-alignment of external support with national policy priorities is a major threat to policy relations between education and labour even though national government asks for diversion of funding to critical policy priorities and education needs to address skills gaps in the market to correspond with a diverse labour market. Nevertheless, development partners will not compromise their positions in development assistance, which adds a layer of challenges to having a diverse education for a wide range of skills and employment opportunities both in the local and the global market."

Lastly, participant 111 stated that intervention into the policy and technical capacity from outside is another common form of assistance received by Solomon Islands. According to participant 110, development partners hired technical advisers from outside to provide technical support and advice to strengthening the capacity of selected policy areas or departments in the education and labour sectors. The primary aim is to provide technical advice on key policy areas that need strengthening and inputs for development. Participant 110 stated:

"From my experience and involvement in policy reviews in the education sector, there is little outside influence through membership with international organisations, but engagements of individual technical advisers are common in education policies and curriculum development. Development partners directly involve and manage funded programmes with support from the national government. There is an awareness that 
technical advisers always try to include development interest by massaging internal policies to reflect their intentions."

As identified by participants 110 and 111, Solomon Islands' education regime and economic policies are not immune to global influence and support by development partners and free market forces. Thus, the domestic policy institutions' and authorities' control over key policy decisions and issues is diminishing due to domination by global influences and different development ideas.

\subsubsection{Increasing perception on international labour migration}

"Labour migration and development is a new policy concept for Solomon Islands. People understand the internal and external labour migration as a form of movement; people cross borders into a new region or country for employment purposes, social needs and economic needs" (112).

However, the increase of understanding and awareness of education, development and labour migration is due to rapid global integration and cooperation. The growing population shapes the perception and behaviour of the public, policymakers and political leaders to view labour migration as an alternative solution for the weakening local economy and high job shortage. According to interviewee (102):

"Education has been highlighted as an important factor to support sending people to work abroad under existing international cooperation. Hence, quality tertiary education as an essential feature is still missing to prepare graduates for job opportunities overseas."

In addition, interviewee 119 provided the following scenario:

"For instance, a doctorate student in physics will not work in Solomon Islands because of the lack of laboratory and facilities to accommodate this sort of professional but instead will go abroad to utilise his or her specialisation and skills in an external, sophisticated environment that have the right facilities." 
Participant 119 suggested that many regional and international economic cooperation and trade arrangements are considered formal routes that Solomon Islands can utilise in order to benefit from potential labour migration.

Finally, there is limited knowledge on Solomon Islands' participation in the global labour market. Issues such as remittances and skills transfer attract national debate. According to participant 118:

"A national trade policy framework has captured only briefly how labour migration policy would look in Solomon Islands. Besides that, people migrate depending on outside arrangement or individual choice based on their qualification. It requires effective policy discussion around education and labour migration to understand the potential benefits for the national economy."

However, as mentioned by 117, the Ministry of Education and Labour Division have very little input on the development of that policy. It is still a work in progress for national policymakers to fully recognise the importance of international labour migration. Poor availability of information and statistics also hinders the overall understanding of education and its direct influence on labour migration. The regional debates and policy interest in labour migration is increasingly becoming a popular language and discussion nationally. According to interviewee 117:

"It caught public attention when the seasonal labour migration was formalised between Solomon Islands and New Zealand and Australia. People thought it was impossible for Solomon Islands to join a regional seasonal scheme. While both scheme and potential expansion into skills sector will offer potential for Solomon Islands' top local qualified graduates to work in New Zealand and Australia".

The experiences in seasonal employment schemes amplify the perception and general interest among the public and policymakers to see labour migration as a positive development. As supported by interviewee 120, it instilled an outward looking mindset, 
which started to penetrate the policy realm and dialogue of the country. As raised by participant 119:

"The question is how to establish a policy mechanism and framework that is pragmatic and realistic to generate benefits from the global labour market and international labour migration policies and arrangements. While in return, the maximisation of these benefits will help the national labour market and economy."

Thus, participant 110 stated that a mutually respected engagement and cooperation with regional and international countries is fundamental to formalising a system that would convince policymakers and leaders to be optimistic about labour migration and development. Thus, it will change people's behaviour and perceptions towards national education policies and its link to labour migration and development in the global system.

\subsubsection{Brain drain vs brain gain}

One of the great concerns raised by many participants is that the domestic workforce will collapse and lose its qualified workers to offshore labour markets. However, according to 119 and 120 , the brain drain concern is a manageable concept. As further suggested, policymakers see liberalising economies for external workforces will offset the number of workforce going out, if strong labour practices and competitive job opportunities offered locally lure professionals from overseas. In addition, participant 119 suggested:

"This brain drain is an old concept. Nowadays, the widely used concept is brain gain. Earlier developing countries are so concerned about brain drain. Asian countries of India, China, Philippines and Pakistan, people from these countries migrated largely to Western countries. First generation of qualified engineers and doctors moved to developed countries to find a better life and jobs. In order for Solomon Islands to benefit from the global labour market, the responsible authorities need 
to make improvements to the existing education system to respond to external labour needs and dynamics."

Solomon Islands is experiencing a gradual out flow of professionals. However, the economy still survives with increasing graduates every year. There are reciprocal benefits related to labour migration such as skill transfer between host and recipient countries. As highlighted by 102:

"Solomon Islands should be less concerned about loss of skills but focus more on a diverse education that supplies skills to different markets. Likewise, once the domestic business environment and policy is favourable and attractive to foreign investors and workers, they can come in to work by replacing domestic professionals who plan to migrate overseas. For instance, SINU has recruited top executive staff from India, Canada, Australia and PNG to assume key faculty positions. While few qualified Solomon Islanders are currently working overseas."

Thus, expertise and talent is brought in to improve SINU's tertiary standard and faculty courses. At the same it shows Solomon Islands' open market policies, where education links to skill development for local, national and global skills jobs and economic prospects. But as reiterated by 119:

"Solomon Islands can potentially join in existing global labour markets once it utilises the formal arrangement with existing development community and bilateral or multilateral economic means. Besides that, the global economy is open and rapidly interconnected; that allows Solomon Islanders to work anywhere in the world if they have the right skills and competency."

This chapter highlights and categorises the findings from the interviews according to three major headings. Firstly, Solomon Islands' education system is diverse and offers primary, secondary and tertiary education nationally. The aim is to develop and train individuals to become successful in their careers and become part of a qualified human capital and workforce to contribute to the national development and economic growth. 
In addition, traditional knowledge is still relevant in supporting local economy and community development initiatives. Yet it faces consistent education policy and curriculum rejection even though there is wider recognition. Secondly, the educational internal policy framework continues to undertake reforms and reviews to address the growing policy mismatch between the education and the labour market skills needs. In addition, the improved level of internal collaboration, with technical support from development partners, continues to address these structural limitations. Lastly, the current education system and strategies recognise the potential socioeconomic benefits of labour migration. Thus, adjusting the education system to align training to regional and global labour market standards and demands is paramount. Due to increased awareness domestically on the global forces and negative implications such as brain drain, the national education is gradually working on policy frameworks to utilise potential external labour market demands. 


\section{Chapter 6: $\quad$ Discussion}

\subsection{Introduction}

Solomon Islands has a diverse education system that produces human resources for diverse needs, employment careers and development of the country. Broadly, the national education system is informed by different development theories to produce a wide range of skills, abilities and talents for the range of diverse labour market needs of the economy. This includes indigenous knowledge as the foundation for traditional economy. Likewise, the formal and Western education system involves an open and conventional education that enhances professional skills and competencies for national and global labour markets. This chapter will focus firstly on the negligence and the continuous overlooking of traditional knowledge as a significant part of the local economy by policymakers and national education system. Later, the discussion will highlight the importance of traditional knowledge to local economy and community development. Furthermore, this discussion will include the basic education for all and how it contributes to the national labour market and development. Finally, the discussion will highlight the national tertiary education and overall policy notion and link to the potential opportunities of the global labour market through labour migration.

\subsection{Diverse education that supports local needs}

Indigenous knowledge has existed and evolved over many generations. For a long time, it has been less exposed to the Westernisation and colonisation discourses. Since the arrival of formal education in the $19^{\text {th }}$ century until today, the path of Western education has generally overlooked traditional epistemology and pedagogy. A hegemonic education system has been established, where disciplines and curricula are based on Western and scientific thought. As suggested by Hewson, the Western education and science are based on generating ideas, skills and values on the basis of

empiricism and criterion of rationalism (Hewson, 2015, p. 26). Many developing countries of the global south have been introduced to Western education doctrines as a form of propagation to spread Western knowledge and reject traditional knowledge 
as it is seen as failing to promote development and growth. The intention is to proliferate development, including formal education, to surpass indigenous knowledge and diverse world views. However, Solomon Islands' people are reluctant to give away their traditional ways and indigenous knowledge despite poor recognition. Until today, the struggle by indigenous people to practise and promote their traditional epistemologies under the regulated formal education system still existed.

The continuous negligence of indigenous education and epistemologies by the national education is a common trend in Solomon Islands. As reiterated by Sumida and Valdiviezo, the education system and policies have historically devalued indigenous knowledge and ways of life in the context of schooling and development (Sumida Huaman \& Valdiviezo, 2014). The non-recognition created space for suspicions and deeper division between the Western education system and traditional worldviews in Solomon Islands. Indigenous knowledge all over the world is malleable, changing to Western ideas of modernisation and development practises (Briggs \& Sharp, 2004). There are many ongoing reforms and structural programmes to address the shortcomings of the national education curricula and policies supported by development partners and international agencies. Yet these reforms continue to suppress and ignore the value of indigenous knowledge and indigenous rights of many rural Solomon Islanders. The recent wave of reforms took place under RAMSI in key government sectors, including education, to restore credibility and stability and to provide inclusive education for Solomon Islands (Anderson et al, 2008). Even though many policymakers and development partners acknowledge the importance of traditional knowledge, it exists outside the formal system.

The local economy has been ignored by the central government and the education system for a long time. Indigenous people are forced to live in a constructed and psychic world while little is left in their lives; nor is the recognition of their indigenous consciousness and intelligence, ingenuity and inventiveness in their world (Kawagley, 2006). The national education has deprived the creativity and intelligence of the rural Solomon Islands. Domestic work often performed by women using traditional 
knowledge is regarded as non-economic under a capitalist view (Fleming \& Palomino Schalscha, 2016). Since the arrival of modern education, it has clearly labelled the functions of indigenous knowledge as non-rational and backward. As mentioned by Gegeo, the collision of these two bodies of knowledge unveil the critical and major divisions between these two world views to define development as a single and linear concept (Gegeo \& Watson-Gegeo, 2002). In the case of rural Solomon Islands, community projects have failed because of ignorance and the isolation of indigenous knowledge from development processes. The general assumption that national formal education and development will solve development problems in rural communities is a massive mistake. This struggle is further confirmed by Gegeo and Watson Gegeo (1999), saying that formal adult learning emphasises the Western education system while ignore the indigenous epistemology as an essential requirement to form an integral part of the planning and management of community development. To a certain degree, indigenous knowledge and local economy is regarded as a shadow curriculum to shoulder the failures of the national economy. Therefore, the traditional market always recognises the value of indigenous knowledge even if it is discounted under modern development approaches and education system.

However, traditional economy is not only seen as diverse and isolated but viewed as an alternative development for rural people. As encapsulated by Gibson-Graham, in diverse economies, there are many ways of remunerating labour, not only through cash (Gibson-Graham \& Roelvink, 2011). The current national education system has a constructed pattern of ignorance regarding traditional knowledge, despite the general understanding that it is a powerful alternative tool for indigenous peoples' subsistence activities. The local labour provides that alternative and means to Solomon Islands low skilled workforce. Indigenous knowledge offers alternative learning to the local economy to produce talents, abilities and skills that support reciprocal communal relations and network. For example, as stated by participant 103, skills such as carving, weaving of baskets and building traditional canoes are learnt through watching, practical participation and listening to elders. These skills represent heritage and communal responsibilities of individuals. Thus, the relation and connection to the 
authority, environment, land and sea is crucial. As argued by some post-development writers, alternative development rejects development because of the homogenisation and Westernisation of world views and mindset which led to many critical dilemmas and failures in developing countries (Nederveen Pieterse, 2010). In the context of Solomon Islands, it not only resulted in failures but a lack of credibility and effective solutions to address local socioeconomic needs. Thus, Solomon Islands' rural people's unique needs, pride and identity comes from indigenous knowledge.

Moreover, the Solomon Islands economy comprises cultural practices and subsistence agricultural economy. One of the aims of the national education is to provide community and technical training to individuals to manage resources in an efficient and effective manner (MEHRD, 2007). In short, the local economy is the most dominant sector that acts as the safety valve for the indigenous community. As articulated by Regenvanu: "traditional economy is the source of resilience for the majority of the populations, and it has allowed them to weather the vagaries of the global economy over past decades" (Regenvanu, 2010). Solomon Islands relies on its traditional economy for food, household materials and natural resources that can be exchanged for cash and daily use. The formal educational system in Melanesia should transform its structure and syllabus to consider traditional knowledge as an important discipline to the local economy that provides livelihoods, security and sustainable development to the indigenous people (Regenvanu, 2010). This is where TVET is needed in order to provide skill-based training for communities to improve and utilise the hidden talents to support community development. Unfortunately, the traditional economy does not feature in national economic policies because its contribution to the national wellbeing is not adequately recognised or quantified (Regenvanu, 2010). A shift in policy is needed to acknowledge the value and why indigenous knowledge is important to Solomon Islands' traditional economy.

Conversely, the growing bias between indigenous knowledge and Western dogmas is becoming more apparent. Indigenous knowledge is often seen as a barrier to development and progress. Indigenous people are frozen in time and guided by a 
knowledge that reinforces the past and has less focus on the future (Battiste, 2005). The local economy benefits from unique behaviours, specialisations, skills and traditional knowledge. In many villages, indigenous epistemologies provide skills that continue to foster community development, informal and self-employment, and increased food security through careful management of natural resources (World Bank, 2012). The local economy absorbed many who dropped out of school in the national education system to support the livelihood and community resilience. As highlighted by Gegeo and Wastson-Gegeo (1998), the majority of students who fail their exams in primary and secondary return to the village, work in plantations, gardens or fishing. This refers to the traditional economy as a safety net to absorb school dropouts despite a convincing argument that only conventional education is relevant for today. So, to exclude indigenous knowledge from any development equation dialogue and rely only on the Western education system and mainstream development ideas would isolate a large portion of the Solomon Islands population who depend on the traditional economy.

Despite the marginalisation of indigenous knowledge in the commercial labour market, it is widely recognised among indigenous people and by the national education system. Even the national government and policy stakeholders have begun to acknowledge the importance of co-existing with the formal education system. Indigenous knowledge is far richer and diverse than the assumption that it is a singular process that is based on ideas about people's relationship to the environment and traditional setting (Hviding, 1993). Traditional societies bases for community, kinship and social relations are vital, even the modern complex systems started to emerge (Smelser, 1966). The diversity itself, is not enough to describe the value and role in which indigenous knowledge plays in local economy and cultural heritage. And this is what Gegeo defines as the ultimate aim of community development in rural Kwara'ae, where people seek happiness, total completeness, key cultural values, security, sharing and love (Gegeo \& Watson-Gegeo, 2002c). In other words, the ultimate meaning of the traditional economy for rural people is to be honest and proud about their ways of learning and their knowledge, and embrace life that provides satisfaction, security and stability for local communities. 
National education and indigenous knowledge are both fundamental to strengthening the local informal workforce and the rural sector. Gegeo and Watson-Gegeo (2002) suggested beyond the recognition of indigenous knowledge contexts, Western education has been slow to recognise that indigenous knowledge also involves critical thinking about their own culture, history, knowledge with the next step being critical reflection. In other words, indigenous knowledge does not literally mean failure because of alienation by modern development approaches and theories, but has its own logical ways of analysing and contributing to development from an indigenous scope. As explained by Gegeo, (2002) regarding the people of Kwara'ae, development fails because the initiation and planning of development activities only uses Western models that produced poor results while ignoring indigenous knowledge. As such, the traditional economy has been misrepresented and undermined by mainstream education and formal government systems. However, indigenous skills and knowledge has survived decades because they are culturally fitting and practical to Solomon Islands. This means that indigenous epistemology and ontology represent an authentic story of the traditional economy in Solomon Islands. Thus, indigenous knowledge remains a sacred practice and cultural significance so under the national education uncertainty of negligence it will not change its philosophy and role in the local economy for cultural identity, livelihood and community development.

In addition, the increasingly institutionalisation of indigenous knowledge through conferences, development plans and broad acceptance by the development community of its inherent value also highlights the direct shift to address the needs of the poor (Briggs, 2005). This view is also echoed by post-development to respect other alternatives to development. Without indigenous knowledge and basic education, the local economy as the backbone of the largely rural population would have collapsed and disappeared a long time ago. Only recently, scholars and practitioners have suggested that indigenous knowledge should constitute the core development models of the third world to address indigenous needs (Battiste, 2005). Indigenous knowledge can help local tourism activities like sightseeing and cultural exhibitions to show case 
the richness of local economy. The curriculum development centre is mandated to facilitate the inclusion of indigenous education to encourage traditional knowledge, customs, medicine, music and dance, and arts and crafts (MEHRD, 2007). The belief that indigenous knowledge is marginal and trivial, and available only to absorb a larger portion of school dropouts and rural young people is a false judgement. Solomon Islands' indigenous knowledge is not about competition and comparisons to modern education disciplines but about empowering indigenous people's livelihoods, cultural practices and accumulation of wealth in the local economy.

Finally, indigenous people with historical continuity of resources-use practices often possess a broad knowledge base of the behaviour of complex environments in their localities (Gadgil et al; 1993). Indigenous epistemology has evolved to fit different circumstances. Today, re-emergence of indigenous knowledge in policy discussion and academic world is associated with the global agendas of sustainability and conservation to address poverty, hunger and climate change challenges. Indigenous knowledge started to emerge as a central figure in modern debates about sustainable development because of the way in which such knowledge has apparently allowed people to live in harmony with nature (Briggs, 2005). The key practices of conservation, sustainability and community development have been the underlying rationale of the traditional economy for many decades yet ignored by formal education disciplines. But today, more practitioners and academics revisit the significance of traditional knowledge to become a core part of the fight against unsustainable development practices and homogeneous development thought. But in Solomon Islands' local economy, a harmonious life and indigenous meaning of existence is more important than long-term and modern complex economic development formulas and discourses.

\subsection{Education for national labour market and economy}

The Solomon Islands' education system is based on two key rationales. One is human capital development, which aims to promote economic growth, and the other is the humanistic view of education, which promotes right of individuals to have access to 
basic education (MEHRD, 2007). The development frameworks of modernisation and radical perspectives influence national education policies. The rise in globalisation, knowledge economy and modern socio-political dynamics, opens the discussion and older arguments about the centrality of human capital investment to individual and national economic performance (McGrath \& Akoojee, 2007). As the national economy grows and becomes more competitive in the free market, the need to build its capacity in human capital also rises to match the behaviours and needs of the national labour market. The Ministry of Education is mandated to lead investment in the human capital for national labour market, development and economic growth. To support this, an investment in human capital is necessary for middle and low-income countries to ensure higher economic growth and resist income divergence across countries (Qadri \& Waheed, 2013).

At the national level, primary and secondary education dominates the policy dynamics and priority of the national government. The national education is heavily politicised by attaching basic education to nation building, progress and economic development. The national assumption is to increase the expansion of basic education over technical skill development training. The aim is to improve numeracy and literacy levels that are necessary for the national labour economy only. Most of the national budget and development assistance goes towards national basic education. As captured in the national education action plan, all children in the Solomon Islands, regardless of gender, ethnicity, religion, location or disability, must have access to basic education, which includes primary and secondary education (National Education Action Plan of Solomon Islands 2007-2009, 2007). The responsibility of the education system is to ensure that adequate facilities and resources are available with trained teachers to deliver quality education to students across the country. Sometimes, it is very difficult to measure the quality of delivery and accessibility to basic education and the impact on the national economy. But largely, the national education system's main function in providing equitable access to Solomon Islands is successful as many Solomon Islands children continue to receive basic education. 
Although Solomon Islands' education sector is struggling in many policy areas, its obligation to provide basic and quality education to Solomon Islands remains largely on track. The education strategic framework for the Solomon Islands is directly associated with the Millennium Development Goals (MDG) adopted at the turn of the century by the UN. In particular, the emphasis on achieving access to universal basic education for all Solomon Islands children in the national education strategic goals is derived directly from the second MDG (now SDG) No. 2 sets out an aim of achieving universal primary education (Education strategic framework 2007-2015, 2007). With domestic and development support through funding and resources, Solomon Islands continues to enjoy the services provided under the education system to deliver the humanistic and social aspect of education. However, much of the global agenda overlooks the core economic and commercial aspect of the economy to link education to the national labour market. Thus, the universal and basic education role to improve literacy and numeracy adopted by Solomon Islands education is aligned towards global obligations and responsibility while underperforming in key social and economic areas of the national economy.

The rise of neoliberalism in the 1980s has exposed Solomon Islands' national education sector and system beyond national capacity and strength. The arrival of privatisation, deregulation and public sector reforms with the rolling out of state became religion and global order of the day (Desai \& Potter, 2014). Solomon Islands' education system and policy regime have gone through a series of changes and reviews since the postcolonial period. In 2004, Sector-Wide Approaches (SWAPs) emerged as an opportunity for the government and donor partners to commit resources to implement a collaborative programme of work developing sectorial policies and strategies, institutional reforms and capacity building (UNICEF, 2014). As a result, several challenges were flagged, such as poor government structure, lack of resources and capacity that impacted on the education and national economy. A shift in the education system to new perspectives and dynamics started to emerge. The national education priorities which, traditionally, used to focus more human resources and economic development for national labour needs started to move towards an 
international notion of universal education and development. Most of the reforms supported by development partners started to shift in their interest and priorities. Generally, national labour needs and critical training has been left out of formal development dialogue and policy making of the national economy. Therefore, Solomon Islands is a heavily subsidised economy and an increasingly volatile political environment having been through many reforms before, resulting in some very general impacts nationally.

The overall national education landscape and standard is moderate and nationally driven. There are ongoing adjustments aiming to improve the education policy and institutional frameworks and regulations to precisely deliver, apart from basic education, quality facilities and curricula to prepare students for the national labour market. The World Bank-led global mechanism developed in recent years, called Education for All, targets part of the global development agenda to commit member states to address humanistic issues of development (Coxon \& Munce, 2008). While it promotes global responsibility and basic education, the domestic downside is that it consistently failed to deal with the socioeconomic and political needs of Solomon Islands. On paper, these quality education goals echoed strong commitment to improve basic literacy but in reality these policies are not aligned to national labour priorities. The technical and skills base of the national economy continues to suffer from diversion of priority to humanistic education rationale. A comprehensive and coherent policy which explicitly outlines the long-term aim to produce basic education and support the smooth transition to specialised skills training for the national labour market simultaneously is still missing. Positive progress has been made so far but demands strategic improvements and a national skill development plan to address these challenges.

Solomon Islands has increased investment in human capital development nationally to maximise national benefits. This has helped national education to consistently supply the needed basic manpower and skills to the national economy. Basic education is regarded as the solution to increase literacy to improve quality of life and social 
wellbeing. The definition of basic education in the Solomon Islands context has to reflect on the balance between the local and global aspects (Sanga \& Thaman, 2009). In other words, basic education equips students with essential skills and knowledge that can fit into the national economy which is sometimes influenced by local context but mostly aligned to global development and capitalist doctrines ideals (Sanga \& Thaman, 2009). The dominance in basic education is on the rise in Solomon Islands as many early childhood schools and primary education are established (UNICEF, 2014). The mass establishment of community high schools to provide education to the mass rural population supports the national obligation to improve basic education. Thus, the shift in education policy from teacher-centred to student-centred learning is in alignment to universal education notion.

As stated by the Education Ministry in its 2010 corporate plan, the tertiary education focus is to ensure that the development of a good system to prepare human resources for the 'knowledge economy' of today (Policy Statement and Guidelines for Tertiary Education in Solomon Islands, 2010). 'Education is seen as a virtual substitute for the lack of natural resources: human capital development supposed to replacement for natural capital' (Gamlen et al., 2016, p. 4). It is possible to agree that the overall education system is effective in producing the necessary skills for the labour market and economic growth to reduce heavy dependences on depleting natural capital. The current skill base and human resources stock represent the national obligation supported by the existing education strategic policies to enhance basic skills and knowledge deemed appropriate for the national labour market. At the micro-level, it helps households with fewer children to invest more in education while at the macrolevel, it decreases unemployment and allows more saving to boost the capital investment in infrastructure and new jobs (Gamlen et al., 2016). Solomon Islands is taking aggressive measures to address these serious internal institutional processes and policy gaps to marry education and the national labour market perfectly to achieve a steady national social and economic development. 
One of the national market niches targeted by national education in collaboration with SINU is the country's teaching sector. It is highly regarded as one of the dominant employers of graduates from SINU and other regional universities. Every year, SINU produces hundreds of graduates as primary to secondary teachers. And all of them are absorbed into the national labour market. Most teachers are placed with provincial schools across the country. The high number of teaching graduates yearly represents a productive national education system that is highly relevant and corresponds to the national teaching needs. This also plays an important role in promoting a quality teaching and professional delivery of knowledge to the younger generation. The following is a summary of the national tertiary education vision for the quality of education and training:

All Solomon Islanders will have equitable access to a responsive and relevant tertiary education that will enable them to fully participate in economic, social and cultural life in their communities and to develop their skills and competencies needed to make Solomon Islands' workforce effective and productive (Policy Statement and Guidelines for Tertiary Education in Solomon Islands, 2010, p. 9).

This has reaffirmed the rationale behind the national education system and SINU'S commitment to invest in skill development for national market. The SINU's School of Education and Humanities has policies for training and increasing the numbers of teaching careers in Solomon Islands, and continues to produce quality teachers every year to the national labour market.

Finally, the public and private sector also benefits from the skills and knowledge produced by formal education. Many students coming out of the system have found work in either the private or the public sector. These are the largest employers, employing many qualified workers. SINU is the backbone institution that produces nearly all the teachers, health workers, trade skills and business administrators employed in the public and private sectors. So the qualifications and skills produced by national institutions such as SINU and foreign universities support the national 
development prospects. These are the technical people on whom local industries and national business households depend for productivity, innovations and positive turnovers. Participant 103 suggested that education is considered the catalyst for producing the essential pool of national talented workers ready to take Solomon Islands into the modern technological age. Furthermore, a 2007 national study highlighted that of the skilled labour opportunities in the private sector, about $40 \%$ are for management and administration, $20 \%$ to $30 \%$ are for those with professional skills, and $30 \%$ to $40 \%$ are for those with technical and vocational skills (The World Bank, 2007). Thus, a combination of different types of skill levels is significant in building a strong labour force for the national economy and will influence Solomon Islands policy behaviour to take strategic and innovative actions to strongly link education to national labour needs.

\subsection{National education for regional and global labour market}

Solomon Islands education system recognises the potential of being integrated into the global economy and labour market through education and migration. The national tertiary education policy is not explicitly precise on the joint connection between national education and labour migration. However, it recognises the potential opportunities offered by the global labour market. In support of that, national tertiary policies and plans are starting to focus tertiary education on the global market needs. National reforms in education strategies have considered the idea of labour migration more recently. It is a new concept for Solomon Islands but at least the policy elite and national institutions are starting to understand the benefits and positive impacts the global labour market opportunities will have on the national economy. So having a readily available nationally qualified pool of workers in several specialised fields is vital. The global labour market includes jobs opportunities from unskilled to skilled provided by regional and international countries, and organisations are potential alternative labour markets for Solomon Islands' workforce.

Today, free market liberalisation under neoliberalism has dominated Solomon Islands' economy and labour markets' behaviour. The free market doctrines of new 
liberalisation and global integration enable the mobility of services and goods freely into Solomon Islands. Education plays a central role in facilitating societal responses to the strains and paradoxes thrown up by globalisation and ensure socioeconomic benefits accrue from development and integration with the global economy (Little \& Green, 2009). The education system engaged in a series of adjustments to meet the global standards and disciplines. As a result, Solomon Islands' economy has been connected to rest of the world through training, education, commerce and global cooperation. Thus, many educated individuals can now work anywhere in the world due to global market integration. Market liberalisation has connected developed countries and developing countries together in terms of education and labour migration while eliminating any systematic, territorial and political barriers to achieve development. The national education regime is silently providing individuals with necessary attributes, skills and competencies demanded in the external labour market.

Solomon Islands continued effort to gain access to, and enjoy the full potential of, the global labour market has just started. The large scarcity of national employment opportunities has prompted policymakers to consider external labour markets as an alternative solution. And so, for priority areas like quality tertiary education to maximise benefits from potential external labour markets, it is important to start fitting them into national education plan and strategies. Solomon Islands' government has expressed a strong commitment to have a potential labour mobility arrangement with Canada after a formal visit by the Chairman of Canadian International Training \& Education (CITREC) (SI eyes Canada's Labour mobility opportunities, 2016). For example, this will be an expansion from an existing relationship established between the government of Canada and Guadalcanal Province in Solomon Islands. The arrangement includes a joint memorandum of understanding to provide scholarships to selected students from Guadalcanal to study in Canada in specified subjects and later get employment in certain agreed sectors for a set period of time (Canadian Employers present job offers to GP CITREC graduates, 2016). The first graduates from CITREC were offered jobs by the tourism and hospitality sectors to start employment for between 3 and 24 months duration in May, 2016 (Canadian Employers present job 
offers to GP CITREC graduates, 2016). According to interviewee 101, the Canadian government approached SINU five years ago to set up similar training programmes to facilitate Solomon Islanders working in the care-giving industry. But due to political issues and national government unstable policy priorities, has let Guadalcanal Province pursue the interest. But now, the national government sees this opportunity as a potential employment market for Solomon Islands to exploit.

The national education system represents a diverse model that also actively produces skilled labour for the global labour market. Although the record in Solomon Islands may not be as successful as in other Pacific countries, the trend of highly qualified people moving out is becoming noticeable and growing. The external labour market offers opportunities for well-educated Solomon Islanders to find better jobs and living conditions in other countries. Homogenised neoliberal policies of privatisation, trade liberalisation and structural adjustment initiated by powerful Western economies become a boost for global labour migration (Potter, 2012). RAMSI is the recent external player that helped by initiating intervention programmes to rescue and bring the education system back to its original status (Anderson et al, 2008). This assumption has stimulated the national education policies and plans to ensure that open economy is the considered path towards development and economic growth where citizens and workers are free to move for employment purposes. According to participant 119, Solomon Islands has already experienced migration of several top educated national citizens to offshore labour markets. Solomon Islands is currently engaged in seasonal labour schemes SWP with Australia and RSE with New Zealand. Today, globalisation has enabled easy mobility of skills and talent from Solomon Islands to the rest of the world. An expansion into semi-skilled and skilled sectors will bring more job opportunities and benefits for Solomon Islands, especially for the educated workforce. Thus, the Ministry Education must devise appropriate reforms to release the full potential of individuals so that they are equipped with necessary academic credentials, soft skills such as good attitude and technical skills that correspond with global labour market demands. 
The global cooperation and economic relations has boosted prospects for Solomon Islands' education to trade skills and talents demanded in the global labour markets. The close partnership and interconnectedness of education systems and disciplines has helped Solomon Islands' education to deliver the same Western standard of learning and training practices that are in high demand in the global economy. One of the common syndromes is that developing countries are not able to grant university graduates from developed countries appropriate positions, material resources and salaries that correspond with their knowledge, skills and experience (Zhatkanbaeva et al, 2012). The competition between national and global labour for skills is another advantage for Solomon Islands to consider. As supported by interviewee 103, more than half of Solomon Islanders who have graduated with a PhD are working outside the country because the national labour market cannot afford to provide jobs that correspond with their specialisation and skills. This kind of challenge persuades local professionals to look overseas for jobs for career enhancements. The adopted Western education model has shaped educational strategies and portfolios to emulate and produce competitive human resources that are analogous to the modern global labour market. Now the national education system is no longer isolated and considered a national labour market driven by dynamics, but rather linked to the international labour market.

In addition, the global and regional organisations like UN and Pacific Forum Secretariat are major market targets for many educated workers in Oceania, including Solomon Islands. Some educated Solomon Islanders have worked for these regional bodies. For example, five Solomon Islands police officers, for the first time in history, have travelled to South Sudan for an international peace-keeping mission under the UN after undertaking intensive training in Australia supported by RAMSI. This characterises an integrated world that represents dynamism and job opportunities for countries that prepare skills for the global market needs. These international commitments and economic relations are classic cases of available opportunities in the regional and the global market. It is up to the national education system to explore these opportunities. As suggested by interviewee 119, “highly educated Solomon Islanders don't have to 
find jobs anywhere in the world, the jobs will search for you because of your skills and specialisation." The economic and trade paradigm shift externally has impacted on education policies to undertake adjustments that satisfy regional and global economic and labour markets. As reinforced by Mearsheimer (1994), the state must not think in narrow self-interest, but instead choose to equate its national interest with the broader interests of the international community. Solomon Islands must utilise the existing partnerships established with key regional institutions like USP and development partners such as Australia and New Zealand to upgrade its national education standards to align with regional and global standards.

In addition, the Solomon Islands education system has produced number of qualified workers who have worked in traditional markets like PNG and Vanuatu. The Melanesian Spearhead Group and the PACER plus agreement are potential mechanisms that promote regional labour migration opportunities. A number of Solomon Islands' doctors are working in PNG and other regional countries due to strong cultural and political relations. There is even higher demand for Solomon Islands' teachers in PNG. Likewise, the Vanuatu government also facilitated the recruitment of several trained nurses from Solomon Islands to work in Vanuatu between 2011 and 2014 under a special arrangement between both governments (Godwin, 2014). All of these have reflected well on the overall reputation of the national education system, standard and benchmark in regional labour migration. More so, the tertiary education policy in ensuring that institutions such as SINU are well equipped with adequate resources and expertise to produce highly skilled labour that is marketable in Vanuatu and PNG. There is a demand for Solomon Islands workers in the regional market, but unless the education institutional structures are aligned with market needs, it will not be easy to send workers overseas based on many requirements and attributes set by the Pacific region.

Solomon Islands' increasing integration into the global labour market may bring substantial benefits to the development and economy as a whole. One of the potential labour market problems in developed countries like Australia and New Zealand is aging. 
These are two of the largest economies but also close development partners with Solomon Islands. According to a World Bank report, improved labour market outcomes require a boost in the quality of education at all levels so that workers skills, both cognitive and behavioural attributes, meet employers' demand in the economy and globally (World Bank, 2012). Solomon Islands must diversify its education policies and prepare for potential markets like the old aging in Australia and New Zealand. For example, Australia Pacific Technical College (APTC) has rolled out training programmes in Solomon Islands that enable training of individuals to acquire life skills that correspond with Australia and New Zealand market standards. Through bilateral and multilateral arrangement, Solomon Islands can compete fairly in sectors such as age care and horticulture to maximise the benefit of remittances and skills enhancement. But in order for Solomon Islands to be successful, the education system must be open for positive interventions and free market principles to align to external market forces.

Solomon Islands tertiary education mission has encapsulated the broad perspective and long-term view of a labour market-friendly system. As captured in the national tertiary policy 2010, "all Solomon Islanders will have equitable access to a responsive and relevant tertiary education to develop their skills and competencies needed to make Solomon Islands' workforce globally competitive and to link them to international employment opportunities" (Policy Statement and Guidelines for Tertiary Education in Solomon Islands, 2010). The education system needs to be vigilant with an available work-ready pool and keep seeking opportunities available in the global economy. So that when offshore employment opportunities arise, the workforce has the skills to meet the external demand. As outlined by the World Bank, regulatory and institutional barriers to external labour migration reduce income and opportunities for Solomon Islanders while precluding new remittance income streams (World Bank, 2012). Precisely, Solomon Islands' education system's broad perspective and general policy priority aims to produce a workforce that can look beyond its national borders for potential employment and socioeconomic opportunities. 
In summary, Solomon Islands has a diverse education that produces a range of skills and talent to local, national and global labour needs. However, there are ongoing policy challenges with the education system. Indigenous knowledge has been neglected for a long time although it is the backbone of the local economy and subsistence agriculture. At the national level, education continues to promote the humanistic perspective by providing basic education, increasing numeracy and literacy, which connects with the international agendas of education for all and universal right to education. This is to ensure self-consensus on the social responsibility as citizens and participation in national development. Also the national education produces skills that form human capital to stimulate the national development and economic growth to improve wellbeing and quality of life. The current education policy and system does not explicitly produce skills to the global market. However, the mobilisation of a small number of Solomon Islanders from unskilled to highly skilled labour to the global labour market shows the potential opportunities that the global market offers to Solomon Islands. Thus, the awareness and understanding about this potential global market starts to influence the status quo to review national policy to respond to diverse opportunities available to Solomon Islands both nationally and globally. 


\section{Chapter 7: Conclusion}

In summary, the principal purpose of this research was to examine the relation between education and labour migration and development in Solomon Islands. This process has involved disclosing and exploring Solomon Islands' education regime, policy culture and development impacts on the different market levels of the country. The key findings of the research were obtained through qualitative semi-structured interviews, reports and policy documents. The qualitative research applied social constructivism in the process of collection, analysis and construction of views on how the national education system prepares and produces skills and talent to the diverse labour markets. The interviewed participants were selected from national government departments and private institutions based on their roles in education and labour, which gave thorough views and policy insights. In addition, the findings and discussion have been explored from various hypothetical perspectives supported by practical policy documents and reports. The research applied both development theory and practice and examined how they inform the education system and its strategies on the ground. The existence of a multilayered education system and diverse societal and cultural practices competing with the complex economic and political instruments influenced the decision to examine education and labour migration in Solomon Islands. In addition, it precisely represents the motivation to undertake this research on Solomon Islands' national education and the interaction with different policy players and stakeholders in the diverse national economy. The application of development discourses rather than solely disguising this argument and issue with policy perspective helped to guide the findings and analysis that equally represents both the academic and practical perspectives of Solomon Islands' education system in relation to different labour markets and national development.

On a general level, the national education regime and its policies are responding fairly to the labour needs of the economy. Solomon Islands' education has focused on a universal model informed by modernisation and neoliberalism. In addition, the universal and basic education has become the primary role of the national education regime in Solomon Islands, delivered through primary and secondary schools. Many 
Solomon Islanders receive basic learning every year to improve their literacy and numeracy abilities. Due to the popularity of national education, individuals are pressured to migrate internally resulting a high rate of urbanisation in Solomon Islands. More people are attracted to urban centres such as Honiara to have access to reliable schools and find jobs. This also led to an increase in other social-related problems such as unemployment and poor labour conditions due to shortage of jobs.

Most of the basic education ideals are aligned with universal education agendas by global agencies such as the UN. These commit Solomon Islands, as a member, to international conventions in education to fulfil its obligations to meet universal targets and goals while supporting young people to acquire basic skills and knowledge to participate in the national economy. On the other hand, the national education is perceived as the filtering system to determine the next generation of students to sustain national economy. The curriculum and pedagogy are heavily based on humanistic view. It tests students' abilities and capacities on certain subjects. The alternative education opportunities are slim. The disparity in education policy and the underlying notion of basic education makes it difficult to fully understand the national education's direction and objectives and how it will prepare potential students for the national labour market. Thus, because of this examination-based pedagogy, many students are denied learning prospects, which is contradictory to the national education promise to adequately and equally empower individuals to boost the national economy. The universal education continues to empower marginalised and rural people to understand the developments' failures and criticise the main stream development promise.

Moreover, the accessibility and expansion of Western education has dominated Solomon Islands since independence. Much of the national-level policy is focused on a mixture of modernisation and neoliberal frameworks where capital and human resources development for the national economy is paramount. The notion of education for all is a very much generalised yardstick with which to measure the effectiveness of national education's role in the development of human resources for 
the national labour market. However, this is where the current Solomon Islands' national education system stands. The change in curriculum by shifting focus from a teacher-centred to a learner-centred approach will enhance investment to boost the national skills base. This indicates the shift from a modernisation approach to a privatised and deregulated education system. Although it lacks production in high number of specialised skills and competencies, the intention to provide education for personal and human capital development, regardless of place, ethnicities and geographical location, is very much dynamic. Thus, national education is used as a vehicle to shape the individuals from early stages to obtain the attributes and behaviours, skills and knowledge that are considered vital to boost and stimulate national development and economic growth.

However, the current education policy and curriculum has been neglecting the traditional knowledge. Traditional knowledge continues to operate outside the socioeconomic and political systems. Even though $80 \%$ of Solomon Islands' rural communities use traditional knowledge to sustain their livelihood and subsistence agriculture, the national government still marginalises local economy. This is because of the suspicion of its uncertainties in quantification, unscientific and peripheral to the universally recognised scientific rationales and development. The local economy, including cultural practices and subsistence agriculture, are very important in various ways: identity, natural resources management, learning environment and home to many today, thus the national education system needs to seriously consider a strategic policy initiative to formally recognise its valuable contribution to the wellbeing and living standards of many rural societies. A space based on trust and relation is essential to acknowledge and examine how indigenous perspective and local economy can fit into Solomon Islands' education policy and be recognised as alternative development.

Furthermore, the historical heritage of the indigenous epistemologies and ontologies of Solomon Islands are not invented concepts but are a set of doctrines that is culturally significant and inherited through generations in rural Solomon Islands before the arrival and imposition of Western education. Traditional knowledge unleashes 
competencies and talents for the local market that sustain the cultural practices and livelihood of the local economy. This results in internal migration where people move to their respective islands and villages if they fail to move further in their formal education. Recognising indigenous knowledge as an alternative learning system will also improve the relation between local communities and national government with regards to providing incentives to recognise their skills and contribution to the local economy. By understanding and recognizing the traditional knowledge, it will enlighten the holistic notion and mission of a set of national pedagogies to embark on a logical but diverse human resources development framework that does not discriminate against alternative forms of learning. A local driven education with a systematic link between national and local economy would encourage local migration. Thus, local people will feel as part of the national development process by engaging through local decision contribution anchored on indigenous knowledge and epistemologies to manage natural resources.

Likewise, the growing interest in Solomon Islands on labour migration needs support from national policymakers from education and labour authorities to align strategic policies to the global labour market tides. It will set a strong foundation for sustainable and long-term engagement of education in training of skills and competencies for global labour markets. It is extremely important to have a legitimate framework that promotes and connects education to the global labour market. It is evident that there is a fragmentation of structural and political support to harmonise the interaction between education and labour skills to benefit from the global labour market. The national tertiary education continues to develop skills for the global labour market but in an unsystematic way. Yet Solomon Islands is experiencing a slow but gradual mobility of a variety of skills, from unskilled to the highly skilled professionals, to the global labour market. Labour migration is happening in Solomon Islands through a smallerscale and regulated model. From an outside perspective, the declining working population in developed countries like New Zealand and Australia offers potential jobs opportunities in all kinds of skills for Solomon Islands. Since Solomon Islands has political and economic relations with many countries, including Australia and New 
Zealand, the increasing possibility and potential to benefit from labour migration is still a relevant priority for the country. Therefore, a comprehensive policy intervention would help to broaden the national economic base and focus more on tertiary education in order to expand and explicitly address the external labour market interests and opportunities to generate socioeconomic prospects and development.

There are gaps and inconsistencies in the internal policy regime between the education system and diverse labour markets, which trigger poor collaboration and coordination. As Solomon Islands' young population is growing rapidly, the economy must diversify in terms of education policies, business and its labour market to offer alternative employment opportunities that match different labour needs from local, national and global markets. The domestic labour markets, including local and national labour, require more policy improvement and continuous support to make a sustainable contribution to Solomon Islands' prospects. The ultimate focus to expand the national skill and human resource development must revitalise its core functions and roles to start considering potential labour markets outside Solomon Islands. The education system requires major adjustments and reviews so that it supports the ambition to export skilled labour to the potential global labour markets. There are significant changes needed in the national education standards and qualifications so that local graduates can be recognised globally. This will enable many qualified Solomon Islanders to migrate anywhere for employment. The gradual shift in policy culture and recognition towards tertiary education by national government and Ministry of Education is a positive indication of how diverse learning and education will advance the call for a development path that rests on local and global labour market opportunities.

The national education policy recognises diversities in the economy and labour markets. The education policy framework has started to realise these differences as potentialities where a flexible approach is required to enhance an inclusive and diverse local labour market. The impacts from local to global in terms of economics, technology, cultures, politics and demographics are genuine and becoming more 
frequent, thus Solomon Islands' education system must learn to change to respond to these rapidly changing environment and diverse market trends. Solomon Islands is not immune to development changes so the education system must see these changes and challenges as positive learning curves that can help to discover innovative ways and mixed approaches to address different needs. Despite many failures, challenges and opportunities ahead, Solomon Islands' overall education system will still depend on its limited capacities and available practical policies with long-term vision to continue to produce relevant skills, knowledge and competencies for the local, national and global labour market.

Solomon Islands as a developing economy and development theories of neoliberal and alternative economy thought still inform its education policy and system. The policy framework is coherent for diverse educational portfolios. As the world is already sceptical about the relevance of modernisation and neoliberalism, Solomon Islands economy is far from full integration into the global system. Development through the eyes of the developed world has forbidden Solomon Islands' diversities. The failures in development should empower policymakers to make strategic innovations and connections to improve national education. In response to these failures, Solomon Islands is leaning towards diverse development trajectories and practice that are centred on human welfare and positive economic transformations at different market levels. Thus, at the national level, the cooperation and inspiration has started to emerge and drive the national economy, informed by modern and neoliberal education strategies, to link education and migration and development.

Finally, education is indispensable to migration and the development of Solomon Islands. It is clear from the findings that the overall rationale of Solomon Islands' education is to train human resources to drive the national economy and development. Solomon Islands' education system is informed by reviews and analysis based on different development theories from modernisation, radical, neoliberal to postdevelopment. Despite many shortcomings, national education adopted a balanced and diverse education system that responds to the domestic multilayered needs and 
demands of the economy. The current education system is rooted in free enterprise principles but also embraces diversity, encompassing the wide ranging needs and skills of the national economy and development. In addition, the education maintained a strong philosophy and vision to train the national workforce to become self-reliant, innovative and contribute productively to the private and public sector needs. Furthermore, the education system and its policies strive to produces skill that meet global labour market expectations which, in return, will reciprocally contribute to national development and progress. 


\section{References}

Akin, D. K. (2013). Colonialism, Maasina Rule, and the Origins of Malaitan Kastom. University of Hawai'i Press.

Alhojailan, M. I. (2012). Thematic analysis: A critical review of its process and evaluation. West East Journal of Social Sciences, 1(1), 39-47.

Altbach, P. G., Reisberg, L., \& Rumbley, L. E. (2009). Trends in global higher education: Tracking an academic revolution. UNESCO Pub.; Sense.

Ananiadou, K. (2013). Revisiting Global Trends in TVET: Reflections on Theory and Practice. UNESCO-UNEVOC International Centre for Technical and Vocational Education and Training.

Anderson, T. (2008). RAMSI: intervention, aid trauma and self governance. Journal of Australian Political Economy, (62), 62.

Battiste, M. (2005). Indigenous knowledge: Foundations for first nations. World Indigenous Nations Higher Education Consortium-WINHEC Journal.

Bennett, J. A. (1987). Wealth of the Solomons: A history of a Pacific archipelago, 18001978. University of Hawaii Press.

Bennett, J. (2002). 'Roots of conflict in Solomon Islands-though much is taken, much abides: legacies of tradition and colonialism'. ANU State, Society and Governance in Melanesia (SSGM). Discussion Paper 2002/5. Australian National University, Canberra.

Braun, V., \& Clarke, V. (2012). Thematic analysis. In H. Cooper, P. M. Camic, D. L. Long, A. T. Panter, D. Rindskopf, \& K. J. Sher (Eds.), APA handbook of research methods in psychology, Vol 2: Research designs: Quantitative, qualitative, 
neuropsychological, and biological. (pp. 57-71). Washington: American Psychological Association.

Bray, M., Zhan, S., Lykins, C., Wang, D., \& Kwo, O. (2014). Differentiated demand for private supplementary tutoring: Patterns and implications in Hong Kong secondary education. Economics of Education Review, 38, 24-37.

Briggs, J. (2005). The use of indigenous knowledge in development: problems and challenges. Progress in Development Studies, 5(2), 99-114.

Briggs, J., \& Sharp, J. (2004). Indigenous knowledges and development: a postcolonial caution. Third World Quarterly, 25(4), 661-676.

Castles, S. (2000). International Migration at the Beginning of the Twenty-First Century: Global Trends and Issues. International Social Science Journal, 52(165), 269281.

Chinnammai, S. (2005). Effects of globalization on education and culture. Retrieved from https://www.openpraxis.org

Connell, J. (2014). The two cultures of health worker migration: A Pacific perspective. Social Science \& Medicine, 116, 73-81.

Connell, J., \& Brown, R. P. (1995). Migration and remittances in the South Pacific: Towards new perspectives. Asian and Pacific Migration Journal, 4(1), 1-33.

Cook, I., \& Crang, M. (1995). Doing Ethnographies. University of East Anglia. Retrieved from https://www.researchgate.net

Corporate Plan 2016-2019: Ministry of Commerce, Industry, Labour and Immigration. (2016). 
Coxon, E., \& Munce, K. (2008). The global education agenda and the delivery of aid to Pacific education. Comparative Education, 44(2), 147-165.

Craig, D., \& Bedford, R. (2013). Labour Mobility and Solomon Islands Development. ANU SSGM in Brief. Retrieved from http://ips.cap.anu.edu.au

d'Aiglepierre, R., \& Wagner, L. (2013). Aid and Universal Primary Education. Economics of Education Review, 37, 95-112.

Daniel, G. (2009). Solomon Islands Diagnostic Trade Integration Study (pp. 1-335). Honiara, Solomon Islands.

De Haas, H. (2010). Migration and Development: a theoretical Perspective ${ }^{1}$. International Migration Review, 44(1), 227-264. https://doi.org/10.1111/j.1747-7379.2009.00804.x

Desai, V., \& Potter, R. B. (Eds.). (2014). The companion to development studies (Third edition). London ; New York: Routledge.

Dinnen, S., \& Firth, S. (Eds.). (2008). Politics and state building in Solomon Islands. Canberra: ANU E Press ; Asia Pacific Press.

Escobar, A. (2010). LATIN AMERICA AT A CROSSROADS: Alternative modernizations, post-liberalism, or post-development? Cultural Studies, 24(1), 1-65.

Fleming, K. (2015). Diverse Education for Diverse Economies: The relevance of Rural Training Centres in the Solomon Islands. Retrieved from http://researcharchive.vuw.ac.nz/handle/10063/4266

Fleming, K., \& Palomino Schalscha, M. (2016). Re-envisaging Education from a Diverse Economies Perspective: The Role of Rural Training Centres in the Solomon Islands. 
Foshay, A. (1991). The curriculum matrix: Transcendence and mathematics. Journal of Curriculum and Supervision, 6(4), 277-293.

Freire, P. (1974). Education for Critical Consciousness. New York: Sheed and Ward.

Freire, P. (2000). Pedagogy of the oppressed (30th anniversary ed). New York: Continuum.

Fuller, A. (2015). Vocational Education. In International Encyclopedia of the Social \& Behavioral Sciences (pp. 232-238).

Gadgil, M., Berkes, F., \& Folke, C. (1993). Indigenous knowledge for biodiversity conservation. Ambio, 151-156.

Gamlen, A. (2014). The new migration-and-development pessimism. Progress in Human Geography, 38(4), 581-597. https://doi.org/10.1177/0309132513512544

Gamlen, A., Murray, W. E., \& Overton, J. (2016). Investigating education, migration and development - Moving triangles in the Pacific: Moving triangles. New Zealand Geographer. http://doi.wiley.com/10.1111/nzg.12146

Gegeo, D. W., \& Watson-Gegeo, K. A. (1999). Adult education, language change, and issues of identity and authenticity in Kwara'ae (Solomon Islands). Anthropology \& Education Quarterly, 30(1), 22-36.

Gegeo, D. W., \& Watson-Gegeo, K. A. (2002). Whose knowledge?: Epistemological collisions in Solomon Islands community development. The Contemporary Pacific, 14(2), 377-409.

Gibson-Graham, (first). (2005). Surplus possibilities: postdevelopment and community economies. Singapore Journal of Tropical Geography, 26(1), 4-26. 
Gibson-Graham, J. K. (2008). Diverse economies: performative practices for `other worlds'. Progress in Human Geography, 32(5), 613-632. https://doi.org/10.1177/0309132508090821

Gibson-Graham, J. K., \& Roelvink, G. (2011). The nitty gritty of creating alternative economies. Social Alternatives, 30(1), 29.

Godemann, J., Haertle, J., Herzig, C., \& Moon, J. (2014). United Nations supported Principles for Responsible Management Education: purpose, progress and prospects. Journal of Cleaner Production, 62, 16-23.

Held, D. (2004). Global Covenant: The Social Democratic Consensus to the Washington Consensus. Cambridge: Polity.

Hewson, M. G. (2015). Embracing Indigenous Knowledge in Science and Medical Teaching (Vol. 10). Dordrecht: Springer Netherlands. Retrieved from http://link.springer.com/10.1007/978-94-017-9300-1

Hviding, E. (1993). Indigenous Essentialism? 'Simplifying' Customary Land Ownership in New Georgia, Solomon Islands. Bijdragen tot de Taal-, Land-en Volkenkunde, (4de Afl), 802-824.

ILO. (2009). Decent Work Country Programme for Solomon Islands 2009-2012. www.ilo.org/public/english/bureau/program/dwcp/download/solomon.pdf ILO. (2015). International Labour Migration Statistics: A guide for Policymakers and Statistics Orgnizations in the Pacific. Suva, Fiji.

Island Sun. (2016). Canadian Employers present job offers to GP CITREC graduates. http://theislandsun.com 
Johnson-Bailey, J., Merriam, S., Ntseane, G., Lee, M.-Y., Kee, Y., \& Muhamad, M. (2000).

Power and Positionality: Negotiating Insider/Outsider Status in Multicultural and Cross-Cultural Research. DOCUMENT RESUME, 620.

Kamens, D. H., Meyer, J. W., \& Benavot, A. (1996). Worldwide patterns in academic secondary education curricula. Comparative Education Review, 40(2), 116-138.

Kawagley, A. O. (2006). A Yupiaq worldview: A pathway to ecology and spirit. Waveland Press.

King's College London. (2013). The Private Sector, the Solomon Islands and the Peace Economic Dividend: Learning from the RAMSI Experience. London.

Kritz, M. M. (2006). Globalisation and internationalisation of tertiary education. In Symposium on International Migration and Development, Turin, Italy (pp. 2830).

Kvale, S. (2008). Doing interviews. Sage. Retrieved from https://books.google.co.nz/books?

Little, A. W., \& Green, A. (2009). Successful globalisation, education and sustainable development. International Journal of Educational Development, 29(2), 166174.

Maclean, R. (Ed.). (2009). International handbook of education for the changing world of work: bridging academic and vocational learning.

Maringe, F. (2015). Higher Education Market. In International Encyclopedia of the Social \& Behavioral Sciences (pp. 850-861). 
McGrath, S., \& Akoojee, S. (2007). Education and skills for development in South Africa: Reflections on the accelerated and shared growth initiative for South Africa. International Journal of Educational Development, 27(4), 421-434.

MFAET. (2015). Solomon Islands Labour Mobility. Honiara, Solomon Islands.

Ministry of Education and Human Resources Development. (2007). Education Strategic Framework. Honiara, Solomon Islands.

Ministry of Education and Human Resources Development. (2010). Policy statement and guidelines for tertiary education in Solomon Islands. Honiara, Solomon Islands.

Ministry of Education and Human Resources Development. (2015). Education White Paper. Honiara, Solomon Islands.

Moore, C. (2007). The misappropriation of Malaitan labour: historical origins of the recent Solomon Islands crisis. Journal of Pacific History, 42(2), 211-232.

National Education Action Plan of Solomon Islands 2007-2009. (2007).

National Education Action Plan of Solomon Islands: 2010-2012. (2009).

Nederveen Pieterse, J. (2010). Development theory: deconstructions/reconstructions (2nd ed). Los Angeles : London: SAGE.

Neuman, W. L. (2005). Social research methods: Quantitative and qualitative approaches (Vol. 13). Allyn and bacon Boston, MA.

OECD. (2012). Managing Aid for Trade and Development results.

OECD. (2012). Policy framework for Investment.

Policy Statement and guidelines for National Curriculum: Solomon Islands. (2009). 
Potter, R. B. (Ed.). (2012). Key concepts in development geography. Los Angeles, Calif: SAGE.

Prescott, S. M. (2008). Using talanoa in Pacific business research in New Zealand: experiences with Tongan entrepreneurs. AlterNative: An International Journal of Indigenous Scholarship, 4(1). Retrieved from http://search.ebscohost.com

Qadri, F. S., \& Waheed, A. (2013). Human capital and economic growth: Cross-country evidence from low-, middle- and high-income countries. Progress in Development Studies, 13(2), 89-104.

Regenvanu, R. (2010). The tradional Melanesian economy resilient in global economic crises. Pacific Ecologist, (19): 53-57.

Ritchie, J. (Ed.). (2010). Qualitative research practice: a guide for social science students and researchers (Reprinted). Los Angeles, Calif.

Ritchie, J., \& Lewis, J. (Eds.). (2003). Qualitative research practice: a guide for social science students and researchers. London ; Thousand Oaks, Calif: Sage Publications.

Rodriguez-Pose, A., \& Vilalta-Bufi, M. (2005). Education, migration, and job satisfaction: the regional returns of human capital in the EU. Journal of Economic Geography, $5(5), 545-566$.

Rose, G. (1997). Situating knowledges: positionality, reflexivities and other tactics. Progress in Human Geography, 21(3), 305-320.

Sanga, K., \& Thaman, K. H. (2009). Re-thinking education curricula in the Pacific: Challenges and prospects. He Parekereke. 
Schriewer, J., \& Nóvoa, A. (2015). Education, History of. In International Encyclopedia of the Social \& Behavioral Sciences (pp. 172-177).

Shin, J. C., \& Harman, G. (2009). New challenges for higher education: Global and AsiaPacific perspectives. Asia Pacific Education Review, 10(1), 1-13.

Smelser, N. J. (1966). The modernization of social relations. Modernization: The Dynamics of Growth. New York: Basic Books, 110-121.

Solomon Islands (Ed.). (2002). Solomon Islands human development report 2002: building a nation. Windsor, Qld: Mark Otter for the Government of Solomon Islands.

Solomon Islands Government. (2009). 2009 Population and Housing Census: Report on Migration and Urbanisation.

Solomon star. (2016). SI a low mobility Nation. http://www.solomonstarnews.com/news/national/11286-si-a-low-mobilitynation-report

Solomon star. (2016). Sl eyes Canada's Labour mobility opportunities. http://www.solomonstarnews.com/news/national/9430-si-eyes-canada-slabour-mobility-opportunities.

Suaalii-Sauni, T., \& Fulu-Aiolupotea, S. M. (2014). Decolonising Pacific research, building Pacific research communities and developing Pacific research tools: The case of the talanoa and the faafaletui in Samoa: Pacific research in Samoa. Asia Pacific Viewpoint, 55(3), 331-344. 
Sultana, F. (2007). Reflexivity, positionality and participatory ethics: Negotiating fieldwork dilemmas in international research. ACME: An International E-Journal for Critical Geographies, 6(3), 374-385.

Sumida Huaman, E., \& Valdiviezo, L. A. (2014). Indigenous knowledge and education from the Quechua community to school: beyond the formal/non-formal dichotomy. International Journal of Qualitative Studies in Education, 27(1), 6587. https://doi.org/10.1080/09518398.2012.737041

Sustainable Development Goals. (2015).

The World Bank. (2007). Solomon Islands Study to Support the Development of a National Skills Training Plan.

UN-DESA and OECD. (2013). Level Dialogue on Migration and Development.

UNESCO. (2015). Education for All: 2000-2015 Achievements and Challenges. Paris, France.

UNICEF. (2014). Solomon Islands Case Study in Education, Conflict and Social Cohesion. Thailand.

United Nation Development Programme. (2010). Millenium Development Goals progress report for Solomon Islands. Honiara.

Vaioleti, T. M. (2006). Talanoa research methodology: a developing position on pacific research. Waikato Journal of Education 12, 21-34.

Vanuatu Daily Post. (2014). Solomon Nurses contracts end December 2014. http://dailypost.vu/news/solomon-nurses-contracts-end-december/article.

World Bank. (2012). SKills for Solomon Islands: Opening new opportunities. 
Zhao, Y. (2015). Globalization in Education. In International Encyclopedia of the Social \& Behavioral Sciences (pp. 247-253). Elsevier. Retrieved from http://linkinghub.elsevier.com/retrieve/pii/B9780080970868921135 Zhatkanbaeva, A., Zhatkanbaeva, J., \& Zhatkanbaev, E. (2012). The Impact of Globalization on "Brain Drain" in Developing Countries. Procedia - Social and Behavioral Sciences, 47, 1490-1494.

https://doi.org/10.1016/j.sbspro.2012.06.848 


\section{Appendices}

Appendix 1: Human ethics approval

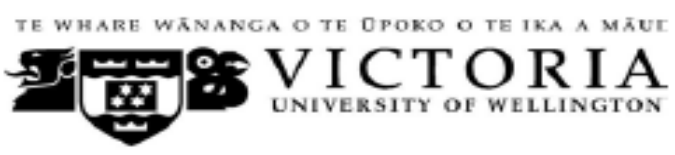

MEMORANDUM

Phone $\quad 0-4-4635480$

Email susan.corbettilvuw.acn

\begin{tabular}{l|l}
\hline TO & Ezekiel Parairae \\
\hline COPY TO & Prof John Overton \\
\hline FROM & AProf Susan Corbett, Convener, Human Ethics Committee \\
\hline
\end{tabular}

\begin{tabular}{l|l}
\hline DATE & 08 November 2016 \\
\hline PAGES & 1 \\
\hline \multicolumn{2}{|c}{} \\
\hline SUBJECT & $\begin{array}{l}\text { Ethics Approval: } 22085 \\
\text { Education and Labour Migration in Solomon Islands }\end{array}$ \\
\hline
\end{tabular}

Thank you for your application for ethical approval, which has now been considered by the Standing Committee of the Human Ethics Committee. Due to technical problems with the online system at the time of your submission, the Convenor agreed with your supervisor to provide retrospective approval.

Your application has been approved from the above date and this approval applies retrospectively for the period beginning 22 April 2016 .

Kind regards

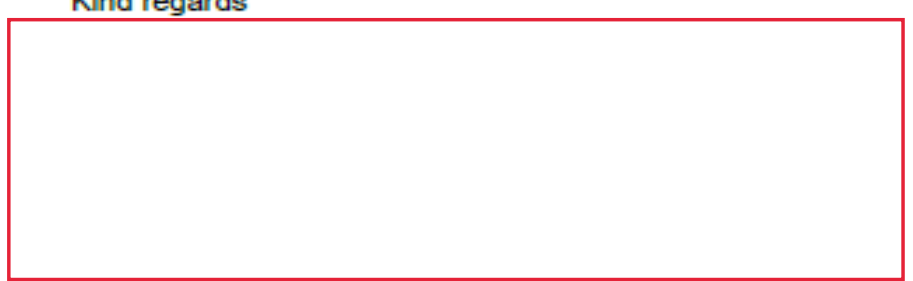

Convener, Victoria University Human Ethics Committee 
Appendix 2: Fieldwork and interview schedule

\section{FIELDWORK PLAN}

\begin{tabular}{|l|l|}
\hline Date of departure & $26 / 04 / 2016$ \\
\hline Date of Return & $26 / 07 / 2016$ \\
\hline Country & Solomon Islands \\
\hline City/Town & Honiara \\
\hline Research Title & Education and labour migration in Solomon Islands \\
\hline
\end{tabular}

\begin{tabular}{|l|l|l|l|l|l|l|l|l|}
\hline Activity & $\begin{array}{l}\text { Week } \\
\mathbf{1}\end{array}$ & $\begin{array}{l}\text { Week } \\
\mathbf{2}\end{array}$ & $\begin{array}{l}\text { Week } \\
\mathbf{3}\end{array}$ & $\begin{array}{l}\text { Week } \\
\mathbf{4}\end{array}$ & $\begin{array}{l}\text { Week } \\
\mathbf{5}\end{array}$ & Week 6 & Week 7 & $\begin{array}{l}\text { Week } \\
\mathbf{8}\end{array}$ \\
\hline Planning & & & & & & & & \\
\hline $\begin{array}{l}\text { Appointment } \\
\text { and seeking } \\
\text { permission }\end{array}$ & & & & & & & & \\
\hline $\begin{array}{l}\text { Data } \\
\text { collection- } \\
\text { Interview }\end{array}$ & & & & & & & & \\
\hline $\begin{array}{l}\text { Data } \\
\text { Transcription }\end{array}$ & & & & & & & & \\
\hline $\begin{array}{l}\text { Data } \\
\text { Analysis }\end{array}$ & & & & & & & & \\
\hline Data entry & & & & & & & & \\
\hline $\begin{array}{l}\text { Return from } \\
\text { Fieldwork }\end{array}$ & & & & & & & & \\
\hline
\end{tabular}


Interview schedule

\begin{tabular}{|c|c|c|}
\hline Department/Organization & Date & Time \\
\hline SINU & $17 / 05 / 2016$ & $9.30-10.30$ \\
\hline SINU & $17 / 05 / 2016$ & $2.00-3.00$ \\
\hline Labour Division & $18 / 05 / 2016$ & $10.00-11.00$ \\
\hline Labour Division & $18 / 05 / 2016$ & $11.00-12.00$ \\
\hline Labour Division & $18 / 05 / 2016$ & $1.00-2.00$ \\
\hline Labour Division & $18 / 05 / 2016$ & $2.00-3.00$ \\
\hline USP & $19 / 05 / 2016$ & $2.00-3.00$ \\
\hline Labour Division & $24 / 05 / 2016$ & $10.00-11.00$ \\
\hline Economic Reform Unit & $27 / 05 / 2016$ & $10.00-11.00$ \\
\hline Education Ministry & $30 / 05 / 2016$ & $10.00-11.00$ \\
\hline Education Ministry & $30 / 05 / 2016$ & $11.00-12.00$ \\
\hline Education Ministry & $31 / 05 / 2016$ & $9.00-10.00$ \\
\hline Education Ministry & $31 / 05 / 2016$ & $10.00-11.00$ \\
\hline Education Ministry & $31 / 05 / 2016$ & $2.00-3.00$ \\
\hline Education Ministry & $02 / 06 / 2016$ & $1.00-2.00$ \\
\hline MFAET & $03 / 06 / 2016$ & $10.00-11.00$ \\
\hline Education Ministry & $06 / 06 / 2016$ & $1.00-2.00$ \\
\hline MFAET & $04 / 07 / 2016$ & $10.00-11.00$ \\
\hline MFAET & $05 / 07 / 2016$ & $10.30-11.30$ \\
\hline MFAET & $05 / 07 / 2016$ & $2.00-3.00$ \\
\hline
\end{tabular}




\section{Interview Questions}

Topic: Education and labour migration in Solomon Islands: Policy interaction between the education system and the labour market.

\section{Leading questions}

Discuss role of education within the development in Solomon Islands.

What is the thinking behind education policies and strategies?

- Traditional education

- Primary education

- Secondary education

- Tertiary education

- Vocational education

\section{$\underline{\text { Key question areas }}$}

1. What are existing national institutional frameworks, strategies and policies that promote education and labour migration?

2. Do the current education policies addresses the domestic and external labour market skills needs? And if not why?

3. What are the gaps between education system and labour market levels?

4. Who are the key stakeholders in policy consultation and formulation?

5. Do external actors and development ideas influence the policy formulation and development in education and labour sectors?

6. How do you see education will support migration as an alternative opportunity for development?

7. What are some socio-economic benefits and positive outlook for pursuing this joint approach between education and labour?

8. What key areas in education and labour policies requires change in order to have an inclusive education-labour policy?

9. What are the likely challenges of a collaborative education-labour migration policy? Do you think it will result in brain drain? How can your departments deal with it?

10. Do you have any final addition and comments? 


\title{
Appendix 3: Ministry of Education and Human Resources Approval
}

\author{
THE RESEARCH ACT 1982 \\ (No. 9 of 1982)
}

\section{RESEARCH PERMIT}

Permission is hereby given to:

I. Name: Mi. Eekiel Paraike

2. County: Solonon lstands

3. Rescarch subject areas: Education and Labour migration: The Policy relationship between Fducation and labour migration in the Solomon Islands.

4. Ward (s): Homam

5. Prosines: honiaracits Council

6. Conditions:

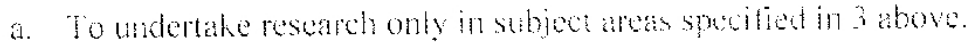

b. To andertake research only in the wad (s) and Province (s) specilied in 4 and 5 above.

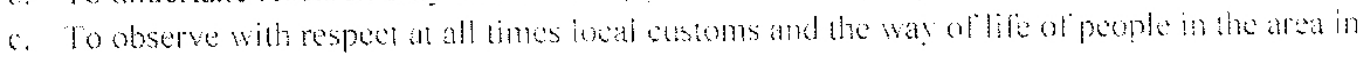

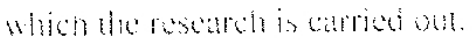

1. Not to ake pat at any lime in any polital or missionaty activies or lowal disputes.

e. To leave four (4) copies of your final research report in linglish wh the Solomon isknds Government Ministry responsible for research at your own expense.

i. A research lee of SBD 500.00 and deposit stm of $S B D 200.00$ must be paid in tull or the Research Pemit will be cancelled. (See sec. 3 subject 7 ol the Research Ast).

g. This permit is valid until $3 \theta^{\text {th }}$. fune 2016 provided all conditions are adhered to.

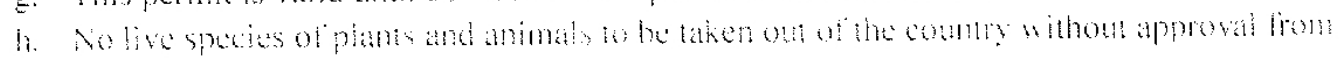
retevan: authorities.

i. A labure lo observe he above conditions will resalt in atomatic cancellation of this permit

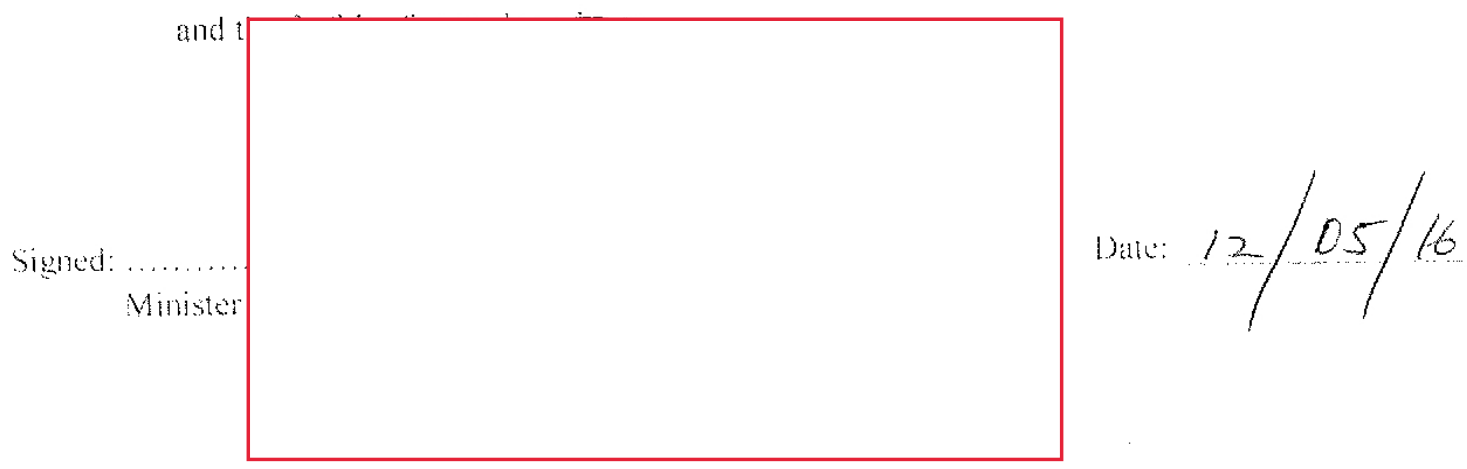




\section{Appendix 4: Participant information sheet}

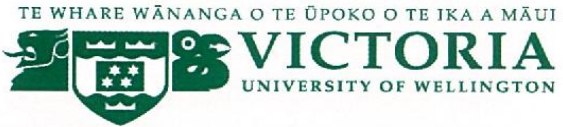

\section{Education and Labour migration in Solomon Islands}

\section{INFORMATION SHEET FOR PARTICIPANTS}

Thank you for your interest in this project. Please read this information before deciding whether or not to take part. If you decide to participate, thank you. If you decide not to take part, thank you for considering my request.

\section{Who am I?}

My name is Ezekiel Parairae and I am a Masters student in Development Studies at Victoria University of Wellington. This research project is work towards my thesis.

\section{What is the aim of the project?}

This project is to examine and study the policy relationship between education and labour migration in Solomon Islands.

This research has been approved by the Victoria University of Wellington Human Ethics Committee.

\section{How can you help?}

If you agree to take part I will interview you in a public place, such as a café. I will ask you questions and we will have a discussion around key themes. The interview will take 30 minutes. I will record the interview if you agree and write it up later. You can stop the interview at any time, without giving a reason. You can withdraw from the study up to four weeks after the interview. If you withdraw, the information you provided will be destroyed or returned to you.

\section{What will happen to the information you give?}

I understand that the research is not confidential and I agree to being named in the final report.

or

I am aware that I will not be named in the final report but my organisation will be named and I have the authority to agree to this on behalf of the organisation.

\section{What will the project produce?}

The information from my research will be used in my Masters thesis. You will not be identified in my report. I may also use the results of my research for conference presentations, and academic reports. I will take care not to name you in any presentation or report unless you give your permission. 


\section{If you accept this invitation, what are your rights as a research participant?}

You do not have to accept this invitation if you don't want to. If you do decide to participate, you have the right to:

- $\quad$ choose not to answer any question;

- $\quad$ ask for the recorder to be turned off at any time during the interview;

- $\quad$ withdraw from the study up until four weeks after your interview;

- $\quad$ ask any questions about the study at any time;

- $\quad$ agree on another name for me to use rather than your real name;

- be able to read any reports of this research by emailing the researcher to request a copy.

If you have any questions or problems, who can you contact?

If you have any questions, either now or in the future, please feel free to contact either:

\section{Student:}

Name: Ezekiel Parairae

University email

parairezek@myvuw.ac.nz

[Note: students should not provide personal

cell phone numbers]

\section{Supervisor:}

Name: John Overton

address: Role: Coordinator of Development Studies

School: Geography, Environment and Earth

Science

Phone: 044635281

john.overton@vuw.ac.nz

\section{Human Ethics Committee information}

If you have any concerns about the ethical conduct of the research you may contact the Victoria University HEC Convener: Associate Professor Susan Corbett. Email susan.corbett@vuw.ac.nz or telephone +64-4-463 5480 . 


\section{Appendix 5: Consent form}

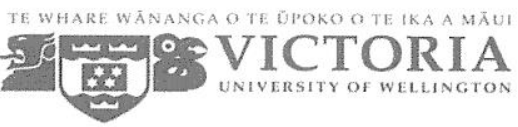

\section{Education and Labour Migration in Solomon Islands}

\section{CONSENT TO INTERVIEW}

This consent form will be held for [5] years.

Researcher: Ezekiel Parairae, Geography, Environment and Earth Science, Victoria University of Wellington.

- I have read the Information Sheet and the project has been explained to me. My questions have been answered to my satisfaction. I understand that I can ask further questions at any time.

- I agree to take part in a (audio) recorded interview.

I understand that:

- I may withdraw from this study up to four weeks after the interview, and any information that I have provided will be returned to me or destroyed.

- The information I have provided will be destroyed five years after the research is finished.

- Any information I provide will be kept confidential to the researcher and the supervisor. I understand that the results will be used for a Masters report and a summary of the results may be used in academic reports and/or presented at conferences.

- My name will not be used in reports, nor will any information that would identify me.

- OR I consent to information or opinions which I have given being attributed to me in any reports on this research:

- I would like a summary of my interview:

Yes No

Signature of participant:

Name of participant:

Date:

Contact details: 